NBSIR 78-1542

\title{
State-of-the-Art Study of Heat Exchangers Used With Solar Assisted Domestic Hot Water Systems \\ (Potential Contamination of Potable Water Supply)
}

F. Eugene Metz

Mary Jane Orloski

Building Economics and Regulatory Technology Division

Center for Building Technology

National Engineering Laboratory

National Bureau of Standards

Washington, D.C. 20234

July 1978

Prepared for

Office of the Assistant Secretary

Conservation and Solar Applications

Department of Energy

Washington, D.C. 20545

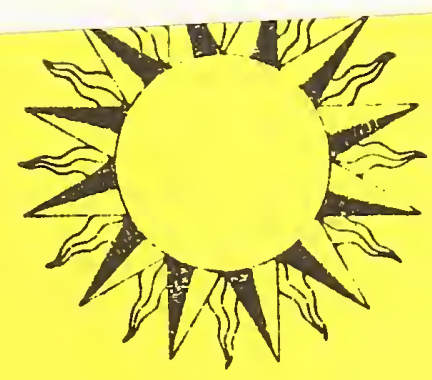


STARE-OP-THE-ART STUDY OF HEAT

EXCHANGERS USED MUTH SOLAR

ASSISTED DOMESTIC HOT MATER

SYSTE留S

IPOTENTHAL COMTAMHATION OF

POTABLE WATER SUPPLY

F. Eugene Mietz

Mary Jane Orloski

Building Economics and Regulatory Technology Division

Center for Building Technology

National Engineering Laboratory

National Bureau of Standards

Washingion, D.C. 20234

July 1978

Prepared for

Office of the Assistant Secretary

Conservation and Solar Applications

Department of Energy

Washington, D.C. 20545

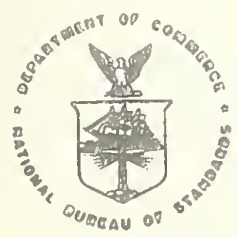

U.S. OEPARTMET OF COMMERCF, Jumita M. Krops, Secretary

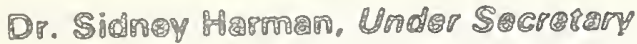

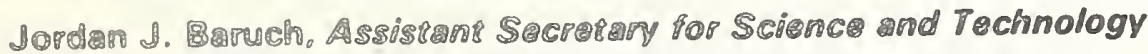

NATHONAL URE OF STANDARDS, Emost Amblor, Director 
In discussing the state of the art of solar system heat exchangers, certain commercial and proposed products are identified and judgments inferred in order to provide a descriptive characterization of their features. Inclusion of a given product in no case implies a recommendation or endorsement by the National Bureau of Standards, and the presentation should not be construed as a certification that any product would provide the indicated performance. Similarly, the omission of a product does not imply that its capabilities are less than those of the included products. Many diverse heat transfer processes and safety standards are discussed but there is no intent to advocate or censure these practices. 
The authors wish to express appreciation to the following individuals for their help, advice and encouragement in the preparation of this publication:

Carl W. Conner, U.S. Department of Energy

Robert D. Dikkers, National Bureau of Standards

William Freeborne, U.S. Department of Housing and Urban Development

Robert Sparkes, Dubin-Bloome Associates

David Waksman, National Bureau of Standards

Michael E. McCabe, National Bureau of Standards

James H. Pielert, National Bureau of Standards 

State-of-the-Art Study of Heat Exchangers

Used With Solar Assisted Domestic Hot Water Systems

(Potential Contamination of Potable Water Supply)

PAGE

1.0 INTRODUCTION..................................... 1

1.1 Criteria for Solar Demonstration Programs............... 1

1.2 Potential Hazards................................. 1

1.3 Double Failure Concept............................ 5

2.0 HEAT TRANSFER FLUIDS ............................... 6

2.1 Characteristics of Fluids used in the Demonstration Programs 6

2.2 Toxicity of Heat Transfer Fluids...................... 11

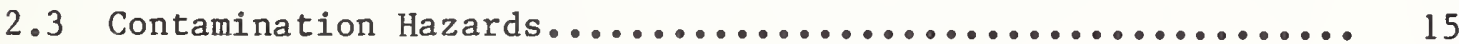

2.4 Selection of Heat Transfer Fluids.................... 17

3.0 HEAT EXCHANGERS................................ 17

3.1 Causes of Failure............................... 17

3.2 Discussion of Generic Heat Exchanger Types.............. 19

3.3 Availability of Heat Exchangers for Solar............... 27

3.4 Heat Exchanger Selection.......................... 28

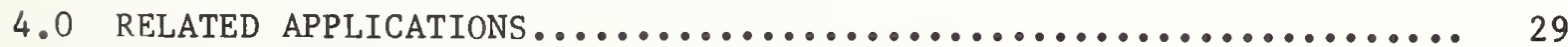

4.1 Heat Exchangers Used in Food Processing................ 29

4.2 Heat Exchangers Used in Food and Beverage Dispensing....... 30

5.0 EXISTING CODES AND STANDARDS........................ 32

5.1 Codes and Standards for Solar Hot Water Systems.......... 32

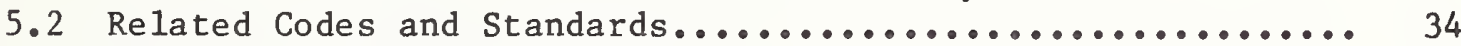

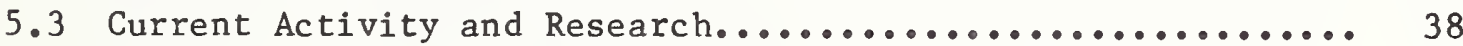

5.4 Need for Safety Guidelines.......................... 40

6.0 SUMMARY AND RECOMMENDATIONS $\ldots \ldots \ldots \ldots \ldots \ldots \ldots \ldots \ldots \ldots \ldots \ldots \ldots \ldots$

REFERENCES.................................................. 44

APPENDIX A - Illustrations of Heat Exchanger Types................ A-1

APPENDIX B - Toxicity Studies of Heat Transfer Fluids and Common Additives............................ B-1

APPENDIX C - Refrigerating Systems Classification by Types......... C-1 
This report presents the results of a non quantitative state-of-the-art study of heat exchangers used with solar assisted domestic hot water systems where a heat exchange interface exists between the potable water supply and a heat transfer fluid. Emphasis is placed on the potential for contaminating the potable water supply if failures should occur. The study considers (1) characteristics of various heat exchanger types and their relative safety; (2) characteristics of heat exchanger fluids (toxicity, corrosivity, thermal properties, etc.); (3) regulatory considerations; and (4) designs of similar systems with potential for contamination.

Key Words: contamination; corrosion; heat exchanger; heat transfer fluids; potable water; solar energy; standards; toxicity. 
The Solar Heating and Cooling Demonstration Act of 1974 (PL 93-409), provides for a "demonstration within a three-year period of the practical use of solar heating technology, and for the development and demonstration within a five-year period of the practical use of combined heating and cooling technology." The Act called for the development of performance criteria to assure safe, reliable and efficient solar equipment to further public acceptance of solar heating and cooling systems.

The development of "interim performance criteria" within 120 days after enactment was called for by PL 93-409. These criteria were developed by the National Bureau of Standards (NBS) and published for residential application by the Department of Housing and Urban Development (HUD) under the title "Interim Performance Criteria for Solar Heating and Combined Heating and Cooling Systems for Dwellings", January $1975[1] *$.

Subsequent publications include: "Interim Performance Criteria for Solar Heating and Cooling Systems in Commercial Buildings" (IPC)[2] prepared for the Energy Research and Development Administration (ERDA) ${ }^{1}$ by NBS, and "Intermediate Minimum Property Standards Supplement - Solar Heating and Domestic Hot Water Systems" (S/MPS) [3] prepared for HUD by NBS.

"The overall philosophy of the S/MPS and IPC documents with regard to safety is to prevent the creation of a hazard due to the presence of solar equipment, which is greater than that which would be found in a non-solar building"[4].

\subsection{POTENTIAL HAZARDS}

There are potential safety problems involved in the transfer of heat energy from solar collectors to potable hot water supplies used for bathing, washing and food preparation. These potential problems are both chemical and mechanical in nature and apply primarily to liquid transfer and storage systems where a heat exchange interface exists with the potable water supply. Both the chemical composition of heat transfer fluids (e.g., their pH, toxicity and chemical durability) and the mechanical reliability of various system components, i.e., heat exchangers and back flow devices, are of concern.

Except in most unusual cases, it is appropriate to consider the energy transport fluid as non-potable and having the potential for contaminating potable water during the heat transfer process. Even potable or "non-toxic" fluids, in closed systems, are likely to become non-potable due to contamination from metal tubes, solder joints, packing, etc., or by inadvertent installation of a toxic fluid at a later date. The growth of bacteria and fungi within the solid storage of air systems also represents a potential hazard.

1 Now Department of Energy

* Numbers in brackets represent references given on page 44. 
The extent of non-potable characteristics or the degree of toxicity of the transport medium may range from unknown or slight to extreme. The reader is referred to the following publications for detailed information relative to toxicity. $[5,6,7,8]$

Some of the common sources of contamination within the transfer medium are as follows:

o antifreeze additives such as ethylene glycol

o chemical inhibiters to retard corrosion, scaling, etc.

o chemical additives to neutralize decomposition products formed in the fluid over time (e.g., by thermal degradation)

o impurities from the tubes, containers, joints and fabrication compounds, or even outgassing products from various components

o the possibility of dust, bacteria, fungi etc., as may be the case in air storage systems

o decomposition products formed in the transfer medium

Heat transfer to potable water requires an interface with the collector heat transfer fluids. During this process contaminants may enter the potable water supply, because of certain failures within the components. These failures may be individual or in combination and may be brought about by the following:

- faulty fabrication resulting in such flaws as open seams

- faulty installation or damage

o thermal shock (including expansion and contraction)

o mechanical stresses such as overpressure and water hammer

o erosion and/or corrosion (especially pitting)

- significant drop in pressure of water supply where such pressure is intended as a primary means of protection against contamination

In order to present a hazard, such failures must occur of course within a context leading to a mixing of the contaminant with the potable water. This occurrance may be immediate, i.e., if there is a leak in a single wall heat exchanger which is immersed within the potable water, or gradual, i.e., a leak into an intermediate fluid or from an external jacket. Increasing the thickness of a single wall tube may be of little advantage in preventing leaks when pitting occurs, but rather only delays the results.

Similarly in double wall devices in which the walls are in intimate contact, corrosion of one may continue in a straight line path and corrode through the adjacent wall. This is based on the strong chance that a corrosive pit in one wall will be self sustaining beyond the elimination of the initial impurity. Oxygen depletion within the pit results in favorable conditions for the development of a galvanic cell between the pit and the heat transfer fluid thereby sustaining a corrosive action which will continue through an adjacent wall in direct contact or until a source of oxygen is contacted.

The high potential of this occurrence requires that the double walls be separated in order to interrupt this continuous action. This separation may be accomplished by an air space or by an intervening material which will act to stop the corrosion. It is desirable that the separation also aid in the 
detection of the leaks by providing a path or other means of exposing the leaking fluid to routine observation.

Some of the materials that may be used as intermediate layers are:

- solder or brazing
- a "noble" metal
- a potable fluid
- conducting fins, etc.
- conductive adhesive

The layer, to be effective, should stop corrosion due to pitting.

In double wall heat exchangers, failures must occur in two components which are adjacent or into an intermediate medium and then into the potable water as a result of a second failure. Again, contamination of the potable water may be dependent upon a leak as well as pressure differential resulting in flow from the transfer medium to the potable water.

The techniques employed in safeguarding against the contamination of potable water in the heat exchanger process tend to follow this general sequence:

- avoidance of non-potable heat transfer media

- creating increasing degrees of physical separation between the heat transfer medium and the potable water supply

- visual detection of leaks or contamination

- electronic sensing of leaks

- safety switching, activated by pressure sensors (or contamination sensors)

The S/MPS and IPC documents do not present standards to determine the degree of toxicity presented by various liquids. They are primarily concerned with the provision of adequate protection when potentially hazardous substances are used.

The following provision taken from the S/MPS (similar to 4.6 .2 of the IPC) addresses the issue of the protection of potable water and provides this criterion for the heat exchange interface that may exist between a non-potable liquid and potable water.

(S-515-9.1) When non-potable liquid is used in a solar energy system to transfer heat to domestic (potable) hot water, the design of the heat exchanger shall be such that either a minimum of two walls or interfaces are maintained between the non-potable liquid and the potable water supply or protection is provided in such a manner that equivalent safety is provided.

Commentary: Double wall heat exchanger designs are one way of meeting the intent of this criterion. When double wall heat exchanger designs consisting of two single wall heat exchangers in combination with an intermediary potable heat transfer liquid are used, leakage through one of the walls would result in a single wall configuration. Although 
this design is considered to meet the intent of this criterion, there are several other designs that avoid this problem.

The use of single wall configurations which solely rely upon potable water pressure to prevent contamination is not considered to be an acceptable solution. Similarly, extra thick single walls are not considered to meet the intent of this criterion. For approval of other than double wall designs, the procedures described in S-101 should be utilized.

Application of this criterion has caused confusion and concern among various segments of the solar industry, building code officials, and evaluators of solar demonstration systems. These concerns include:

A. Definition of non-potable liquids

B. Definition of equivalent safety

C. Interpretation of criteria to require "double wall" heat exchangers which are allegedly more costly and less thermally efficient than equivalent "single wa 11 " heat exchangers

D. Relationship of heat transfer fluid characteristics (chemical characteristics, thermal properties, stability, hydraulic properties, etc.) to safety of solar systems and service life expectancy of the systems

E. Inadvertent use of toxic transfer liquids in systems not designed to provide an adequate level of protection

The preceeding provision is concerned with the safety of the building occupants due to a failure of a heat exchanger leading to contamination of their domestic hot water (DHW) system in addition to protection of the system supplying water to the building. A complementary provision extends this concern to the potable water supply itself and to the safety of those beyond the immediate occupants. Pollution of the potable water supply can occur by way of backflow caused by back pressure and/or back-siphonage within a cross connection ${ }^{2}$ between the potable fluid in the system. Back pressure may occur with elevated tanks or pumps and back-siphonage can occur when the potable water supply system is under vacuum such as might occur with a broken street water main.

Provision S-615-10.1.3 of the S/MPS supplement provides for backflow prevention.

Backflow of nonpotable heat transfer fluids into the potable water system shall be prevented in a manner approved by the local administrative code authority.

1 BACKFLOW. The flow of water or other liquids, mixtures, or substances into the distributing pipes of a potable supply of water from any source other than its intended source. Back-siphonage is one type of backflow. [9]

2 CROSS CONNECTION. A cross connection is any physical connection or arrangement between two otherwise separate piping systems, one of which contains potable water and the other of unknown or questionable safety, whereby water may flow from one system to the other, the direction of flow depending on the pressure differential between the two systems. [9] 
Commentary: The use of air gaps and/or mechanical backflow preventers are two possible solutions to this problem. The following are some recognized standards that may be acceptable to the local administrative code authority:

Air Gaps

Backflow preventers
-ANSI-A1 12.1.2

-FCCCHR Chapter 10

IAPMO PS 31-74

AWWA C506-69

A.S.S.E. 1011

A.S.S.E. 1012

A.S.S.E. 1013

A.S.S.E. 1015

A.S.S.E. 1020

ANSI-A112.1.1

With the passage of the Safe Drinking Water Act of 1974 [10] and subsequent Environmental Protection Agency (EPA) promulgations establishing maximum contaminant level in the National Interim Primary Drinking Water Regulations [11, 12], new emphasis has been placed on controlling possible cross-connections that might result in contamination of the potable water supply. If a failure should occur along the common wall of a single-wall heat exchanger, there is then a cross-connection between the potable water and the non-potable heat transfer fluid.

The environmental impact of disposing of large quantities of non-potable heat transfer fluids while outside the scope of this report must be recognized as a long-range problem accompanying the increasing shift to solar heating and cooling (SHAC) systems.

This report is concerned primarily with the potential hazards of heat exchanger failure.

\subsection{DOUBLE FAILURE CONCEPT}

Growing out of the S/MPS provision...a minimum of two walls or interfaces are maintained between the non-potable liquid and the potable water...or equivalent safety is provided, is the concept of "double failure" or "double protection." The rationale is that failure of a single component should not result in contamination. With the use of hazardous liquids this implies the use of heat exchanger designs necessitating the independent failure of two components before the potable water is contaminated. The chance of an independent failure of a second component so compounds the risk probabilities that contamination is seen as remote. This raises the issue of detection of the initial failure or leak. The "double failure" concept suggests that means other than physical separation might be utilized to provide equal reliability. This provides for flexibility and increased alternatives for reducing the risk wi thout sacrificing thermal efficiency that often occurs with double wall separation.

Double wall heat exchangers are one way of meeting the intent of the criterion and efforts are being made to develop innovative and cost effective designs. Many of these designs are discussed in Section 3.2, Analysis of Generic Heat 
Exchanger Types. Efforts are also being made to provide leak and/or contamination detection.

Trade-offs between thermal efficiency, cost effectiveness, and risk for both heat exchangers and heat transfer fluids may be necessary to provide acceptable safety. It is the combination of fluid toxicity and heat exchanger reliability that determines the level of hazard.

\subsection{HEAT TRANSFER FLUIDS}

\subsection{CHARACTERISTICS OF FLUIDS USED IN THE DEMONSTRATION PROGRAMS}

The cause of concern for heat exchangers ultimately involves the non-potable characteristics of the heat transfer fluids used in many solar energy systems and an appraisal of the contamination risk to the domestic hot water supply if a leak should occur. The degree of contamination and severity of the danger would be determined by the volume flow of fluid leakage and volume of potable water as well as the toxicity of the fluid composition.

It was mentioned in the introduction that protection against damage by freezing and corrosion results in the use of non-potable heat transfer fluids in many solar heating and cooling systems. Water is the most thermally efficient heat transfer fluid (HTF) but freeze protectants such as the glycols are added to the water (or used to replace it) in many freeze prone areas and corrosion inhibitors such as phosphates and nitrates are commonly used. This is similar to use of coolants in automotive engines.

It is generally thought that the glycols account for about $70 \%$ of the antifreeze fluids currently used in solar energy systems, with glycerin and silicone oils about $10 \%$, and manufacturers' brands of unknown or proprietary mixtures the remaining $20 \%$. There is some confirmation of this by the HUD Residential Demonstration Project description data made available to NBS to date. This data further reveals that there is roughly equal use of ethylene glycol and propylene glycol. Although the information is limited, there is evidence that about half of the demonstration projects using liquid type collectors use water without additives and a small percentage use water with additives such as corrosion inhibitors. This suggests that more than half of the liquid systems are drain down or drain back and therefore do not use antifreeze solutions.

The toxicity of a limited number of pertinant heat transfer fluids and additives are discussed here. A more complete analysis can be found in the Appendix and in referenced documents. Tables $1,2,3$ and 4 give characteristics, properties and general comparisons of some commonly used heat transfer fluids. 
FLUID CHARACTERISTICS

POTENTIAL EFFECT ON SOLAR SYSTEM

1. Toxicity

Potential health hazard

2. Higher viscosity

May require greater pumping power and larger pipes to circulate a given volume of a thicker fluid

3. Low Specific Heat

Necessary to circulate more fluid (volume) to transfer a given amount of heat

4. Flash point may be reached under worst case "no-flow"

Possible fire hazard

(stagnation) collector con-

dition

5. Relatively Shorter fluid life

System owner must monitor, replace, or (before degrading or decomposing) dispose of fluid periodically or risk system damage

6. Cost and Availability

Owner may replace heat transfer fluid with one that is not compatible with the system

7. Poorer oxidative stability

Oxidized (degrades) at low temperatures; may be accelerated by presence of certain metals

8. Poorer thermal stability

Decomposes at higher temperatures into a fluid that accelerates corrosion and may also be more toxic

9. Inhibitor-selection not optimal

May cause premature scaling or corrosion 
Fluid

1. freezes at $32^{\circ} \mathrm{F}$

2. supports galvanic corrosion

3. boils at $212^{\circ} \mathrm{F}$

4. promotes scale formation

5. may change composition in closed system
Water/glycol mixtures
1. will not freeze down to $-35^{\circ} \mathrm{F}$

2. inhibitor technology for ethylene glycol well-suited to offering protection in a multimetal system

3. boils at temperatures higher than water
1. fluid must be replaced frequently or maintained properly (by monitoring $\mathrm{ph}$ )

2. problem of disposal of large amounts

3. decomposes around $280-300^{\circ} \mathrm{F}$ forming sludge and organic acids

4. toxic (ethylene glycol)

5. can degrade building material (roofs)

\section{Hydrocarbons}

1. low cost

2. nonvolatile

3. less toxic than ethylene glycol
1. poor oxidation stability

2. poor thermal stability at high temperatures resulting in sludge and acid formation

3. high viscosity at low temperatures

4. environmental effects similar to motor oil

5. typical closed-cup flashpoints run $300-320^{\circ} \mathrm{F}$, fluids with higher flashpoints have a higher viscosity

6. damage to building from leakage may be irreparable due to odor and low volatility

7. Low heat conductivity

\section{Silicones}

1. do not freeze

2. do not boil

3. do not corrode common metals

4. long life

5. high flashpoint

6. low toxicity, if any
1. low heat capacity

2. high viscosity

3. expensive

4. not biodegradable

5. difficult to seal

6. strong tendency to leak

7. may require more expensive pump (may also be true for hydrocarbons) 
Some commonly used heat transfer fluids are better known by their trade names than for their principal chemical ingredients. The following table lists some of these fluids and their principle ingredients.

TABLE 4 - SOLAR HEAT TRANSFER FLUIDS

Trade Name

*UCAR-17

*DOWTHERM SR-1

UCON -500

*UCON-30

*DOWFROST

*UCAR -35

MOBILTHERM 603

MOBILTHERM LIGHT

SUNTEMP 1

CALORIA HT-43

THERMIA 33

PROCESS OIL-3029

*DOW CORNING 200

SF 96

*THERMINOL 66

*DOWTHERM A

SOLARGARD G
Manufacturer

Union Carbide

Dow Chemical

Union Carbide

Union Carbide

Dow Chemical

Union Carbide

Mobil $0 i 1$

Mobil 011

Resource Technology Corp.

Exxon

Shell

Exxon

Dow Corning

General Electric

Monsanto

Dow Corning

Daystar

\section{Composition}

Ethylene glycol

Ethylene glycol inhibitor < 5\% and red dye < $1 \%$

Polyglycols - may contain phenyl $\beta$ naphthyl amine < 10\%

Ethylene oxide

Propylene glycol - contains inhibitor

Propylene glycol

Paraffinic, neutral oil

Paraffinic, high aromatic oil

Paraffinic, low aromatic oil contains red dye $(<1 \%)$

Paraffinic, low ( $14 \%$ ) aromatic oil

Paraffinic oil - aromatic content $20-25 \%$

Naphthenic mineral oil aromatic content $<10 \%$

Silicone oil

Polydime thylsiloxan

Terphenyl mixture

Diphenyl and diphenyl oxide mixture

Glycerol (USP) $60 \% /$ water $40 \%$

\footnotetext{
${ }^{\mathrm{Data}}$ provided by Sandia report [13] or manufacturers; materials obtained from Sandia Laboratories

*Toxicity information on these products are included in Appendix B (Gosselin et al) [6]
} 


\subsection{TOXICITY OF HEAT TRANSFER MEDIA}

Much of the following information is taken from "Clinical Toxicology of Commercial Products" [6] and from draft reports of work presently underway at Sandia Laboratories [13] and Energy and Environmental Analysis, Inc. [14]. As an aid to the understanding of this material the following definitions and explanations are offered:

- Toxic dose defines the amount of a chemical required to produce some harm in an animal, and is usually given in units of $\mathrm{mg} / \mathrm{kg}$ [milligrams (mg) of the substance administered per kilogram (kg) of subject's body weight ]

- $\mathrm{LD}_{50}$ - a statistically obtained virtual value which represents the best estimation of the dose required to produce death in 50 percent of a statistically defined (significant) population of test animals

- $\mathrm{LD}_{\text {Lo }}$ - the lowest lethal dose (given over any period of time) reported

For the toxicity ratings of Gosselin et a1, [6] Table 1 and Appendix B, the following explanations are noted.

(1) The rating is based on mortality, not morbidity, i.e., it is really a lethality rating. In general a clinically significant illness may be expected after doses of about one-tenth the probable lethal.

(2) Unless otherwise noted, each rating is based on the acute toxicity of a single dose when taken by mouth or gavage.

(3) The toxicity rating reflects an estimate of the probable or mean lethal dose, not the minimal fatal dose. (Suggested in Gosselin et a1, that minimal lethal doses recorded in the clinical literature are usually lower than those implied by current ratings.)

(4) Implicit in the use of data based on laboratory animals is the conventional assumption that the mean lethal dose in man lies in the same class as does the $\mathrm{LD}_{50}$ for test animals. (Suggested in Gosselin et al, that the glycols may be even more hazardous to man than to test animals).

(5) For patients who are heavier or lighter, (than the reference 150 lbs adult) probable lethal doses are proportionally larger or smaller and can be readily estimated from the values of $\mathrm{mg} / \mathrm{kg}$ recorded in the table.

(6) Information in Gosselin et al includes toxicity ratings for complete commercial products as marketed, as well as for single substances (usually technical grade).

Glycols applicable to solar use include ethylene glycol, propylene glycol and perhaps dipropylene glycol. Aqueous solutions of 50 percent (by weight) and greater of both ethylene and propylene glycol are commonly used. "When using 
glycols in these situations, simultaneous use of oxidative corrosion inhibitors should be avoided, as these latter substances will degrade glycol to glycolic acid--a contributing agent to metal corrosion." [14] (dipotassium phosphate is frequently used as a corrosion inhibitor with glycol antifreeze).

The following quote from unpublished minutes of the recently-held Semi-Annual Program Review Meeting for Environmental-Related Projects in Solar Heating and Cooling of Buildings and Agricultural and Industrial Process Heat, Washington, D.C., February 1978, sponsored by the Department of Energy addressed the problem of the formation of glycolic acids.

"A significant finding of the discussions at the meeting dealt with the potential toxicity of the glycols. Glycols may form glycolic acids under conditions present in solar systems. These glycolic acids can then form glycolate salts which are highly toxic compounds."

Another source also indicates the problem of the formation of organic acids under some operating conditions but suggests that these would be in small quantities [15].

Generally under ordinary conditions of industrial use, the most commonly used glycol, ethylene glycol is considered to be only moderately toxic. However, severe and even fatal poisoning has occurred following its ingestion.

The following information taken from, Draft Environmental Impact Statement of the National Solar Heating and Cooling Program, [14] discusses the toxicity characteristics of the glycols as well as most of the common freeze protectants used in solar heating and cooling systems. For a more complete coverage including corrosion inhibitors, miscellaneous heat-transfer media, bactericides, insulation and sealing materials, see Appendix B. An attempt is made to include the lowest lethal dose reported $\left(\mathrm{LD}_{\mathrm{LO}_{0}}\right)$ and the equivalent lethal dose for a child.

Toxicity of Glycols

o "Ethylene Glycol -- Ingestion may produce injury of sufficient severity as to threaten life following acute ingestion of large doses. Ingestion of small doses over time can cause moderately toxic systemic effects(2) ${ }^{1}$. The $\mathrm{LD}_{\mathrm{Lq}}$ (oral) for humans of ethylene glycol has been reported at $1500 \mathrm{mg} / \mathrm{kg}$ (3). More than 50 human fatatities from the ingestion of

1 References 2, 3, 4, of the report cited above correspond to references [17, $8,6]$ of this report.

2 Another source cites, "Up to 60 deaths in a single year have been reported from ethylene glycol or diethylene glycol," Poisoning: Diagnosis and Treatment, Driesback, Robert H., Lange Medical publications, 1974. 
ethylene glycol have been reported ${ }^{2}$ and the mean lethal dose $\left(L D_{50}\right)$ appears to be about 100 milliliters (ml) in adults (4). For a child to ingest the equivalent of the $\mathrm{LD}_{\mathrm{Lo}}(1500 \mathrm{mg} / \mathrm{kg})$, approximately $30 \mathrm{ml}$ of ethylene glycol or 0.15 liters or 0.04 gallons $(5.1 \mathrm{oz}$. of a 20 percent solution would have to be consumed"

- "Propylene Glycol - Propylene glycol has low toxicity. Industrially, its uses include serving as a general food additive. Orally adminstered doses of propylene glycol to rats have resulted in an $L_{50}$ of $21 \mathrm{~g} / \mathrm{kg}$ (2). This would correspond to a child consuming approximately 2 liters or 0.55 gallons $(70 \mathrm{oz}$ ) of a 20 percent propylene glycol solution. However, at this dose, a theoretical $\mathrm{LD}_{\text {Lo }}$ could be surpassed"

o "Dipropylene Glycol -- Similar to propylene glycol (i.e., having a low toxicity). Oral doses to rats have given an $L_{50}$ of $15 \mathrm{~g} / \mathrm{kg}$ (3). The human oral lethal dose is probably between 100 and $300 \mathrm{~m} 1$ of pure solution for adult, or between 100 and $300 \mathrm{mi}$ of pure solution for a child (4). For a child, the probable oral lethal dose is between 0.5 and 1.5 liters ( 17.5 to $53 \mathrm{oz}_{\text {• }}$ ) of a 20 percent solution."

"Siloxanes (Silicon Fluids) - Siloxanes, are of the general formula - $\mathrm{R}_{2} \mathrm{SiO}$ in which $\mathrm{R}$ is usually an alkyl group. The toxicity of these compounds generally is low; many studied do not have toxic properties at all and most have little or no irritant effect (2)."

"Dow Corning 200 has been fed to rats in oral doses as high as $20 \mathrm{~g} / \mathrm{kg}$ with no discernable effects. Transitory conjunctive irritation may be caused by introducing Dow Corning 200 to the eye, but no permanent effects have been observed. No evidence that silicone fluids are absorbed through the skin exists (5)."

"Paraffins (Alkanes) - Effects of Paraffin hydrocarbons vary with volatility. For solar system fluid use, high molecular weight hydrocarbons would be used. These high molecular weight (and less volatile) compounds exhibit anesthetic effects and, at the same time, an increasing irritant action as molecular weight accrues. The semi-refined, fully-refined, and crude paraffins are recognized carcinogens; implanted paraffins in mice produced tumors in doses as low as $600 \mathrm{mg} / \mathrm{kg}$ (3). Such effects from acute oral ingestion are unlikely, however. (oral data were not available)."

"Aromatic and Other Synthetic Hydrocarbons - This family of synthetic fluids primarily encompasses organic compounds containing modified (polychlorinated) triphenyls (the Therminol Fluids). The polychlorinated triphenyls are a series of technical mixtures containing products that vary in composition and degree of chlorination. Therminol 66 (modified triphenyl by Monsanto) has an oral $\mathrm{LD}_{50}$ of $10.2 \mathrm{~g} / \mathrm{kg}$ to rats and a dermal $\mathrm{LD}_{50}$ of approximately $6.8 \mathrm{~g} / \mathrm{kg}$ to albino rabbits. Therminol 55 (synthetic hydrocarbons from Monsanto) has an oral $\mathrm{LD}_{50}$ of $15.8 \mathrm{~g} / \mathrm{kg}$ to rats and a dermal $\mathrm{LD}_{50}$ of $7.9 \mathrm{~g} / \mathrm{kg}$ to albino rabbits (6). To equal the $\mathrm{LD}_{50}$ dose level of Therminol $66(10.2 \mathrm{~g} / \mathrm{kg})$, a child would have to ingest approximately $200 \mathrm{ml}$ ( 6.8 ounces) of the solution. It should be noted that, at this dose level, a theoretical LD Lo $_{0}$ could be surpassed." 
The results of two comprehensive toxicity studies [5,6] of heat transfer fluids and common additives were compared in a recent draft report on Hazardous Properties and Environmental Effects of Materials Used in Solar Heating and Cooling (SHAC) Technologies [13]. Excerpts from these studies are included in Appendix B 1 through B 7 and relate to (1) heat transfer fluids; (2) fluid treatment chemicals; (3) outgassing products; (4) thermal degradation products; (5) thermal storage media; (6) solids, outgassing products; and (7) combustion products.

The following examples give some insight into the scope of the hazard created by some commonly used chemicals.

On a scale of 1 to 6, one of the studies Gosselin, et al [6] rates the following materials:

\section{Transfer fluids}

propylene glycol . . . class 1. . . practically non-toxic

ethylene glycol. . . . class 2. . . .slightly toxic

\section{Fluid treatment chemicals}

$$
\begin{aligned}
& \text { sodium nitrate.... . class 4. . . .very toxic } \\
& \text { *potassium dichromate.. . class 5. . . extremely toxic }
\end{aligned}
$$

Other studies have given similar ratings for these transfer fluids and inhibitors [5].

The above ratings are defined and given some relevance in table 5 . The ratings are based on the acute toxicity of a single dose taken orally. The ratings presented in table 5 are based on $\mathrm{LD}_{50}$ 's in $\mathrm{mg} / \mathrm{kg}$ obtained in laboratory animals.

\footnotetext{
* Chromate salts are also recognized carcinogeus of the lungs, nasal cavity and paranasal sinus; and suspected carcinogeus of the stomach and larynx.
} 
TABLE 5 (From Gosselin, et al.)

Toxicity Rating or class
Probable Oral LETHAL Dose (Human)

Dose

For $70 \mathrm{~kg}$ person (150 1b)

A taste (less than 7 drops)

Between 7 drops and 1 tsp.

Between 1 tsp. and 1 ounce

Between 1 oz. and 1 pint (or 1 lb.)

Between $1 \mathrm{pt}$. and $1 \mathrm{qt}$.

More than 1 quart (2.2 $\left.1 \mathrm{~b}_{\text {. }}\right)$

1 Practica11y nontoxic

5-15 gm/kg

Above $15 \mathrm{gm} / \mathrm{kg}$

$\begin{array}{llll}2 \text { Slightly toxic } & 5-15 & \mathrm{gm} / \mathrm{kg} & \text { Between } 1 \mathrm{pt} \text {. and } 1 \mathrm{qt} . \\ \begin{array}{l}\text { Practically } \\ \text { nontoxic }\end{array} & \text { Above } 15 & \mathrm{gm} / \mathrm{kg} & \text { More than } 1 \text { quart (2.2 1 b.) }\end{array}$

\subsection{CONTAMINATION HAZARD}

The fact that the heat transfer fluids used in solar energy systems are a combination of several treatment fluids is of concern and does not appear to be adequately addressed in the available literature. In some instances, corrosion inhibitors and other additives are more toxic than the antifreeze solutions themselves. Although these are usually used in small concentration, it is important to know their effect on the toxicity of the fluid as a whole.

In considering the hazard to man from the use of any compound, there are several factors which must be considered. In reality, almost any material can have toxic properties under certain circumstances. The toxicity of a material is determined by its potential to produce a deleterious response upon contacting or entering the body. The hazard is determined not only on the basis of its toxicity but also on the basis of probability that a person will be exposed to the material under various conditions of use.

The following scenario suggests the level of hazard that might exist in a somewhat realistic context.

A penetration in the common wall of a single-wall heat exchanger would permit mixing of the heat transfer fluid and the potable water with a dilution factor. For example, suppose the heat transfer loop to the collector contained 6 gallons of 50\% ethylene glycol and water, and the hot water tank had a 120 gallon capacity. Total loss of the heat transfer fluid into the potable water would result in a mixture of concentration:

$$
\frac{3 \text { gallons }}{120 \text { gallons }}=2.5 \%
$$


This assumes no additional water is introduced into the tank.

Table 6 indicates the number of quarts of fluid a person, by body weight would have to drink of a certain concentration of ethylene glycol solution to obtain a lethal dose. The quantities to be consumed for children are relatively small considering that the concentration of the resulting mixture could be on the order of $2.5 \%$. This represents the "acute toxicity level" as defined in reference [17], i.e., single dose size. It is not known how the "chronic toxicity level" which is the ingestion over time is related to the "acute toxicity level."

TABLE 6 - LETHAL DOSE OF ETHYLENE GLYCOL SOLUTION ${ }^{1}$

Person's Body Weight
Number of Quarts to be Consumed for a Letha1 Dose by Concentration 2

\begin{tabular}{|c|c|c|c|c|}
\hline & $1 \%$ & $2 \%$ & $2.5 \%$ & $3 \%$ \\
\hline $251 \mathrm{~b}$ & $1.7 \mathrm{qt}$. & $0.8 \mathrm{qt} .(25.6 \mathrm{oz})$ & $0.7(22.4 \mathrm{oz})$ & $0.6 \mathrm{qt} .(18.1 \mathrm{oz})$. \\
\hline $501 \mathrm{~b}$ & $3.4 \mathrm{qt}$ & $1.7 \mathrm{qt}$. & 1.3 & $1.1 \mathrm{qt}$ \\
\hline $751 \mathrm{~b}$ & $5.0 \mathrm{qt}$. & $2.5 \mathrm{qt}$. & 2.0 & $1.7 \mathrm{qt}$. \\
\hline $1001 \mathrm{~b}$ & $6.7 \mathrm{qt}$. & $3.4 \mathrm{qt}$ & 2.7 & $2.2 \mathrm{qt}$. \\
\hline $2001 \mathrm{~b}$ & $13.4 \mathrm{qt}$ & $6.7 \mathrm{qt}$. & 5.4 & $4.5 \mathrm{qt}$. \\
\hline
\end{tabular}

1 The preceding table is developed from the following calculations.

The lethal dose of ethylene glycol by body weight [15] is:

Converting this to pounds:

$$
\frac{1.4 \mathrm{ml}}{1 \mathrm{~kg}} \quad \frac{\text { (volume of ethylene glycol) }}{\text { (body weight of person) }}
$$

Converting to quarts/1b:

$$
\frac{1.4 \mathrm{ml}}{\mathrm{kg}} \times \frac{\mathrm{kg}}{2.2051 \mathrm{~b}}=0.6349 \frac{\mathrm{ml}}{1 \mathrm{~b}}
$$

$$
\frac{1 \mathrm{gal}}{3785 \mathrm{ml}} \times \frac{4 \mathrm{qt}}{\mathrm{gal}} \times 0.6349 \frac{\mathrm{hl}}{1 \mathrm{~b}}=0.000671 \frac{\mathrm{qt}}{1 \mathrm{~b}}
$$

Therefore, a lethal dose is $0.000671 \frac{\mathrm{qt}}{1 \mathrm{~b}}$

For example, a $100 \mathrm{lb}$ person would ingest a lethal dose from:

$$
0.000671 \frac{\mathrm{qt}}{\mathrm{Ib}} \times 100 \mathrm{IB}=.0671 \mathrm{qt}(2.15)
$$

(This is equivalent to 1 quart ( $32 \mathrm{oz}$ ) ) of $6.7 \%$ concentration of ethylene glyco1 or 6.7 quarts of a $1 \%$ concentration).

2 This represents the "acute toxicity level" as defined in reference [16], i.e., single dose size. It is not known how the "chronic toxicity level" which is the ingestion over time is related to the "acute toxicity level." 
It is to be noted that these examples do not assume the presence of inhibitors or stabilizers in the heat transfer solution and the corresponding effect they might have on the toxicity of the solution. It is also noted that this scenario does not account for additional water supply coming into the tank to replace that which is drawn off. If this factor is taken into account the resulting concentration may be reduced by as much as $50 \%$.

\subsection{SELECTION OF HEAT TRANSFER FLUIDS}

There is growing awareness of the importance of the selection of the heat transfer fluid to the performance and reliability of the solar energy systems. Many factors are to be considerd in this choice. Basic considerations include thermal performance, cost effectiveness, reliability and safety. Consideration must also be given to system type, size and materials, operating conditions, climate, and level of maintenance and monitoring capability. Similar consideration should be given to the selection of additives such as inhibitors and detectants as well as liquid concentration.

The following fluid characteristics summarize some of the most important selection considerations.

(a) Stability, both thermal and oxidative, for the operating temperatures including stagnation, liquid range (freezing to boiling temperatures), decomposition temperature and vapor pressure.

(b) Thermal properties i.e. specific heat and thermal conductivity.

(c) Flash point and fire point.

(d) Hydraulic or transport properties such as specific gravity and viscosity at operating temperatures.

(e) Metal comptability, dielectric and corrosive characteristics.

(f) Toxicity (including additives and products of decomposition), local health department approval.

(g) Cost and service life estimates under operating conditions.

Since the heat transfer fluid is "common" to most other components within the solar loop, it's early selection within the design process will influence other design decisions with respect to operating temperatures, flow rates, materials and protection.

The reader is referred back to tables 1,2 and 3 for information on fluid characteristics listed above.

\section{HEAT EXCHANGERS}

\subsection{CAUSES OF FAILURE}

Heat exchangers used in solar assisted domestic hot water systems are subject to a wide variety of degradation mechanisms some of which are unique to this particular application. Corrosion is a threat at both the interface with potable water and the heat exchange fluid. The composition of the heat transfer fluid can be modified to retard corrosion but of course alteration of the potable water supply is usually not considered except in the case of water softeners. In different areas of the country there is a wide difference in the mineral content and $\mathrm{pH}$ characteristics of the water supply. Consideration must also 
be given to the use of individual well water and the water variations that are introduced because of them. Heat exchangers will be subject to the same conditions that have led to the very rapid deterioration of conventional hot water heaters in parts of California and New England. Conditions of highly conductive water (California) and nonconductive water (New England) have greatly reduced the service life of hot water heaters in some cases (sometimes as short as 2 years) [18]. But in solar hot water systems, the potable water is also exposed to the threat of contamination by the heat transfer fluid. Special efforts are needed to resolve these kind of problems.

A range of metals may be used for heat exchangers or in the immediately adjacent plumbing system. These may include steel, galvanized iron, copper, bronze, brass and aluminum; however, copper and steel are most commonly used in heat exchangers. Each of these metals, to a greater or lesser degree, adds its own particular corrosion problems to a closed recirculating system even if dielectric isolation of dissimilar metals is provided.

In fresh water supply systems, the corrosion resistance of copper depends on the presence of a surface oxide film through which oxygen must diffuse in order for corrosion to continue. The film is easily disturbed by high velocity water or is dissolved by either carbonic acid or the organic acids which are found in some fresh waters or soils, leading to an appreciably higher corrosion rate. The following discussion is taken from Corrosion and Corrosion Controls [19].

"For example, in hot water in Michigan, zeolite softened with resultant high concentration of $\mathrm{H}_{2} \mathrm{CO}_{3}$, was found to perforate copper water pipe within 6 to 30 months. The same water unsoftened, on the other hand, was not nearly as corrosive because a protective film of $\mathrm{CaCO}_{3}$ containing some silicate was deposited on the metal surface."

Heat transfer fluids are most often pumped through heat exchanger components at a wide range of temperatures and in various systems at a range of pressures and flow rates. It is generally recognized that flow rates should be maintained below 4 to $6 \mathrm{fps}$ to prevent erosion corrosion. These factors have significant affect on corrosion rate as well as mechanical stresses within heat exchanger coils. Very high temperatures (350 to $400^{\circ} \mathrm{F}$ ) which may occur under "stagnation" conditions will cause some heat transfer fluid components (such as the glycols) to break down and become acidic. Under these conditions the fluid is more corrosive and probably more toxic.

The manner in which the system is fabricated greatly affects its susceptibility to attack. Crevices, deposits and miscellaneous debris can obstruct access of dissolved oxygen to the metal surface and thereby set up differential aeration cells. The latter are detrimental to all of the metals involved, but especially to aluminum, monel and stainless steels.

Inappropriate combinations of different metals in a single system cause severe galvanic corrosion. Direct couples may develop during operation of the system. Traces of metals dissolved from upstream portions of the system frequently deposit on contact with more active components which can lead to serious attack of the more active metals. Impingement attack of copper is a rather common source of trouble in some larger installations such as apartment and institutional buildings. According to Hatch [20] the difficulty often stems from 
an unfortunate choice of materials, because copper is particularly susceptible to attack of this nature. Impingement attack on copper can also be caused by the separation of dissolved air from the water due to excessive pressure reduction or excessive flow velocity.

"Copper also may suffer localized attack (i.e., pitting) which does not involve excessive flow velocities. It is fortunate that pitting of this type seldom is encountered because its causes are not fully understood." [20]

The following list elaborates on some of the causes of heat exchanger failures mentioned earlier in the introduction.

- Corrosion

- increases with temperature

- increases with excessive velocity or flow rate (corrosion and erosion)

- pH affects both type and velocity of corrosion

- affected by cavitation

- affected by crevices, deposits and miscellaneous debris (deposit attack)

- affected by amount of dissolved oxygen and presence of trace impurities (chlorides, heavy metal ions, etc.)

- affected by the composition of the heat transfer fluid

- affected by stress (stress corrosion-cracking)

o Thermal Stress

- expansion and contraction

- thermal shock

- freeze up (expansion)

- Mechanica1 Stress

- fabrication and installation

- impact

- bending, cracking

- faulty seams

- loss of strength and ductility (intergranular corrosion)

Current corrosion test methods that are applicable to solar energy components are 1isted in Table 7.

See also Section S-515-2.3.2.3 (pp 5-16 to 5-30) of the S/MPS for further discussion of corrosive conditions.

\subsection{DISCUSSION OF GENERIC HEAT EXCHANGER TYPES}

Thermal performance is the paralle1, if not equal, consideration to safety in heat exchangers. The thermal performance of the heat exchanger is a key ingredient to the total domestic hot water (DHW) system efficiency. In a basic sense, safety is increased with an increase in separation ( $e_{. g}$, the use of multiple walls) between the potable water and the heat transfer fluid (HTF) (which may be non-potable) whereas thermal efficiency is often decreased by such an increase in separation of the two fluids. 
TABLE 7 - CURRENT CORROSION TEST METHODS [3] ${ }^{1}$

Title

Comment

NACE TM-01-71 Autoclave Corrosion Testing of Metals in High Temperature Water

Modify to reflect conditions present in solar systems

NACE TM02-74

Dynamic Corrosion Testing of

Modify to reflect Metal in High Temperature Water conditions present in solar systems

NACE TM-02-70

Conducting Controlled Velocity

Laboratory Corrosion Tests

Modify to reflect conditions present in solar systems

NACE TM-01-69 (1972)

Laboratory Corrosion Testing of Metals for the Process Industries

Describes factors to consider in corrosion testing

ASTM DI384-70 (1973)

Corrosion Test for Engine

Modify to reflect Antifreeze in Glassware conditions present in solar systems

ASTM D2570-73

Simulated Corrosion Testing

Modify to reflect

of Engine Coolants conditions present in solar systems

ASTM D2776-72

Corrosivity of Water in the Absence of Heat Transfer

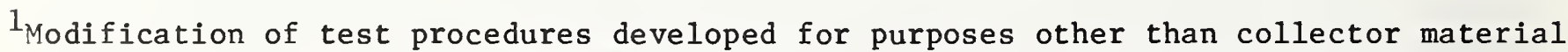
testing shall adequately reflect all expected collector conditions including no-flow conditions. 
Overall conductance for a heat exchanger is the product of the overall heat transfer coefficient (which depends on the thermal properties of each fluid, the fluid mass flow rate and the heat exchanger geometry) and the associated heat transfer surface area. The extent of separation, as required for safety, is greatly affected by the heat exchanger geometry. The other variables which deserve much design considerations are fluid thermal properties, mass flow rate and transfer surface area.

There are wide variations in the effectiveness of heat exchangers used in and proposed for solar DHW systems. There is not widespread knowledge of their relative efficiencies or thermal performances in varied applications. Calculation methods for heat exchanger performance are described in the ASHRAE Handbook of Fundamentals. [21] A minimum effectiveness value of 0.7 is a typical value that is used. This value was also used in the correlation studies which provide the basis for the calculation method used in the S/MPS supplement for sclar installations.

The following brief descriptions are taken from the point of view of solar assisted domestic hot water systems. The description covers a broad range of pertinent type heat exchangers but does not represent an exhaustive study. The discussion includes proposed as well as commercially available heat exchangers.

Unless otherwise stated, the comments are made without regard to materials or transfer fluid types. The comments regarding relative performance and cost are made in a general sense without consideration of transfer fluids, flow rates and specific manufacturing processes. The comments are based on judgment but are appropriate for the evaluation of heat exchanger types. Transfer fluids are taken as non-potable without regard to degree of toxicity.

The graphic illustrations are intended only to express essential relationships; more literal illustrations are included in Appendix A. The illustrations in Appendix A are accompanied by the "key" sketch in the text. These illustrations are not detalled and are used to provide an understanding of the relationship between the heat transfer fluid and the potable water and general configuration of the heat exchangers. The following legend is used with these illustrations:

OIISheat transfer fluid

Inimilintermediate exchange fluid

potable water

Tube in Shel1

Heat exchangers of this type usually consist of a coil (or bundle) of a single tube, usually containing the transfer fluid, immersed in the potable water. The outside surface of the tube is sometimes covered with fins to provide greater surface contact for the heat exchanger process. The tube-in-shell heat exchanger is categorized here as relatively high in thermal efficiency. The efficiency is Improved with optimum placement in the water tank and with outer surface configuration to increase heat exchanger contact. This type is categorized here as low in cost as compared to other heat exchangers discussed. See illustrations, page A-1. 
The tube-in-shell heat exchanger provides only a low category of safety. A fallure of the tube creates an immediate potential for contamination of the potable water by the transfer fluid. Corrosion can attack the tube from either side of the tube wall. Increasing the wall thickness of the tube wall increases the time to failure due to corrosion but is not likely to stop it. There is little means of detecting a leak if one occurs and pressure differential cannot always be considered adequate to prevent contamination. Although the potable water pressure would normally be higher than that of the heat transfer fluid, a drop in water pressure would remove the protection.

This is a very common type of heat exchanger and is frequently used especially in applications not involving potable water. The use of single wall heat exchangers was permitted by local code officials in demonstration projects recently sponsored by the New England Electric Company; however, contractors were required to submit evidence that heat transfer fluids used were not toxic.

Double Tube in Shel1

Most of the preceding discussion applies to this type as we11. The major distinction is that the tube is double formed in a process in which an inner tube is swaged or expanded inside an outer tube so that there is intimate mechanical contact. This increases the cost and lowers, at least slightly, the thermal efficiency. Although it technically meets the safety criterion of providing a double wall between the transfer fluid and potable water, it is still vulnerable to the pit corrosion phenomenon which is likely to proceed in a selfsustaining process in a path through both walls. It is questionable as to whether the extremely tight fit between the two walls aids in the detection of a leak or helps retard contamination. If the two tubes are swaged together and form a tight bond they are essentially one tube.

There is increasing use of this type in solar demonstration programs, although there is continuing controversy as to the margin of safety it provides.

A proposed modification of this type has a spiral formed tube inside another tube in a way that only the ridge of the spiral of the inner tube contacts the wall of the outer tube. This configuration greatly enhances the safety and provides an inner channel for potential leakage to flow out and aid in detection. However, the reduced inner surface contact may reduce efficiency. If the inner channel was filled with an intermediate fluid it would increase the efficiency but would also eliminate leak detection. See illustrations, page A-1.

Tube on She11.... Separated (or double wall separation)

A common version of this type which is currently in use is the wrap-around or "jacket" type. The jacket may consist of, multiple passages or tubes, or a single void surrounding the potable water tank, for circulation of the heat transfer liquid. In some installations, a single tube is wrapped around the perimeter of the potable water tank. Heat transfer efficiency is largely determined by the quality of the contact between tube or jacket and the tank. See illustrations, page $\mathrm{A}-3$. 
A separation between the double walls provides an additional element of safety. This separation may be achieved by a layer of solder or a conductive material between the adjacent walls. The thermal efficiency of the heat exchangers may be improved or reduced depending by how the separation is achieved. There are some heat conductive adhesives which the manufacturers claim will greatly increase the performance of the heat transfer process. The separating material should inhibit the corrosive tendency to penetrate the two adjacent walls. A similar heat exchanger, being developed at this time, consists of two coils of tubes (in this case one is copper and one aluminum) attached by a layer of solder as well as encased in solder. The fabrication involves placing the coils in an ultrasonic vat of molten solder which drives off impurities as well as totally encasing all tube surfaces. The solder is of high zinc content which acts as an anode to the aluminum and copper and inhibits corrosion. The solder encasement also enhances heat transfer between the tubes.

The thermal performance of this particular exchanger is thought to be high. Others of this type vary from medium to high in performance depending on the characteristics of the material or separation between the heat exchanger walls. The cost as well as the level of safety will also vary between medium and high.

The safety level of this type should rank clearly above those of double walls in intimate contact. It is noted that the double wall with separation provides the level of protection that NBS currently proposes as appropriate for use in the solar demonstration programs.

One proposed design of this type enhances the safety by inserting a higher alloy or more noble metal as an interface between the two tubes. The plausible theory here is that the noble metal will intercept the corrosion of either tube and reverse it rather than penetrate the higher alloy interface and the second tube.

Shell and Double Tube

This type consists of two tubes, one containing potable water and the other a heat transfer fluid, both immersed in an intermediate exchange fluid. The intermediate fluid adequately separates the potable water from the heat transfer or the collector loop fluid but is probably somewhat non-potable itself by reason of being stagnated in a closed system or 1 t may contain additives or it may be contaminated by the heat transfer fluid by way of a leak. See illustration, page A-2.

If the tube containing the heat transfer fluid fails due to corrosion, the corrosion pit will contact the intermediate fluid and the electrochemical cell will be disrupted. If the intermediate fluid becomes non-potable because of stagnation or leak, this heat exchange type may be considered single wall, providing only a one wall separation between the non-potable intermediate fluid and the domestic hot water. However, dilution by the potable water of any metal ion by the intermediate fluid would most likely result in a minimal hazard.

One major advantage of this type exchanger is that a strong potential for leak detection is possible if a view glass is placed in the intermediate fluid container and if a concentrated dye is added to the heat transfer or solar loop fluid. This of course does not aid detection of a leak of the intermediate fluid into the potable water. 
The performance as well as the cost of this type is dependent upon the detalls of the design but generally the performance as well as the cost is in the medium range. The safety aspects have been suggested in the previous paragraph. It is important however to not overlook the observation and leak detection potential within the intermediate fluid.

Double Shell and Tube

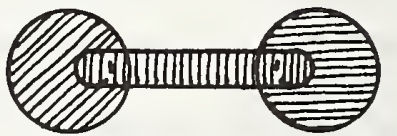

This heat exchanger type has many similarities with the Shell and Double Tube. An intermediate exchange fluid is conveyed by the tube, taking on heat from the solar loop, transporting it and giving it up to the potable water storage.

There are essentially two heat exchangers in the process; one with the solar loop and another with the potable storage. The potable water is adequately separated from the transfer fluid of the solar loop.but it is susceptable to contamination by the intermediate exchange fluid in much the same way as in the double shel1. The intermediate fluid will act as a barrier to a corrosive pit continuing and will generally intercept any leakage of the heat transfer fluid. It is therefore a double wall heat exchanger relative to the heat transfer fluid, though it may be considered only single wall relative to the intermediate fluid. Again there is opportunity for leak detection by providing a view glass in the intermediate tube. There are further similarities in the perFormance and cost categories both falling into the medium range. See illustration, page $\mathrm{A}-2$.

Tubes and Fins

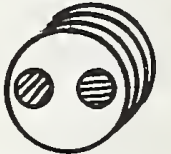

The "fin coll" heat exchanger was initially developed for the refrigeration industry but more recently has been applied to solar assisted domestic hot water systems. It consists of rows of tubes alternately containing heat exchange fluid and potable water connected by closely spaced fins of the same materials, usually copper. The fins conduct heat between alternate rows of tubes and serve to separate the potable water tubes from the non-potable tubes. The fins also provide an area for leaking fluid to drain and become observable. See illustration, page A-4.

Following the claim of the manufacturer and some users as well as engineering judgment these exchangers will be rated here as high in peformance and medium in cost. The extent of separation between potable and non-potable and the potential for leak detection would cause this type to have a very high safety ranking.

The "tube in a block" exchanger might be considered a variation on the "fin co11" exchanger. As the title suggests, this heat exchanger is distinguished by separate tubes containing the heat transfer fluid and the potable water, which are cast in a solid block of metal. In a way similar to the fins of the fin coll, the solid block (usually aluminum) conducts the heat from one tube to the other. The thermal performance and cost of this type would to a great extent depend upon the metal used as the "block". Generally, both cost and peformance will probably be in the medium to high range. 
This type consists of three separate tubes for (1) the heat exchanger fluid, (2) potable water, (3) and intermedlate "dead" passage. The dead passage is positioned between the other two tubes and conducts heat between them through Its walls. This provides a four wall separation between the exchanger fluid and the potable water. The dead passage provides a means of drainage for potential leaks and detection of leaks if proper "weep" holes are provided. There are strong similarities between this exchanger and the "fin coil" previously discussed, with the dead passage functioning in much the same way as the fins in exposing potential leaks but is a more "closed" detail. See illustration, page A-4.

The heat conductance paths through the dead passage tube walls is somewhat indirect and may result in some loss in efficiency. This design is just coming on the market and its cost would be greatly dependant on the manufacturer's process. Use of pressure welded metal sheets may simplify fabrication but could create potential for crevice corrosion.

Because of the extent of physical separation between the exchange fluid and the potable water, as well as the potential for leak detection, the safety for this design is assumed as better than adequate.

She11/Film and Pressure

This heat exchanger type might also be described as a "cascade" design. The potable water is contained in a conventional tank such as galvanized steel with a glass lining. The heat exchange fluid flows over the tank in a cascade bathing the entire surface in a film of exchange fluid. The cascading film is in a non-pressurized chamber so that under normal conditions the potable water is at a higher pressure than the exchange fluid therefore protecting the potable water In the event that a leak occurs. If the potable water pressure should drop for any reason a pressure sensor is actuated and the pump automatically stops the cascade of transfer fluid which drains to a harmless location beneath the tank. It is important to note that the transfer fluid reservoir is below the tank and therefore the container of the potable water is not in contact with the fluid when the film flow is stopped. See illustration, page A-3.

Although only a single wall separation is provided between the exchanger fluid and potable water, the uniqueness of the design stops the pump which stops the flow of the exchange fluid causing it to "fail safe" or in a mode avoiding a hazard. More than one failure would be required to create a hazard, 1.e., a leak and a flow control fallure, and thus essentially double protection is provided.

The thermal performance of this process is taken to be in the high category because of the efficiency of the neat transfer film. The cost may be considered to be moderate since many of the components are conventional water heater elements.

Heat Pipe

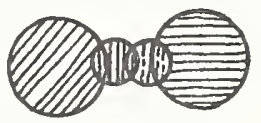

The heat pipe is not currentily used within solar energy systems but its potential for such application deems it appropriate for discussion in this context. 
It is a very effective heat exchanger that has successfully been used in waste heat recovery processes.

The operating mechanism of the heat pipe is very straightforward. The device makes use of a working fluid whose latent heat of evaporation is transferred from a heat source to a heat-utilizing medium by means of an evaporation-condensation cycle. Condensed liquid is returned to the heat source (the heat pipe evaporator) usually by gravity or by a self-contained pumping mechanism, i.e., wicking. The effectiveness of the process is such that heat pipes have been constructed with an equivalent thermal conductance more than ten thousand times greater than copper. Such highly effective heat transfer capability is not, however, the only attribute of the heat pipe. By suitable design, heat pipes can be constructed to serve such functions as precision temperature control, one-way transmission of heat (thermal diode) and heat flux amplification or diminution. The working fluids that can be used to achieve these effects range from liquid hydrogen for cryogenic temperatures to silver and copper at very high temperatures. Ammonia, freon or water would be appropriate working fluids for solar applications. See illustration, page A-4.

The thermal performance potential for heat pipes in both air and liquid solar energy systems is obviously very high but so is the cost at this time. Research and development is currently underway for passive solar applications of heat collection and storage which are strongly indicating cost effectiveness at this time. The working fluids of the heat pipe vary widely with the specific applications and it is premature to discuss the degree of toxicity at this time. The physical separations from the potable water would be single or double wall depending on the design integration with the potable water storage.

\section{Liquid to Liquid (Direct Contact)}

Investigation is in progress at Colorado State University [22] with a heat transfer process that eliminates the mechanical heat.transfer surfaces in the heat exchanger. This process would utilize an immiscible heat transfer liquid in direct contact with the storage water. Although there are no stated intentions of using the process to heat potable water, extensive toxicological evaluation is being made of the liquids proposed for use.

The 1iquid is delivered to the top of the storage tank, is broken up into droplets by a perforated plate and after flowing by gravity through the storage water (without mixing with it) collects in the bottom of the tank. It would then be drawn off and recirculated through the solar collector loop. Efficient heat transfer would occur across the large collective area of the droplets at temperature differences between the droplets and the storage water of only about $1^{\circ} \mathrm{F}$ or less. A temperature differential of up to 10 to $15^{\circ} \mathrm{F}$ is required in some of the more conventional heat exchangers. See illustration, page A-3.

It would be premature to try to evaluate the process as to efficiency, safety and cost. However, if suitable liquids are discovered, the potential for high thermal performance is great.

Plate Heat Exchanger

The plate type is a simple heat exchanger, resembling a plate and frame filter. It is made up of a "package" of gasketed plates, aligned top and bottom on carrying 
bars between two covers, and held by bolts. The plates have corner ports and nozzles with gaskets around these ports which control the flow of the liquids (HTF and potable water) in alternate spaces between the plates. Configuration of the gaskets at the port and perimeter provide two separated gasket walls between the two liquids at the entry port and provides an atmospheric drain channel to prevent possibility of gasket leakage between liquids. Plates can be designed so that there are no contact points between adjacent plates or so that there will be metal-to-metal contact between plates. The plates are stamped or pressed of thin sheets of stainless steel or a variety of other materials. Although there are two gaskets separating the liquids at the ports, there is only a single wall (plate) separating them in the process of heat transfer, therefore as currently used it is a single wall heat exchanger. See illustration, page $\mathrm{A}-5$.

The plate heat exchanger has been..."used extensively by industries having sanitary requirements," [23] e.g., the dairy industry for handling all types of milk and cream and for other beverages and food industries. As discussed in Section 4, the emphasis in these applications is on frequent cleaning and close monitoring of the heat transfer components. The consideration of using this type heat exchanger for solar DHW application is, as with food processing, based strongly upon the potential for disassembly and inspection of the components as well as its high thermal performance. The flexibility of this type lends itself to size and capacity modification, component replacement and cleaning on site.

Although simple in fabrication, the relative cost of this type is likely to depend on the feasibility of installation at the scale appropriate to DHW. Thermal performance is very high relative to most of the other types discussed and safety would be contingent upon the reliability of routine inspection, as mentioned above. This may be difficult to achieve and perhaps inappropriate for residential installation with toxic liquids. Consideration might be given to increased safety by introducing two walls or an intermediate transfer fluid on an alternating basis between the potable water and the heat transfer liquid (solar loop). The double wall or intermediate fluid would have the same advantages and be subject to similar conditions as those discussed in earlier examples.

\subsection{AVAILABILITY OF HEAT EXCHANGERS FOR SOLAR}

There has been a growing concern for the availability of double wall heat exchangers and general lack of awareness of who makes them. Contractors claim difficulty in obtaining them and yet a recent publication, "Solar Engineering Magazine", March 1978, indicates "More manufacturers offer double wall protection than single wall protection. There are 26 with double wall, 10 with single wa11 and 6 offering both features." [24]

Further investigation by the authors indicates that there are a small number of manufacturers making most of the heat exchangers and domestic hot water tanks being used. Many others, basically commercial firms, are marketing these and other components usually as a package solar DHW systems under a wide range of brand names. There is strong evidence that additional heat exchangers, some manufactured for other processes, are becoming available for solar application. 
Five of the largest manufacturers accounting for a large majority (greater than 2/3) of solar related DHW components have received the following certification from the International Association of Plumbing and Mechanical officials (IAPMO):

\section{MANUFACTURER}

American Appliance (Mor-Flo)

A. 0. Smith

Rheem/Rudd

State Industries

Ford Products

\section{TYPE OF IAPMO STATUS}

wrap around jacket type approved by IAPMO as Double Wall

approved by IAPMO as Double Wall

cascade or film flow type approved by IAPMO as Single Wall (IAPMO is currently considering Rheem's

"Double protection" which is provided by a pressure switch)

internal "flue" type coil, glass lined pressure drop warning and leak detection, approved by IAPMO as Single Wall

tube in a tube, somewhat controversial because of tight contact between the two tubes but has been accepted in some demonstration programs as double protecting, Ford has requested IAPMO application.

The W. L. Jackson Manufacturing Co., uses a wrap around, double wall heat exchanger type made by Energy Converters Inc. and may be considered among the large suppliers.

This is not intended to be an all inclusive list of manufacturers of heat exchangers for solar application. Others are listed in the above referenced issue of Solar Engineering Magazine. Still others are achieving double wall protection by using dual single wall exchangers and an intermediate fluid.

\subsection{HEAT EXCHANGER SELECTION}

Heat exchangers to a great extent determine the effectiveness at which collected energy is made available to heat domestic water. It is also the device that separates and protects the potable water supply from contamination if non potable heat transfer fluids are used. Similar to the selection of the fluids, basic considerations for heat exchanger selection include thermal performance, cost effectiveness, reliability and safety.

The following characteristics are important selection considerations:

(a) Heat exchange effectiveness

(b) Pressure drop-operating power, flow rate

(c) Physical design, configuration, size, materials and location in the system

(d) $\operatorname{Cost}(\mathrm{s})$ and availability 
(e) Protection of the potable water supply from contamination by the heat transfer fluids, reliability

(f) Leak detection, inspection, maintainability

(g) Material compatability with other system elements i.e. metals and fluids

(h) Thermal compatability with system design parameters, i.e. operating tempertures, flow rate, fluid thermal properties.

Some of these characteristics are discussed in Section 3.2 and illustrations are given in Appendix A. The interdependence of choice of heat exchangers and heat transfer fluids is to be noted with respect to safety as well as thermal performance.

4. RELATED APPLICATIONS

\subsection{HEAT EXCHANGERS USED IN FOOD PROCESSING}

The uses of heat exchangers in food processing is in many ways an analogous situation to that of domestic water heating in solar assisted systems. Heat transfer fluids very similar to those used in some solar energy systems are brought into close proximity to foods or beverages in a variety of processes. Heat exchangers are used in various phases such as manufacturing, preparation and temperature retention. The processes include such widely divergent activities as scalding poultry and hogs with a mixture of propylene glycol and water, use of ethylene glycol in heat exchangers to cool milk or to make ice cream and other heat transfer means to heat or cool beverages in dispensing machines. The heat transfer process in water fountains and ice making will be covered in a subsequent section.

The major emphasis with food product related exchangers is cleanliness, frequent inspection and accessibility for cleaning. Stainless steel is most frequently used with specific attention given to gaskets and fittings. The heat exchangers most frequently used are single wall, usually of the plate type and frequently "scraped" or with surface configurations to create turbulent flow. The major point to be made is that few standards exist to regulate heat exchangers in food processing and none that determine the types used (such as double wall.)

Occasionally in the processing of milk but more frequently in the freezing of ice cream an aqueous solution of ethylene glycol is used as a heat transfer fluid. The stainless stee1, plate type, heat exchangers used provide only a single wall separation between the ice cream and the ethylene glycol solution.

According to one authority with the Dairy and Food Industries Supply Association (DFISA) this is common practice [25].

Some heat transfer fluids used in solar heating and cooling systems such as propylene glycol and glycerin are known to be used in the preparation of and even as additives to foods, pharmaceuticals, and other products. However, the fluids as used above would most likely be chemically pure, contain no harmful additives and would not be exposed to temperatures that could result in thermal decomposition. Fluids used in solar energy systems are frequently degraded and complicated by some or all of these factors. Furthermore, in most of these food 
related processes there is a system of control and monitoring of the products which is not the case with domestic hot water. Frequently there is also a large amount of product compared to the amount of heat transfer fluid used.

The use of propylene glycol is a common and accepted practice in the scalding of poultry, tripe and hogs. Its use is permitted at "sufficient" levels if removed by rinsing. Labeling is required for chemicals used in washing, denuding or otherwise processing poultry, tripe or hog carcasses including maximum allowable concentrations of use for the preparation. Polyethylene glycol is used as a boiler water additive for steam preparation of similar foods.

Heat exchangers used in food processing are not generally regulated with regard to design or extent of separation of heat exchange fluids and food products. Provisions covering materials used, and accessibility for cleaning dominate the standards written for food related heat exchangers.

The following excerpts taken from "3-A Sanitary Standard for Tubular Heat Exchangers for Milk and Milk Products" (serial 非204) [26] are typical and are cited here for their relevance to issues raised in this report.

Materials

C.1 All product contact surfaces shall be of stainless steel of the American Iron and Steel Institute (A1S1) 300 series of corresponding Alloy Casting Institute ( $\mathrm{ACl}$ ) types, or equally corrosion resistant metal that is non-toxic and non-absorbent except that:

C.1.1 Optional metal alloy may be used formulated by: International Association of Milk, Food and Environmental Sanitarian, United States Public Health Service, The Dairy Industry Committee, but only in applications requiring disassembly and manual cleaning. (See Appendix, Section $G$ for the composition of an acceptable optional metal alloy.)*

The standard developed for plate type heat exchangers for milk and milk products has the following provision under FABRICATION:

$\mathrm{D}-7$

A leak protector groove of sufficient width to be readily cleanable and open to the atmosphere at both ends shall be provided to allow

leakage past gaskets to drain to waste.

\subsection{HEAT EXCHANGERS USED IN FOOD AND BEVERAGE DISPENSING}

The following is taken from the National Sanitation Foundation, Standard for Automatic Ice Making Equipment: [27]

*An Alloy of the composition given above is properly designated "nickel silver", or according to ASTM Specification 非 149-70, may be entitled, "leaded nickel bronze." Copper makes up approximately $62 \%$ of this alloy. 
4.30 Refrigeration Components: (4.30.1) Coils and Tubing: Evaporation coils and refrigerant tubing shall be of such material that it will not contaminate the product and shall conform to cleaning requirements. Refrigeration coils, if exposed within the ice storage bin, shall be finless type and so located that they can be easily cleaned.

Similar wording is used in a provision covering refrigeration components for Vending Machines for Foods and Beverages (Standard 非5) but the following is added:

If a blower or fin type evaporator is used, it shall be enclosed in a housing to protect against spillage of food or beverage, and such housing shall provide for drainage of any accumulation of condensate. Refrigeration coils shall be protected against spillage of foods or beverages.

According to the National Automatic Merchandising Association (NAMA), the most common and almost universal method of heat transfer used to cool potable water, syrup and (in pre-mix units) carbonated soft drinks has been through immersion of the potable liquid in "pre-cooling" coils or submerged syrup wells in refrigerated, atmospheric waterbath compartments [28]. For many years, the immersed water tubing in vending machines was single wall copper in 20-25 foot coils about 12 inches in diameter. For copper poisoning protection, all venders now use stainless steel for both the product water and the syrup tubes (which also are submerged for cooling).

NAMA has never had a report involving accidental contamination of products as a result of tubing immersion. This, of course, does not guarantee that ruptures have not occurred. However, a rupture would result immediately in overflow of the water bath into the waste pail cut-off control (a Manual requirement) and failure of the carbonator to function. A service call would result and probably be reported to the NAMA.

NAMA publishes a Vending Machine Evaluation Manual used in their Machine Certification Program. Last year (1977) their Health-Industry Council approved a proposal to spell out a prohibition of any plumbing connections or fittings in potable cooling water. This has been an unwritten rule and industry practice which has not been included in earlier drafts of the Evaluation Manual. While explaining that waterbath cooling liquids of a toxic nature have not been used, NAMA expressed reluctance to such a practice unless there were standards for:

(a) tubing materials gauge and ductility

(b) pressure tests after forming

(c) corrosion resistance to the coolant used

(d) freedom from fittings on other connections below the overflow spill level

(e) if possible, a shut-off in case of pressure loss or vacuum in the potable water 


\subsection{CODES AND STANDARDS FOR SOLAR HOT WATER SYSTEMS}

Standards and codes for solar energy systems are not yet broadly developed since this represents a relatively new technology. NBS has recently completed review of statutes and state legislation related to solar energy of buildings $[29,30]$. With some notable exceptions there is little definitive work at this time especially on the subject of heat exchangers. There is however, growing commitment and activity to meet the need for standards at the National as well as state levels among standard promulgating organizations.

The building codes of most states and local jurisdictions do not deal specifically with the installation of solar hot water systems. However, minimum guidelines for solar systems were recently proposed in the city of Los Angeles and are undergoing public hearings [31]. The guidelines set out the building permit and operating requirements for installation of solar systems. These guidelines are the only code document in which double-wall designs are specifically required for heat exchangers used with solar assisted domestic hot water systems. The pertinent criterion is:

"Heat Exchangers Containing Potable Water: Double wall separation is required between any toxic fluids and the potable water supply. In addition, the heat exchanger must have an exposed area where leaks in the system can be seen. Only single wall separation is required if a non-toxic fluid is used. However, the system must be under manufacturer's control of guarantee that no toxic fluid will be used in the system. Evidence shall be provided that a quality assurance program is employed by the manufacturer. If the system is not under manufacturer's control, the Testing Laboratory will not approve single wall systems."

This imposes a severe requirement on the heat exchanger manufacture if a single wall design is used. Essentially, he must guarantee that toxic fluid will never be used in the system. There is however a similar provision for the control of heat transfer fluids in refrigeration systems.

The following is taken from the BOCA (Building officials and Code Administrators) Basic Mechanical Code, 1978. [32]

M-812.2 Refrigerant substitution: Substitution of kind of refrigerant in a system shall not be made without the permission of the administrative authority, the user, and the makers of the original equipment, and with due observance of safety requirements including:

1) the effects of the substituted refrigerant of materials in the system;

2) the possibility of overloading the liquid receiver which should not be more than eighty (80) percent full of liquid;

3) the liability of exceeding motor horsepower, design working pressure or any other element that would violate any of the provisions of this article; 
4) the proper size of refrigerants controls;

5) the effect of the operation and setting of safety devices;

6) the possible hazards created by mixture of the original and substituted refrigerant; and

7) effect of the classification of the refrigerant as provided in this article.

The following provisions from SMACNA (Sheet Metal and Air Conditioning Contractor's National Association) [33] demonstrate the position of this group.

SMACNA - Heating and Air-Conditioning System Installation Standards For One and Two Family Dwellings and Multi-Family Housing

Section 25.4 - Domestic Water Preheating Systems

(a) Collectors - Domestic water can be preheated by circulating the potable water supply through solar collectors.

(b) Preheat Coil in Storage - A suitable sized coil installed in the therma 1 storage container of a solar space heating system allows the potable water supply to pass through the heated container prior to entering the auxiliary storage tank. Unless the coil and piping has double wall construction, this method can only be used for liquid type solar systems employing non-toxic storage media.

(c) Preheat Tank in Storage - The domestic water preheat storage tank is located within the thermal storage container of a solar space heating system. The water supply passes through the storage to the preheat tank where it is heated, stored, and piped to the auxiliary water heater prior to distribution. Double wall construction will be necessary unless a non-toxic storage media is used.

(d) Preheat Coil or Tank Outside of Storage - Heated liquid from the thermal storage container of a solar space heating system is pumped to a heat exchanger - coil or tank - for domestic water preheating. If liquid from thermal storage is toxic, the required separation is achieved by two separate heat exchanger coils with a preheat tank or by use of a doublewalled heat exchanger.

The preceeding standards of SMACNA follow very close to the S/MPS (Intermediate Minimum Property Standard, HUD) provisions in the introduction. However, there is no recognition of...providing equivalent safety.

The problem is complicated by the lack of definitive standards as to what constitutes acceptable double wall or equivalent protection as well as the lack of concise definition of non-potable and toxic liquids. Standards for double wall designs are currently being developed by American Society of Mechanical Engineers (ASME).

The Toxic Substances Control Act (P.L.94-469; October 12, 1976) [34] authorizes EPA to protect health and environment from harmful chemicals and mixtures (35). 
The Act creates new requirements for testing, reporting and recordkeeping. A preliminary listing of chemicals listed for further consideration (as toxic) under that Act was published in July 1977 [36].

A summary of provisions directly related to solar energy installations is included in Table 8. Survey of Recommended Installation Procedures for Heat Transfer Systems and Heat Exchangers. [37]

Although there is considerable controversy and local exceptions, current enforcement by building authorities is following close to the attitude expressed in these provisions. The Washington Surburban Sanitary Commission (WSSC) for example takes a very similar approach to the problem "while awaiting more official guidelines from the state" [38]. The WSSC plumbing board recently (June 1978) passed a resolution permitting the use of propylene glycol as a heat transfer fluid with single wall heat exchangers in solar DHW systems which are closed loop systems with pressure fill requirements. Similar criteria are used in approval of systems in which domestic water is heated by more conventional oil or gas fired furnaces. If a toxic transfer liquid is used, double wall separation is required. If there is exposure only to the combustion gases or if a closed loop of stagnant water is used, double wall heat exchangers are not mandatory.

An oil fired boiler by the New Yorker Steel Boiler Co. provides as an option a factory-installed tankless copper coil for domestic hot water. It is frequently used (as are other makes) for outside installations for houses without flues or chimneys. The New Yorker Co. recommends propylene glycol inhibited with dipotassium phosphate as a "non-toxic" heat transfer liquid in such installations. [39]

\subsection{RELATED CODES AND STANDARDS}

The following are citations from codes and standards regarding double-wall separation between potable and non-potable fluids in refrigerant systems.

1. ANSI Al12.11.1, 1973 (ARI Standard 1010-73), "Standard for Drinking Fountains and Self-Contained, Mechanically Refrigerated Drinking Water Coolers" [40]:

"4.4.3 - If a precooler is used, it shall provide more than a single thickness of metal between the potable water and the waste water in the heat exchanger."

2. Military Specification, "Cooler, Drinking Water, Mechanically Refrigerated, Self-Contained, Naval Shipboard" 1965 [41]:

"3.10.1.1 - Refrigerant Coil. The Refrigerant coil shall be nonferrous, external to the water storage tank and continuously bonded to it. The use of additional refrigerant to water cooling by means of tube in tube or tube on tube exchanger will not be permitted. Sufficient coil surface shall be provided to permit operation in accordance with the requirements of 3.12 ." 


\section{HUD \\ INTERMEDIATE \\ STANDARD}

\author{
SMACNA \\ Installation \\ Standards
}
IAPMO
Solar
Code

LOS ANGELES

Mayor's

Committee Code

\section{Piping}

S-615: Refers to

local plumbing

code

Pages 3-2:
Outlines basic
design information;
no standards or
codes given

Pages 3-2,2:

Pump capacity

must match

required head

and $\mathrm{gpm}$

\begin{abstract}
Page 36, Section
402B: Non-potable

water lines must

be posted, "Danger

Unsafe Water."

Other pages list

acceptable piping

Page 25, Section

301: Components

shall conform with

acceptable codes,

rules, regulations,

ordinances
\end{abstract}

Hydraulic

HEAT TRANSFER FLUIDS

\section{Separation \\ S-615-10.1.1 \\ Systems must \\ have minimum \\ 2 walls between \\ potable and non- \\ potable water... \\ (...or provision \\ for equivalent \\ safety)}

Toxic Materials

S-615-8: Any toxic solution must carry a strong non-toxic dye or other means of leak detection (and warning)
None

Page 8-1: A double wall heat exchanger is mandatory with toxic fluids
Pages 35-36

Sections 401 and

402: Direct connections between potable and non-potable lines require backflow prevention devices

None A double wall heat exchanger is mandatory with toxic fluids (Manufacturer must guarantee that toxic fluids are not used with single wall)

HEAT STORAGE SYSTEMS

Heat Exchanger S-515-9 and S-615-12: Manufactured by TEMA requirements. Double-wall between potable and non-potable liquids
Page 4-2. Must be Page 37, Section manufactured to 403E: Copper tube comply with TEMA requirement heat exchanger bundle shall be constructed of not less than Type

L copper tube
Copper tube heat exchanger bundle shall be constructed of not less than Type L copper tube 
"3.10.4 - A precooler, where provided, shall be constructed on non-ferrous seamless tubing. Both inlet and drain water passages shall be fully enclosed with two walls of metal separating the incoming drinking water from the drain water.

3. Chicago Building Code, 1976 [42]:

"Refrigerant Condensers, 83-44

Refrigerant Condensers. No refrigerant condenser of the water jacket type with a common wall between the refrigerant gas and the cooling water shall be directly connected to the city water supply."

It should be noted that provisions for water cooler applications relate to circumstances in which there is direct and usually complete ingestion of the potentially affected potable water. Although the level of toxicity of transfer fluids used in these water coolers may not be as great as some used in solar assisted water heaters, the probability of dilution is also less.

The regulatory control of refrigerants in various refrigerating systems offers another comparison that is pertinent to the consideration of transfer fluids and heat exchangers used with solar assisted domestic hot water systems. The mechanical codes of the model code organizations [BOCA [32], Sect. M-803-805, ICBO [43], Sect. 1503-1507, SBCC [44], Sect. 401-404) contain the following provisions which are outlined here and cited below.

o Refrigerating systems are classified by the method employed for extracting heat. (Determined by the directness the evaporate refrigerant is in contact with the material or space refrigerant is in contact with the material or space refrigerated)

o Refrigerants are classified and grouped by their toxicity or flammability. (ICBO uses two groups, BOCA and SBCC use the same but add a third group)

- The above classifications determine a variety of restrictions and requirements

The BOCA Basic Mechanical Code, [32] 1978 Sections M-803.0, 804.0, 805.0, (pp. 170 to 175) are included in Appendix C.

The following definition of potable water and non-potable water and the provision taken from Section 10.4 (Protection of Potable Water Supply) are taken from the National Standard Plumbing Code [45] and are appropriate to state here. (The same language is included in Section P-1605.0 of the BOCA Basic Plumbing Code).

Potable water - Water free from impurities present in amounts sufficient to cause disease or harmful physiological effects and conforming in its bacteriological and chemical quality to the requirements of Public Health Service Drinking Water Standards or the regulations of the public health authority having jurisdiction. 
Non-potable water: Water not safe for drinking, personal, or culinary use.

10.4.11 - Refrigerant unit condensers and cooling jackets:

Except where Dotable water provided for a refrigerator condenser or cooling jacket is entirely outside the piping or tank containing a toxic or flammable refrigerant as defined in ANSI B9.1, Paragraphs 5.1.2 and 5.1.3 with two (2) separate thickness separating the refrigerant from the potable water supply, inlet connection shall be provided with an approved check valve. Also adjacent to and at the outlet side of the check valve, an approved pressure relief valve set to relieve at five (5) psi above the maximum water pressure at the point of installation shall be provided if the refrigeration units contain more than twenty (20) pounds of refrigerants.

The above definition of potable water is helpful but it does not necessarily provide a definition of potable substances other than water. This also implies that there is no standard definition for non-potable substances such as might be used as heat transfer fluids in solar energy systems.

The precedent established by the classification and grouping of refrigerants may provide a means of utilizing various heat transfer fluids by groups in solar assisted domestic hot water systems with adequate safety. The precedent of classifying refrigerating systems by type may also suggest requirements for the extent of separation of solar loop fluids and potable water.

The separation of services such as water service piping and building drain or sewer offers an additional point of view of protection by separation. Most model codes require a separation by at least 10 feet of compacted earth between these services.

The following provision related to fixtures and devices, including heat exchangers. is cited in the proposed (1978) plumbing code by ICBO (International Conference of Building Officials) [46] under Cross-connection Control.

Sec. 1604. (a) General. 1. Measurement. The minimum reauired air gan shall be measured vertically from the lowest end of a potable water outlet to the floor rim or line of the fixture or receptacle into which it discharges.

2. Size. The minimum required air gap shall be twice the effective opening of a potable water outlet unless the outlet is a distance less than three times the effective opening away from a wall or similar vertical surface, in which cases the minimum required air gap shall be three times the effective opening of the outlet. In no case shall the minimum required air gap be less than shown in Table No. 16-A.

(b) Devices. Approved backflow preventers or vacuum breakers shall be installed with all plumbing fixtures or equipment, the potable water supply outlet of which may be submerged and not protected by a minimum air gap.

The potable water supply system shall be protected against backflow from the following fixtures or equipment by one or more backflow-prevention devices as indicated: 
1. Low inlet to receptacles containing toxic substances

(vats, storage containers, plumbing fixtures):

a. An approved air-gas fitting.

b. Reduced-pressure unit.

c. Pressure vacuum unit.

d. Atmospheric vacuum breaker unit

2. - - - - -

3. - - - - -

4. Coils or jackets used as heat exchangers in compressors, degreasers and other such equipment involving toxic substances:

A. An approved air-gap fitting

B. Reduced-pressure unit

C. Pressure vacuum breaker unit

In section 1602. Installation-General, these provisions are made for protection of the potable water supply and for the labeling and warning of non-potable water lines.

4. Refrigeration Equipment. Except where potable water provided for a refrigerator condensor or cooling iacket is entirely outside the piping or tank containing a toxic or inflammable refrigerant with two separate thickness of metal separating the refrigerant from the potable water supply, inlet connection shall be provided with an approved check valve. Also, adjacent to and at the outlet side of the check valve, an approved pressure-relief valve set to relieve at 5 psi above the maximum water pressure at the point of installation shall be provided if the refrigeration units contain more than 20 pounds of refrigerants.

(f) Identification. In all buildings where dual water-distribution systems are installed. one potable water and other non-potable water, each system shall be identified either by color marking or metal tags or other appropriate method such as may be approved by the building official. Each outlet on the non-potable water line which may be used for drinking or domestic purposes shall be posted: DANGER-UNSAFE WATER

\subsection{CURRENT ACTIVITY AND RESEARCH}

Sandia Laboratories is currently revising an interim report which will be titled "Hazardous Properties and Environmental Effects of Materials Used in Solar Heating and Cooling (SHAC) Technologies" [13]. A draft report has been circulated for comments and contains useful information on toxicity and other characteristics of a large number of chemicals used as heat transfer fluids, fluid treatment, thermal degradation and outgassing products. Much of this information has been taken from work cited earlier in this report (Gosselin et al and Durham), $[5,6]$ excerpts of which are included in the appendix.

The objective of the Sandia report is to ultimately provide a handbook of hazardous properties and environmental effects of potential SHAC materials. 
The intent is to produce a handbook that layman and professional alike can use as a guide in selecting materials for the various SHAC techniques.

Research is underway at Lovelace Biomedical and Environmental Research Institute, Albuquerque. New Mexico on the toxicology of solar heating and cooling materials. This work, supported by the Department of Energy (DoE) addresses itself to the need for characterization of toxicity under normal and abnormal conditions such as combustion and over pressure. The objective is to conduct hazards assessment as needed to define and quantify health effects associated wi.th the large-scale utilization of solar heating and cooling.

This research should add significantly to the knowledge of toxicity of fluids used in solar energy systems and should provide an assessment as to the accuracy of literature on the effects of ingestion of these materials.

The American Society of Mechanical Engineers (ASME) has established a Solar Energv Standards Development Committee which in its scope includes:

"the preparation of a standard for design, materials, fabrication, installation and testing of solar collectors, thermal storage subsystems, energy transport subsystems, heat exchangers, pumps, fittings and valves."

The subcommittee (of the Standards Development Committee) concerned with heat exchangers is active and has taken the direction of seeking classification of heat transfer fluids into three groups and will attempt to determine heat exchanger design standards which correspond to the hazard level established for these groups. General discussion has suggested the following groups although there is apparent difficulty in defining adequate heat exchanger protection as well as levels of toxicity.

\section{HTF GROUPS}

(A) Potable Fluids

(B) Non-potable, practically non-toxic fluids

(C) Toxic fluids

\section{HEAT EXCHANGER PROTECTION}

(1) Single wall with no (leak) detection

(2) Double wall with no (leak) detection

(3) Single wall with (leak) detection or additional level of protection

(4) Double wall with (leak) detection or additional level of protection

Defining non-toxic as distinguished from non-potable fluids is also difficult. The Federal Hazardous Substances Act specifies that:

"The term 'toxic' shall apply to anv substance (other than a radioactive substance) which has capacity to produce personal in jury or illness to man through ingestion, inhalation or absorption through any body surface."

Referring to definitions for potable and non-potable water stated earlier in this report it is difficult to discern any clear difference between the definitions of "non-potable" and "toxic". 


\subsection{NEED FOR SAFETY GUIDELINES}

The solar energy industry represents a new and emerging technology. In spite of its successes, some technical problems still need to be solved. The heat transfer medium and the heat exchanger are among the more significant components of the individual systems. If unduely restrictive requirements are placed on these or other major components progress could be restrained. On the other hand, these components may constitute a real hazard in some systems. A serious breach of safety would not only be a threat to individual health but to the credibility of solar technology. This dilemma requires thorough consideration to assure reasonable cost effective solutions with adequate protection of life and health.

"It is very difficult for the system designer to assess the safety of the heat transfer fluids that are currently on the market. It is also very difficult for the designer to determine the safeguards that must be taken to ensure safe system operation. Data are available in the literature that rank various heat transfer liquids on the basis of their relative toxicity. However, these data do not indicate the cut-off points at which various degrees of protection must be taken. For example, a number of the toxicity tables list propylene glycol as slightly toxic. A substance with such a ranking most likely does not fit under the definition of potable in which case no safety precautions need to be taken, yet it is not as hazardous as many other substances that are used in heat transfer fluids. This problem is compounded by factors such as: (1) the use of additives to modify fluid properties; (2) the possible formation of harmful decomposition products, e.g., by thermal degradation; (3) the fact that liquids are generally available in varying grades of chemical purity; (4) the possibility that the system will be refilled in the future with a hazardous liquid; and (5) the possibility that circulation in a closed loop system for prolonged periods of time will eventually result in the contamination of potable liquids, e.g., by metal ion buildup." [4]

Adequate precedents exist in related systems such as refrigeration systems to establish a concept for safety guideline for these solar energy components. Many of the same trades and individuals familiar with conventional mechanical systems will be involved with the solar energy systems. There is a safety margin to be gained by remaining consistant with established criteria.

Strong consideration should be given to creating an informed and responsible public. An assessment should be made of probable owner involvement with the maintenance and operation of the solar energy systems. Creating a foolproof system may not be necessary or even desirable. With proper instruction. operating manuals, labeling, tagging, etc.. it is not unreasonable to expect a responsible role for the home owner or occupants in regards to inspection for leaks, malfunctions. potential hazards and assuring against the use of improper fluids. Again, there is a margin of safety to be gained developing owner and public awareness and creating an attitude for responsibility. It is when people are unaware that they are most vulnerable.

\section{SUMMARY AND RECOMMENDATIONS}

Findings: The need to utilize a heat exchanger fluid other than water in solar hot water systems coupled with the lack of service experience of these systems has raised an important safety issue with regard to the design of the heat 
exchanger in the collector/storage loop. That is, possible contamination of the potable water supply if failure of a heat exchanger should occur. The level of protection might be developed in keeping with the level of the hazard, but it is important that the complexity of the hazard is not overlooked. These complexities include; the combined effects of a mixture of toxic fluids, volume of contaminant leakage, and dilution within the potable water. It seems appropriate that individuals with training in health and medicine be included in the determination of the hazard level. Risk analyses which include the extent of the hazard as well as the probabilities of failure of the heat exchanger components, pressure differentials and leak detection would be in order.

The margin of safety may be increased by use of back-up measures and fail-safe devices with little increase in cost or effort. These include measures such as: a concentrated tracer dye, pressure drop safety switch and contamination detection safety switch. Warning labels or tagging as well as special fit design of the fluid filler cap will add further to the safety margin.

The objective of this study was to review available information of a technical and regulatory nature relative to the issue which may provide a basis for evaluating solar heat exchanger designs. Another objective was to identify areas of needed research.

The findings of this study relative to this issue are as follows:

A. A clear definition of toxicitv which can be uniformly applied is lacking. Test methods which can evaluate the hazard associated with the accidental missuse of heat transfer fluids are not available.

B. Currentlv available standard tests for heat transfer fluids to evaluate both short-term and long-term effects may not be applicable to solar equipment operating conditions. Tests are needed in the area of corrosivity and degradation of the fluids over time.

C. Generally, building codes contain little in regard to the heat exchanger toxicity question. Those regulations which are available are inconsistent.

D. An insufficient data base is available for the satisfactory prediction of the loss of thermal efficiency when using a "double-wall" heat exchanger as compared to "single-wall" construction in the same system.

E. The historical development of "double-wall" construction in the refrigerant system of drinking water coolers demonstrates the precedent for a conservative approach to the problem of potential contamination of potable water in a solar hot water system as long as failure rate of the materials involved and service life of the system cannot be documented.

F. Even though a solar hot water system is designed to use a "nontoxic" heat exchanger fluid, consideration should be given to the possibility that a "toxic" fluid could inadvertently be installed at a later date. 
G. There is concern that "non-toxic" fluids will become toxic by the use of contaminating additives, decomposition products or from impurities within closed loop systems. There is also concern that the quality or "purity" of some fluids used in solar energy systems may be inferior to those for which toxicity ratings are given or those used in other processes such as food production.

H. Data accumulated during the study will not allow a quantification of "equivalent safety", as specified in Criterion 4.6.2 of the IPC [2]. It is recognized that systems could utilize leak detection techniques such as color change detection, pressure change detection, contamination detection or other means to determine when a heat exchanger has failed and perhaps deactivate the system. These should be evaluated on a case-by-case basis.

I. The selection of a heat transfer fluid requires the consideration of several variables which have impact on system design. No single heat transfer fluid is optimal in all the desired characteristics and tradeoffs should be considered. For example, the desirable property of low toxicity may be offset by high viscosity which may require the increased cost of a larger pumping capacity and piping system.

J. While the design pressure in the collector/storage loop is usually lower than that in the hot water storage tank and therefore would tend to keep the heat transfer fluid in the collector loop from mixing completely with the potable water in the tank in the event of a wall rupture; this is not sufficient protection because it does not accommodate the emergency situation of a loss of city water pressure.

K. There is no direct data available to determine the cost impact of "double wall" heat exchangers.

RECOMMENDATIONS: While this state-of-the-art study has identified a large amount of data relative to solar heat exchangers, considerable data are still needed before a less conservative approach relative to Criterion 4.6 .2 can be taken. At the present time, approval for the use of liquids other than potable water (or documented non-toxic fluids) in conjunction with single wall heat exchangers should be on a case-by-case basis.

Efforts at this time should be placed on the "double failure" concept to provide equivalent protection. A closer correlation between health risk and protection level should be sought. Trade-offs between, heat exchanger protection, transfer fluid toxicity and effectiveness and double failure innovations should lead to cost effective designs for solar DHW systems with retention of high safety standards. As results are obtained from the efforts to classify and group heat transfer fluids and to assess their toxicity under actual operating conditions, the current criterion may be relaxed. Data relative to toxicity, corrosivity, thermal efficiency, etc., can be obtained in part by conducting research listed below, as well as, from documentation of system performance in the DoE and HUD Solar Demonstration Programs.

Specific research and standards needs are as follows: 
1. Thermal performance of "double-wa11" heat exchangers as compared to "single-wall" designs in similar systems. Theoretical predictons should be validated by laboratory testing.

2. Tests methods and standards for evaluating the characteristics of heating transfer fluids such as toxicity, long-term degradation etc., should be developed.

3. Long-term effects of heat transfer fluids on the solar system components (heat exchanger, piping, etc.) should be studied and uniform methods of evaluation developed.

4. Work should be continued in the development of uniform building regulations relative to the safety of solar energy systems. 


\section{REFERENCES}

1. "Interim Performance Criteria for Solar Heating and Combined Heating/Cooling Systems and Dwellings," Nationa1 Bureau of Standards, Washington, D.C. January 1, 1975, (Available through Superintendent of Documents, U.S. Government Printing office, Washington, D.C. 20402, Stock No. 0324-01043).

2. "Interim Performance Criteria for Solar Heating and Cooling Systems in Commerical Buildings," National Bureau of Standards Report NBSIR 77-1187, November 1976 (Available from NTIS, Order No. PB-262-114).

3. "HUD Intermediate Minimum Property Standards Supplement - Solar Heating and Domestic Hot Water Systems," U.S. Department of Housing and Urban Development, 1977 Edition.

4. Waksman, David and Holton, John., "Environmental and Safety Considerations for Solar Heating and Cooling Applications," (publication in preparation) National Bureau of Standards, Washington, D.C.

5. Durham, W.F., "Toxicology" in Dangerous Properties of Industrial Materials, 1975, (Sd) N. I. Sax, ed. Van Norstrant Reinhold Co., Baltimore, Maryland.

6. Gosselin, Hodge, Smith and Gleason, "Clinical Toxicology of Commercial Products," 1975, 4th edition, Williams and Welkins Co., Baltimore, Maryland.

7. Registering the Toxic Effects of Chemical Substances, HEW Publication No. (H 10 SH) 76-191, 1976 Edition.

8. Registry of Toxic Effects on Chemical Substances, Christensen, H.S. and Fairchild, E.J., National Institute for Occupational Safety and Health, U.S. Department of Health, Education, and Welfare, Rockville, MD, 1976 Edition.

9. "Evaluation of Backflow Prevention Devices: A State-of-the-Art Report," National Bureau of Standards Report NBSIR 76-1070, June 1976.

10. Safe Water Drinking Act, Public Law 93-523, 40 FR 11990.

11. National Interim Primary Drinking Water Regulations, Federal Register, December 24, 1975.

12. National Secondary Drinking Water Regulations, Federal Register, March 1977.

13. Searcy, J. Q., "Hazardous Properties and Environmental Effects of Materials Used in Solar Heataing and Cooling (SHAC) Technologies," rough draft, Sandia Laboratories Interim Report, SAND 78-0842, June 1978.

14. Energy and Environmental Analysis, Inc., Draft Environmental Impact Statement of the National Solar Heating and Cooling Program, draft report for the Department of Energy, December 1977. 
15. Benyon, Eric, "Inhibited Ethylene Glycol as the Solar Nexus," International Corrsion Forum, San Francisco, California, March 1977.

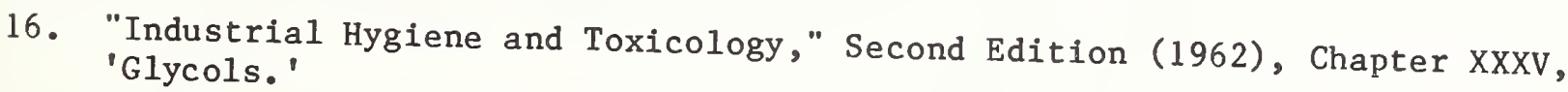

17. Sax, Newton Irving, "Dangerous Properties of Industrial Materials, Reinhold Publishing Corporation, New York (1957). 18. J. C. Harms, A.0. Smith Manufacturing Co, private communication, July
1977. 19. Uhlig, Herbert H. Corrosion and Corrosion Control, Second Edition,
John Weteg \& Sons, Inc.

20. Hatch, George B., "Inhibitors for Potable Water," Corrosion Inhibitors, National Association of Corrosion Engineers, Houston, Texas, 1973.

21. ASHRAE Handbook of Fundamentals, American Society of Heating, Refrigerating and Air-Conditioning Engineers, Inc., 345 East 47 th Street, New York, N.Y.
$10017,1977$.

22. Ward, J., Loss, W., Loff, G., Direct Contact Liquid-Liquid Heat Exchanger for Solar Heated and Cooled Buildings: Pilot Plant Results, Solar Energy Applications Laboratory, Colorado State University, for Department of Energy
Contract No. EY-76-5-02-2867, September 1977 . 23. Hargis, Alice M., Beckman, Arthur, Loiscono, John, "The Plate Heat Exchanger",
American Society of Mechanical Engineers, 1966.

24. Solar Hot Water Packages, Solar Engineering Magazine, March 1978. 25. B. H. Williams, Dairy and Food Industries Supply Association, private
communication, January 17, 1978 .

26. 3-A Sanitary Standards for Tubular Heat Exchangers for Milk and Milk Products, Serial Number 1204, Formulated by: International Association of Milk, Food and Committee, reprinted from, United States Public Health Service, the Dairy Industry Vol. 35, No. 3 . 27. Standard No. 12 for Automatic Ice Making Equipment, National Sanitation Founda-
tion, June 1964, revised November 1977 .

28. David E. Hartley, Public Health and Safety Council, National Automatic Merchandising Association, private communication, February 1978.

29. NBSIR 76-1082, "A Survey of State Legislation Relating to Solar Energy," Robert M. Eisenhard, National Bureau of Standards, April 1976.

30. NBSIR 77-1279, "State Solar Energy Legislation of 1976: A Review of Statutes Relating to Buildings," Robert M. Eisenhard, National Bureau of Standards,
September 1977 . 
31. City of Los Angeles, "Guidelines for Laboratory Approval of Solar Systems," (proposed rule of general application--public hearings held on July 12, 1977) Department of Building and Safety, 402 City Ha1l, Los Angeles, California 90012.

32. Basic Mechanical Code, Building Oficials and Code Administrators, 1978.

33. "Heating and Air-Conditioning Standards for One and Two Family Dwellings and Multifamily Housing Including Solar," Sheet Metal and Air-Conditioning Contractors National Association, Inc., 1977.

34. Toxic Substance Control Act, Public Law 94-469, October 11, 1976.

35. Christensen, Herbert E., and Lugenby D., Thomas T., editors, "The Toxic Substances List 1974 Edition," U.S. Department of Health Education and Welfare: Public Health Service, Center for Disease Contro1, National Institute for Occupational Safety and Health, June 1974.

36. "Preliminary List of Chemical Substances for Further Evaluation," Toxic Substances Control Act Interagency Testing Committee, U.S. Environmental Protection Agency, Office of Toxic Substances, July 1977.

37. Solar Engineering Magazine, August 1977.

38. L. G. Norrington, Washington Suburban Sanitary Commission, private communication, February 1978 .

39. Steve Amicone, New Yorker Steel Boiler Co., Colman, Pa, private communication, February 1978.

40. ANSI Al 12.11.1, 1973 (a1so ARI Standard 1010-73), "Standard for Drinking Fountains and Self-Contained, Mechanically Refrigerated Drinking Water Coolers."

41. Military Specifications, "Cooler, Drinking Water, Mechanically Refrigerated, Self-Contained," Naval Shipboard, MIL-C024116A (SHIPS).

42. Chicago Building Code, Volume 23, Paragraph 83-44, 308 West Randolph Street, Chicago, Illinois 60603, February 1976.

43. Uniform mechanical Code, International Conference of Building Officials (ICBO), 1976.

44. Southern Standard Mechanical Code, Southern Building Code Congress (SBCC), 1976.

45. National Standard Plumbing Code, National Association of Plumbing-HeatingCooling Contractors, 1978.

46. Plumbing Code, draft of proposal, International Conference of Building Officials (ICBO), first printing 1978. 
Appendix A - Illustrations of Heat Exchanger Types

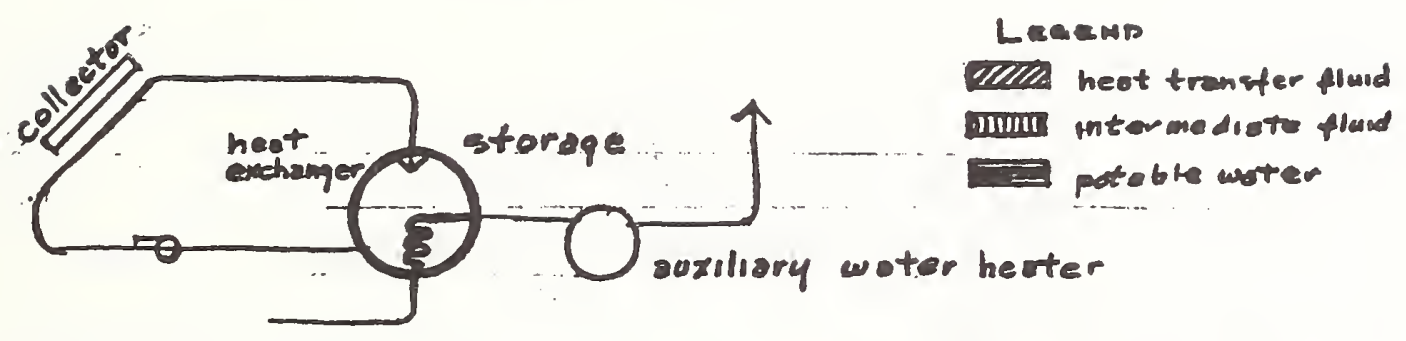

\section{Location DiaGRAm}
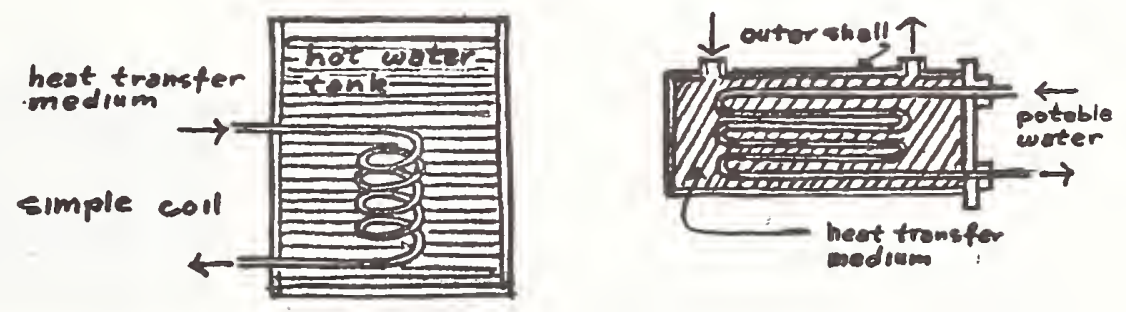

$$
\begin{aligned}
& \text { bosic single-woll } \\
& \text { heat exchangor }
\end{aligned}
$$

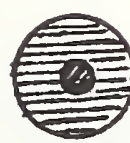

TUDE IN SHEL

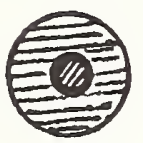

Double Tube in Shell

SPIRALED INNER TUBE

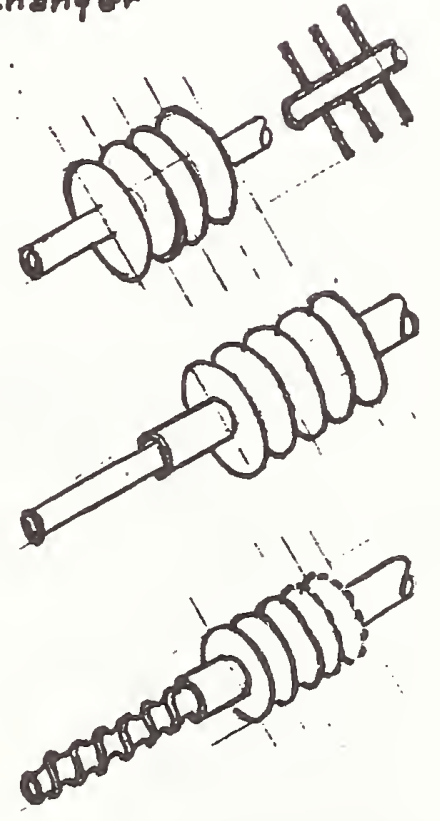




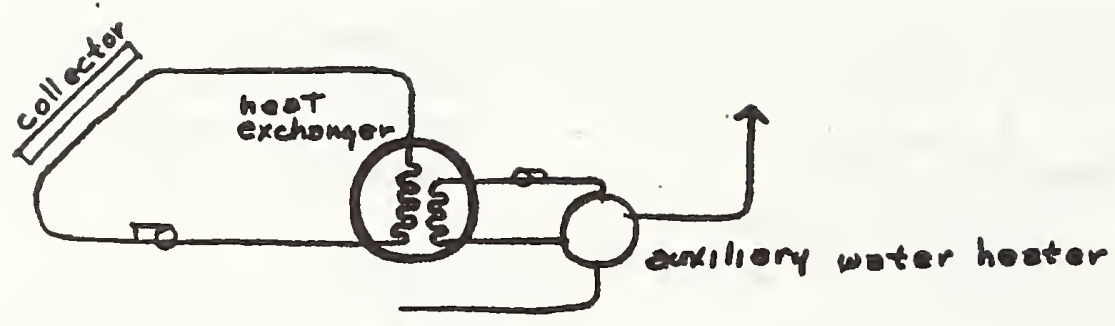

Location DiaGRAM

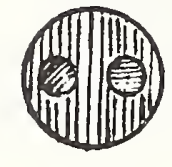

SHELL \& DOUBLE TUEE
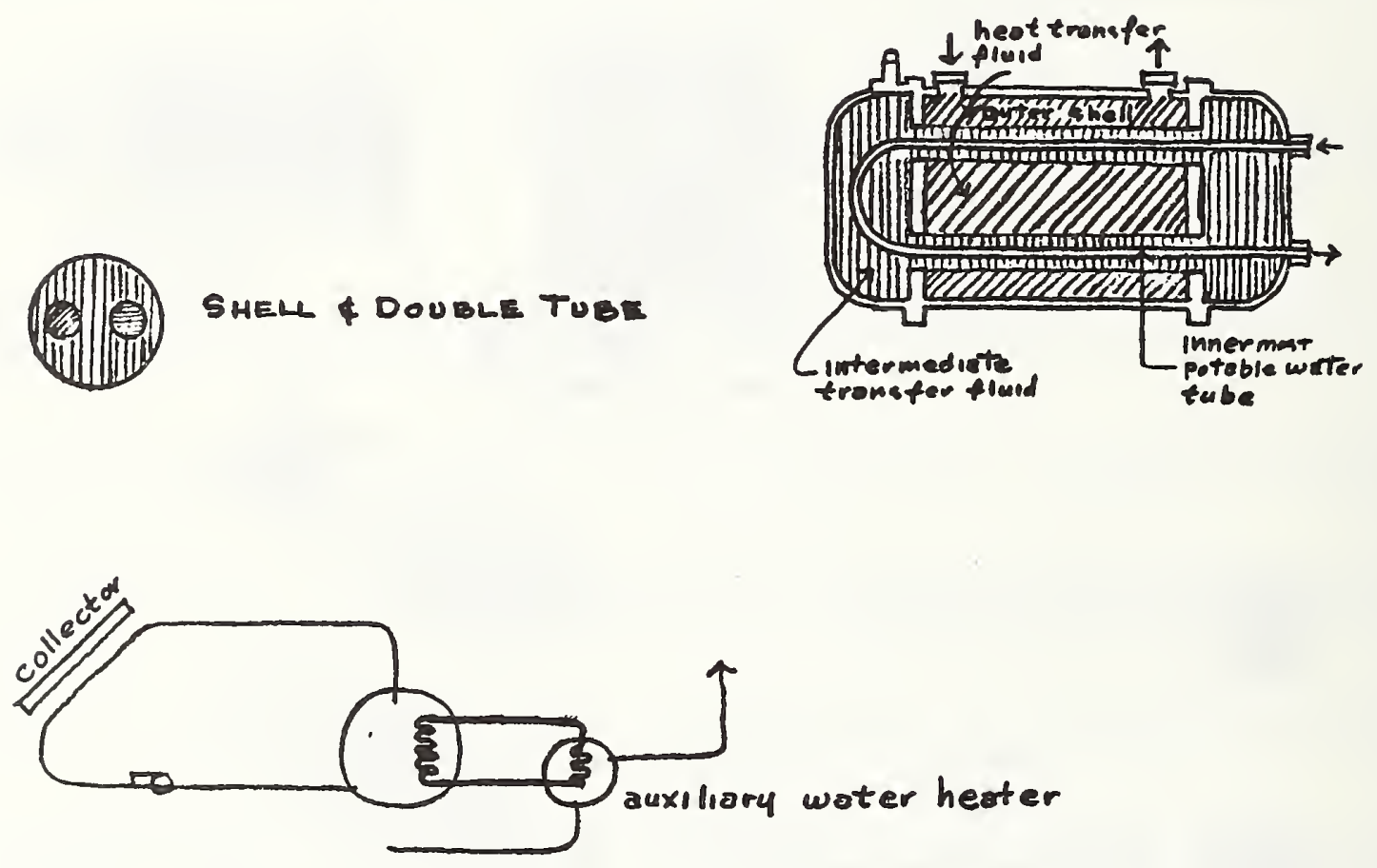

LOCATION DIAGRAm

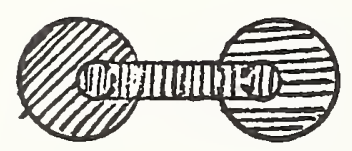

Double shell

C TUBE

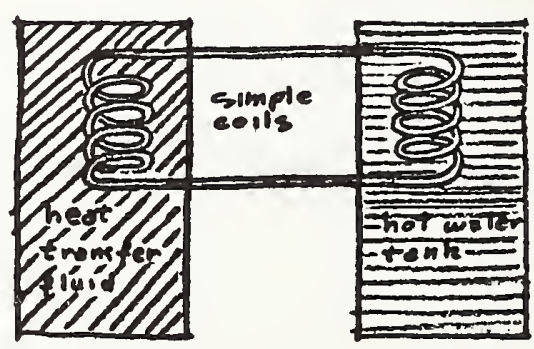

A-2. 


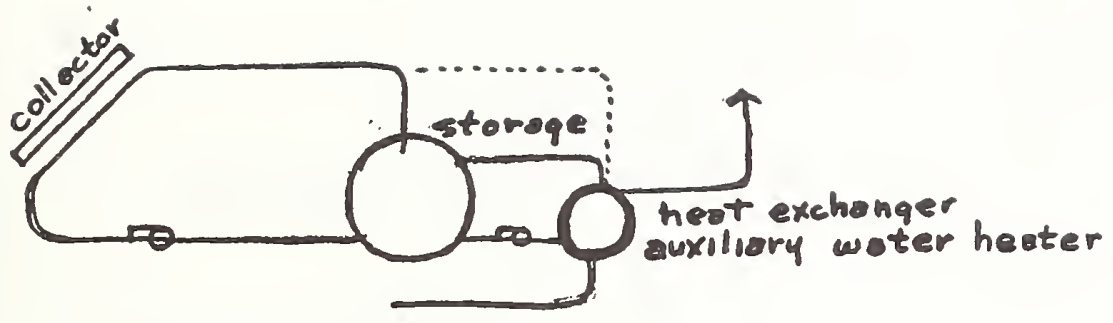

LOGATION DIAGRAM
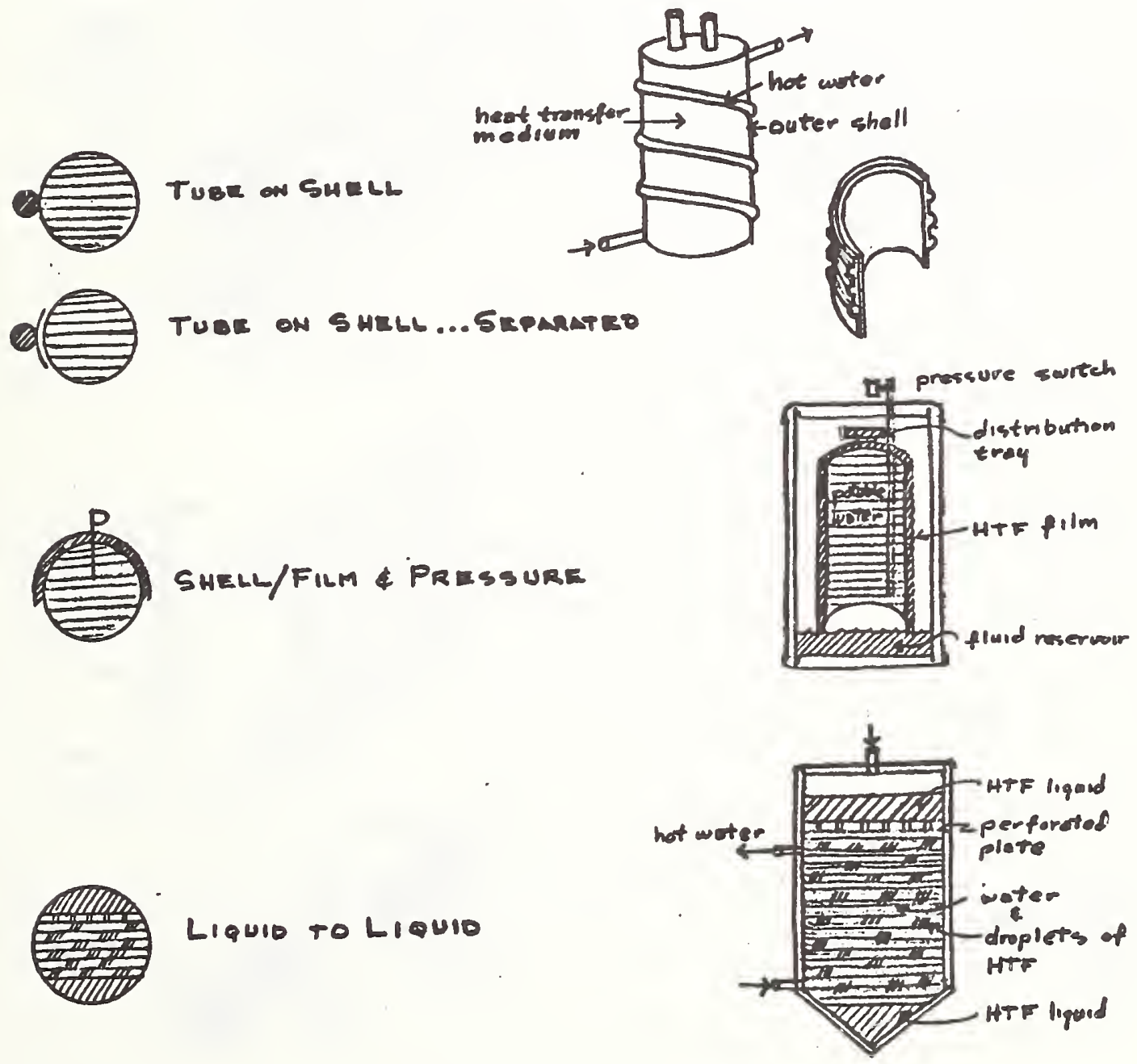


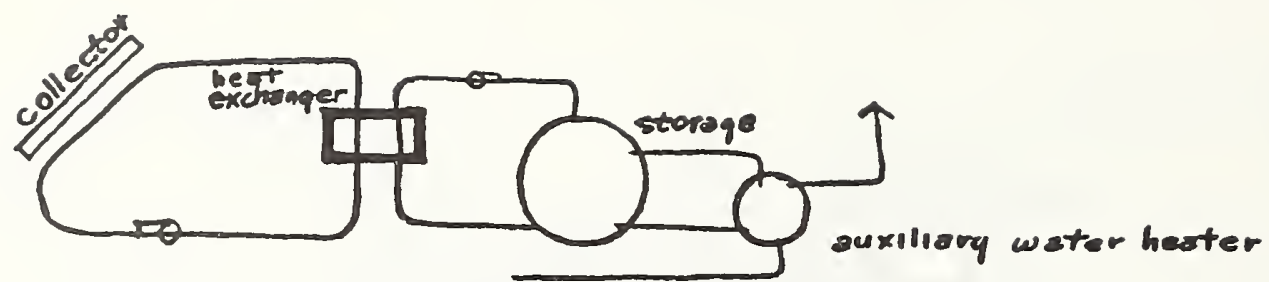

LOcation DingRam
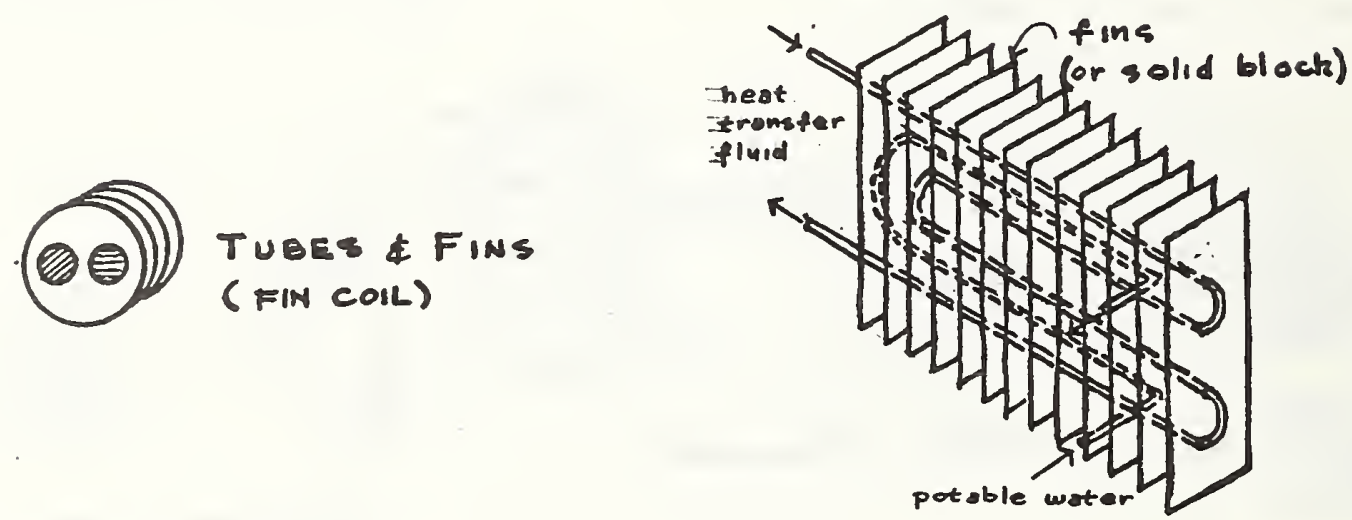

OO TRIfLE TUBE
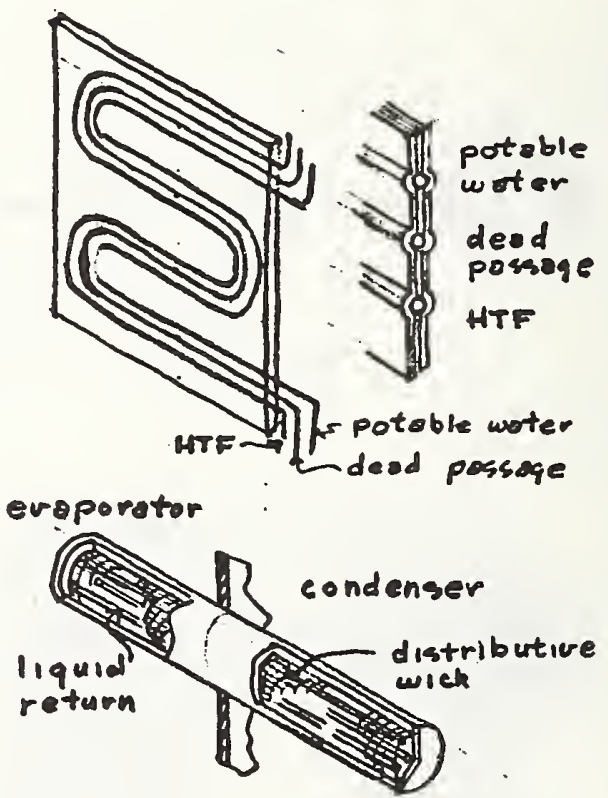

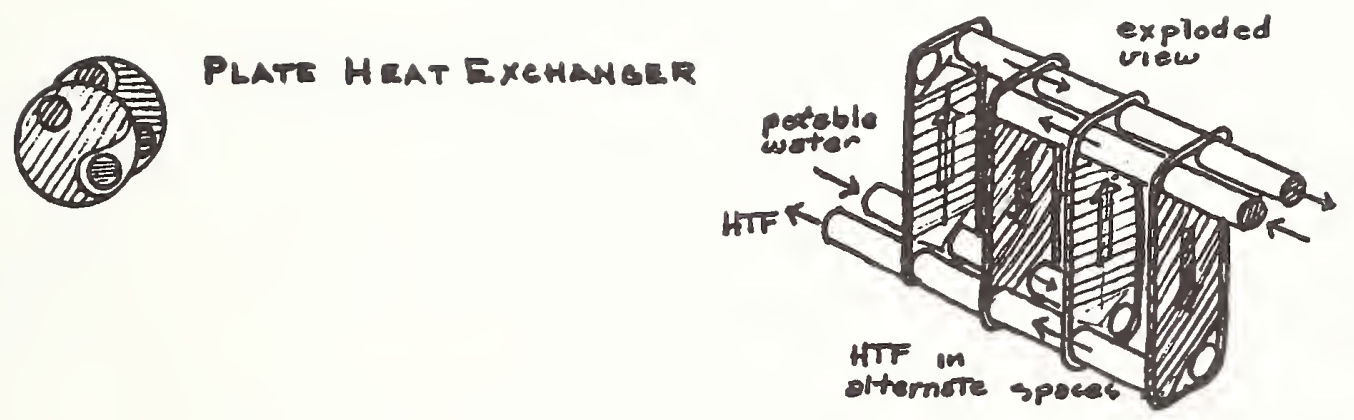

APPENDIX B - TOXICITY STUDIES OF HEAT TRANSFER FLUIDS AND COMMON ADDITIVES $1 /$

Table $\mathrm{B}-1$

Toxicity of Heat Transfer Fluids

CHEMICAL SUBSTANCE (GENERIC)

\section{Toxicity of theat. Transfer Fluids}

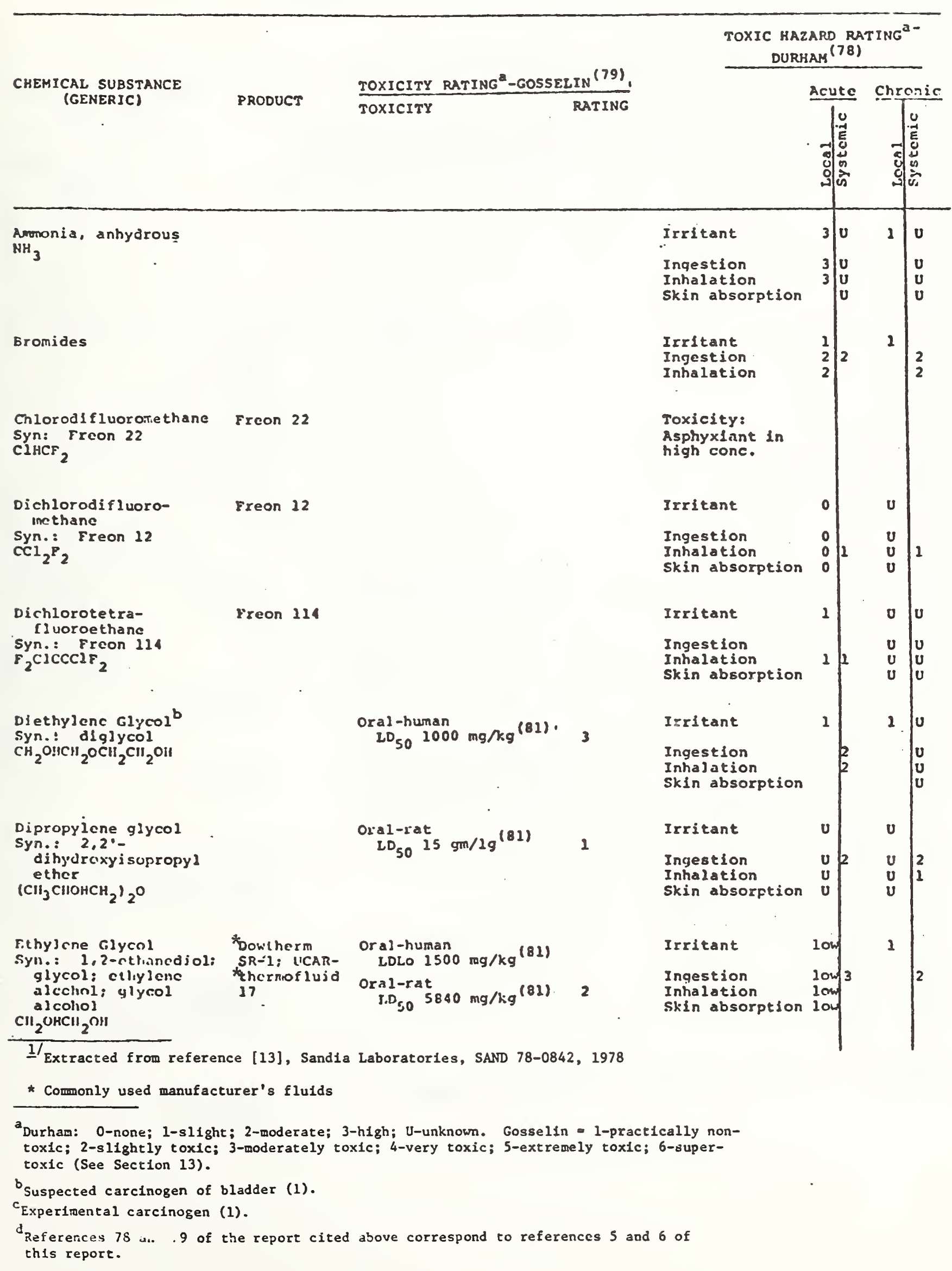




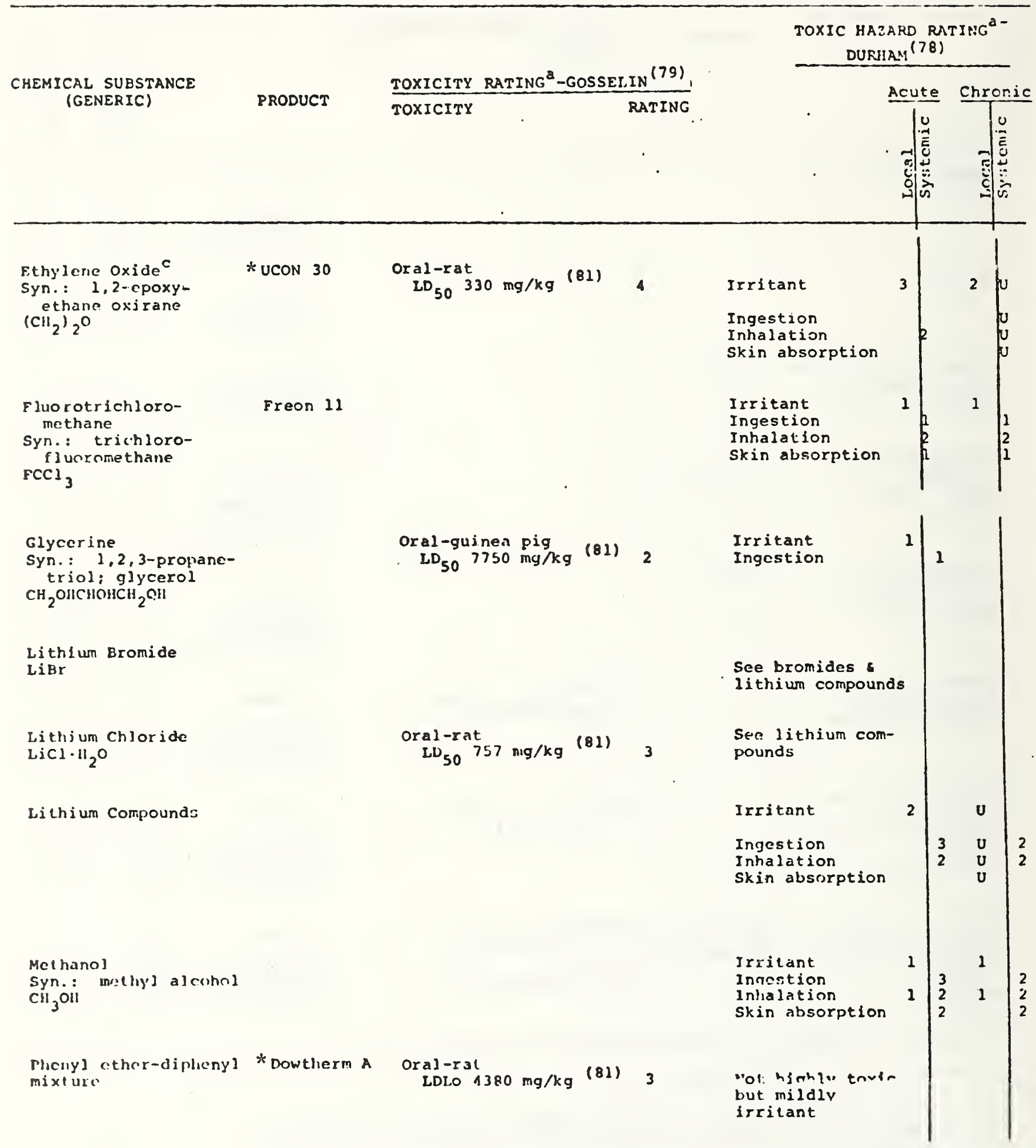




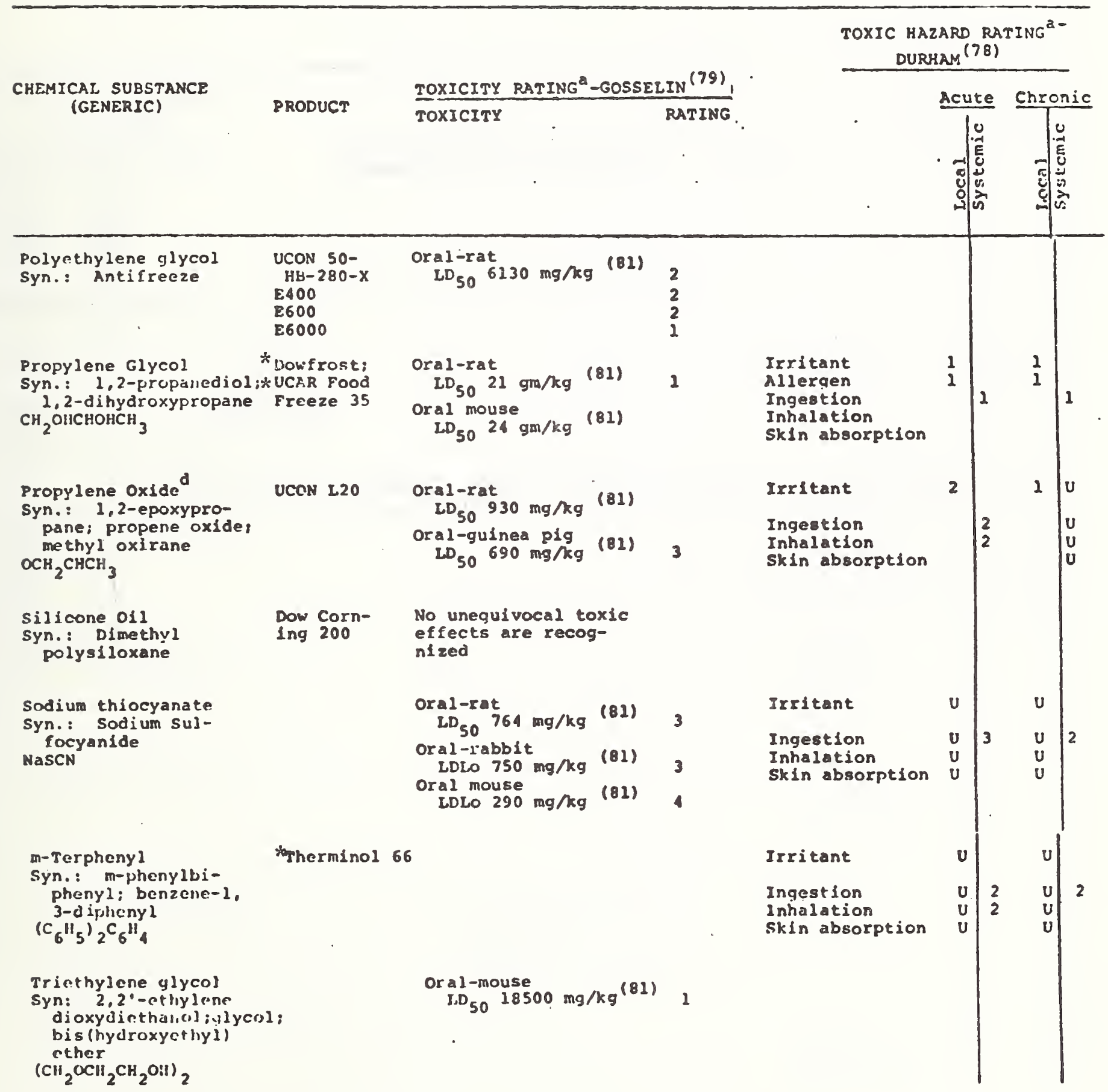




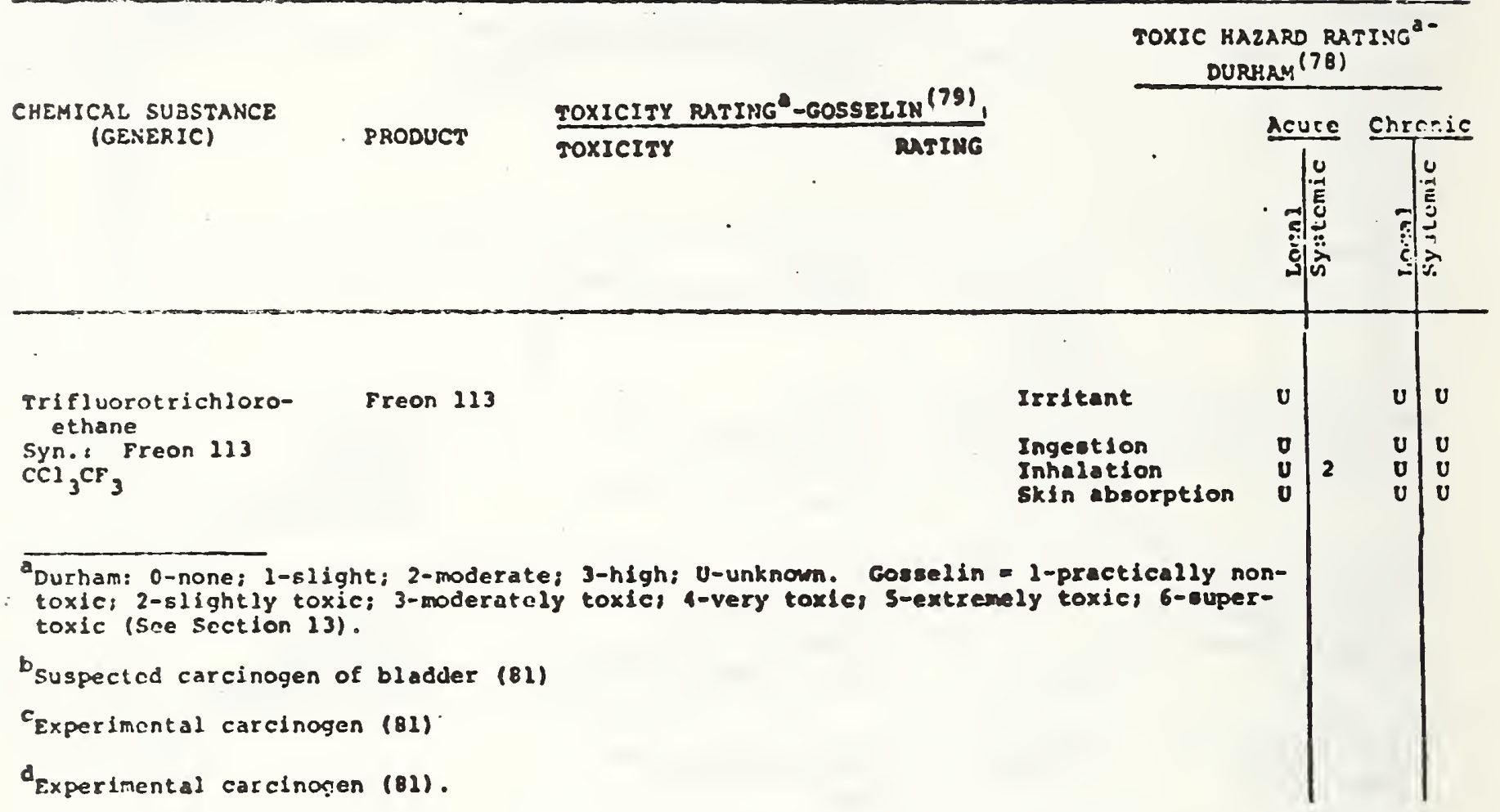


Table B-2

Toxicity of Fluid Treatment Chemicals

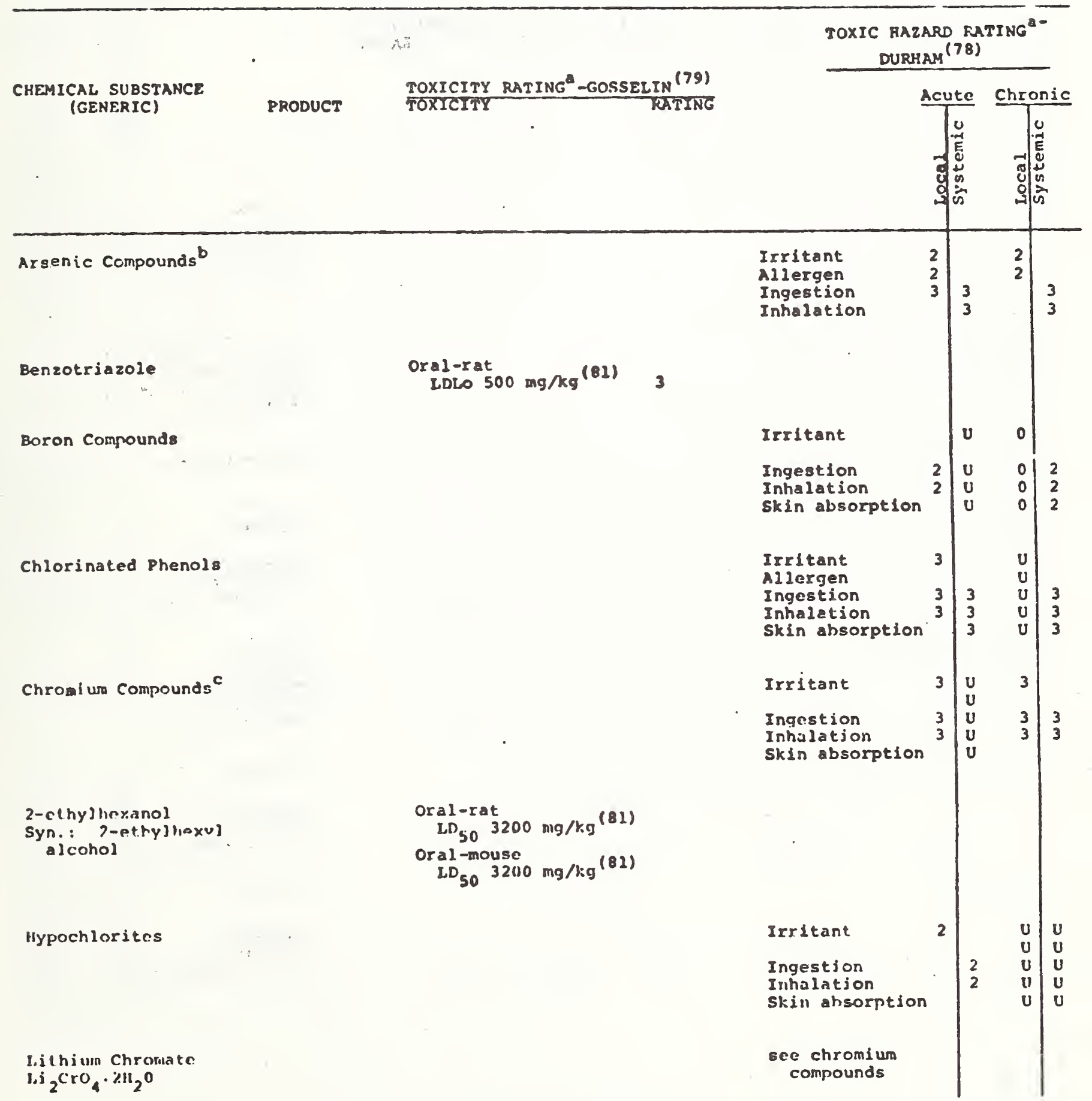




\begin{tabular}{|c|c|c|c|c|c|c|}
\hline \multirow{3}{*}{$\begin{array}{c}\text { CHEMICAL SUBSTANCE } \\
\text { (GENERIC) }\end{array}$} & \multirow{3}{*}{$\frac{\text { TOXICITY RATING }}{\text { TOXICITY }} \frac{\text { GOSSELIN }}{\text { RATING }}$} & \multicolumn{5}{|c|}{$\begin{array}{c}\text { TOXIC HAZARD RATING }{ }^{2-} \\
\text { DURHAM } \\
\end{array}$} \\
\hline & & \multicolumn{3}{|c|}{ Acute } & \multicolumn{2}{|c|}{ Chronic } \\
\hline & & . & न्द्ध & 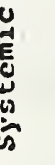 & : & 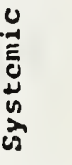 \\
\hline Lithium Compounds & & $\begin{array}{l}\text { Irritant } \\
\text { Allergen } \\
\text { Ingestlon } \\
\text { Inhalation } \\
\text { Skin absorption }\end{array}$ & 2 & & $\begin{array}{l}u \\
u \\
u \\
u \\
v\end{array} \mid$ & $\begin{array}{l}2 \\
2\end{array}$ \\
\hline $\begin{array}{l}\text { Lithium Hydroxide } \\
\text { Syn.: Lithium hydroxide } \\
\text { monohydrate } \\
\text { LOH }\end{array}$ & & $\begin{array}{l}\text { Very caustic } \\
\text { toxic. see } \\
\text { lithiun com } \\
\text { pounds sodiun } \\
\text { hydroxide. }\end{array}$ & & & & \\
\hline $\begin{array}{l}\text { Lithium Nitrate } \\
\text { LiNO }_{3}\end{array}$ & & see nitrates & & & & \\
\hline Mercaptans & & Irritant & 3 & & $v$ & \\
\hline & & $\begin{array}{l}\text { Ingestion } \\
\text { Inhalation } \\
\text { stin absorption }\end{array}$ & & 3 & $\begin{array}{l}\mathbf{v} \\
\mathbf{u} \\
\mathbf{v}\end{array}$ & 2 \\
\hline $\begin{array}{l}\text { Mercury compounds. } \\
\text { organic }\end{array}$ & . & $\begin{array}{l}\text { Irritant } \\
\text { Allergen } \\
\text { Ingestion } \\
\text { Inhalation } \\
\text { skin absorption }\end{array}$ & $\begin{array}{l}3 \\
2\end{array}$ & $\begin{array}{l}3 \\
3 \\
2\end{array}$ & $\begin{array}{l}2 \\
3\end{array}$ & $\begin{array}{l}3 \\
3 \\
3\end{array}$ \\
\hline Nitrates & & Irritant & $\mathbf{v}$ & & $v$ & \\
\hline & . & $\begin{array}{l}\text { Ingestion } \\
\text { Inhnlation } \\
\text { skin absorption }\end{array}$ & $\begin{array}{l}u \\
u \\
u\end{array}$ & $\begin{array}{l}2 \\
2\end{array}$ & $\begin{array}{l}\mathbf{u} \\
\mathbf{u} \\
\mathbf{u}\end{array}$ & $\begin{array}{l}2 \\
2\end{array}$ \\
\hline Nitrites & & irritant & $v$ & & $v$ & \\
\hline & . & $\begin{array}{l}\text { Ingestion } \\
\text { Inhalation } \\
\text { Skin absorption }\end{array}$ & $\begin{array}{l}v \\
v \\
v\end{array}$ & 3 & $\begin{array}{l}v \\
v \\
v\end{array}$ & 3 \\
\hline
\end{tabular}




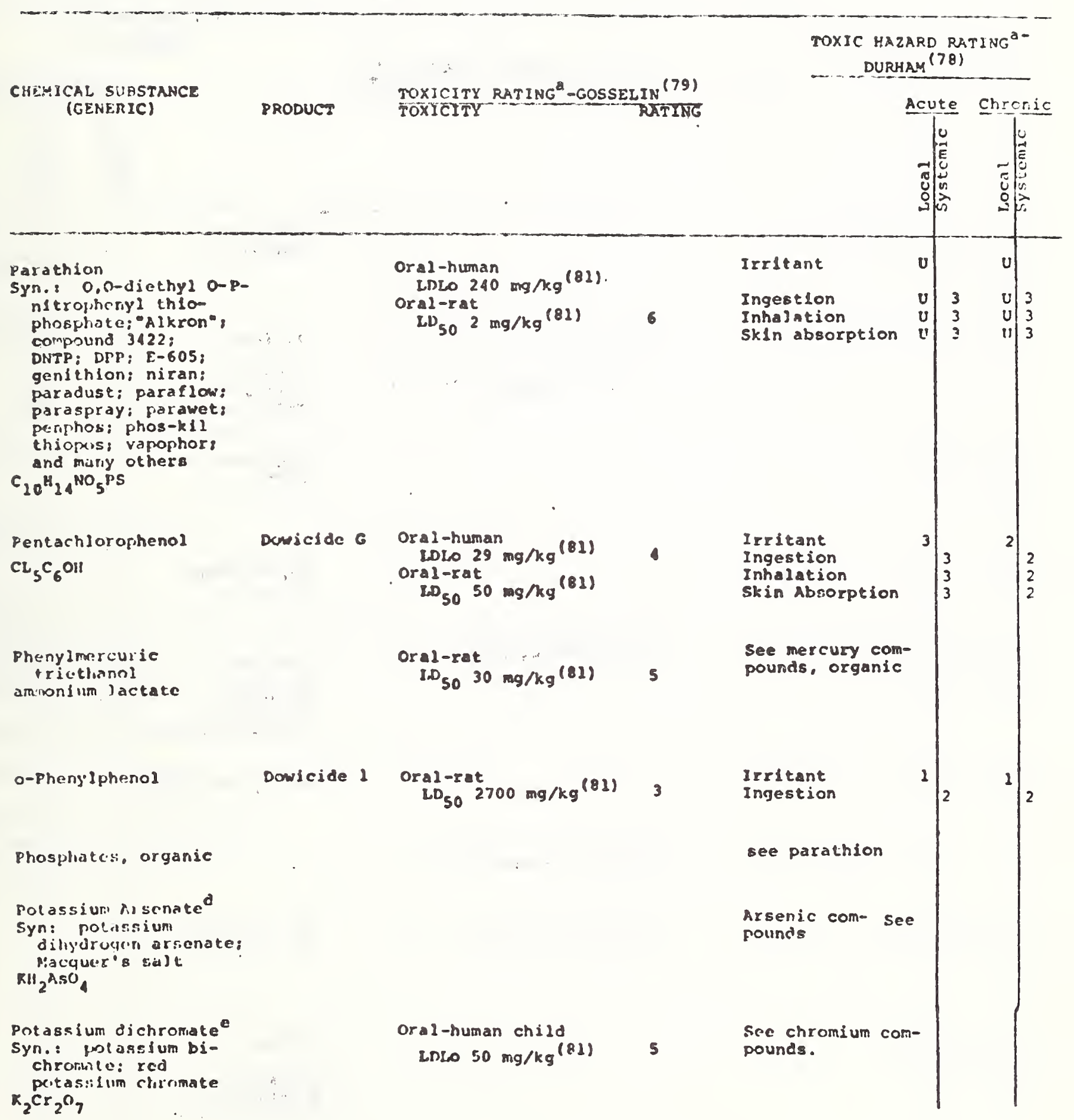




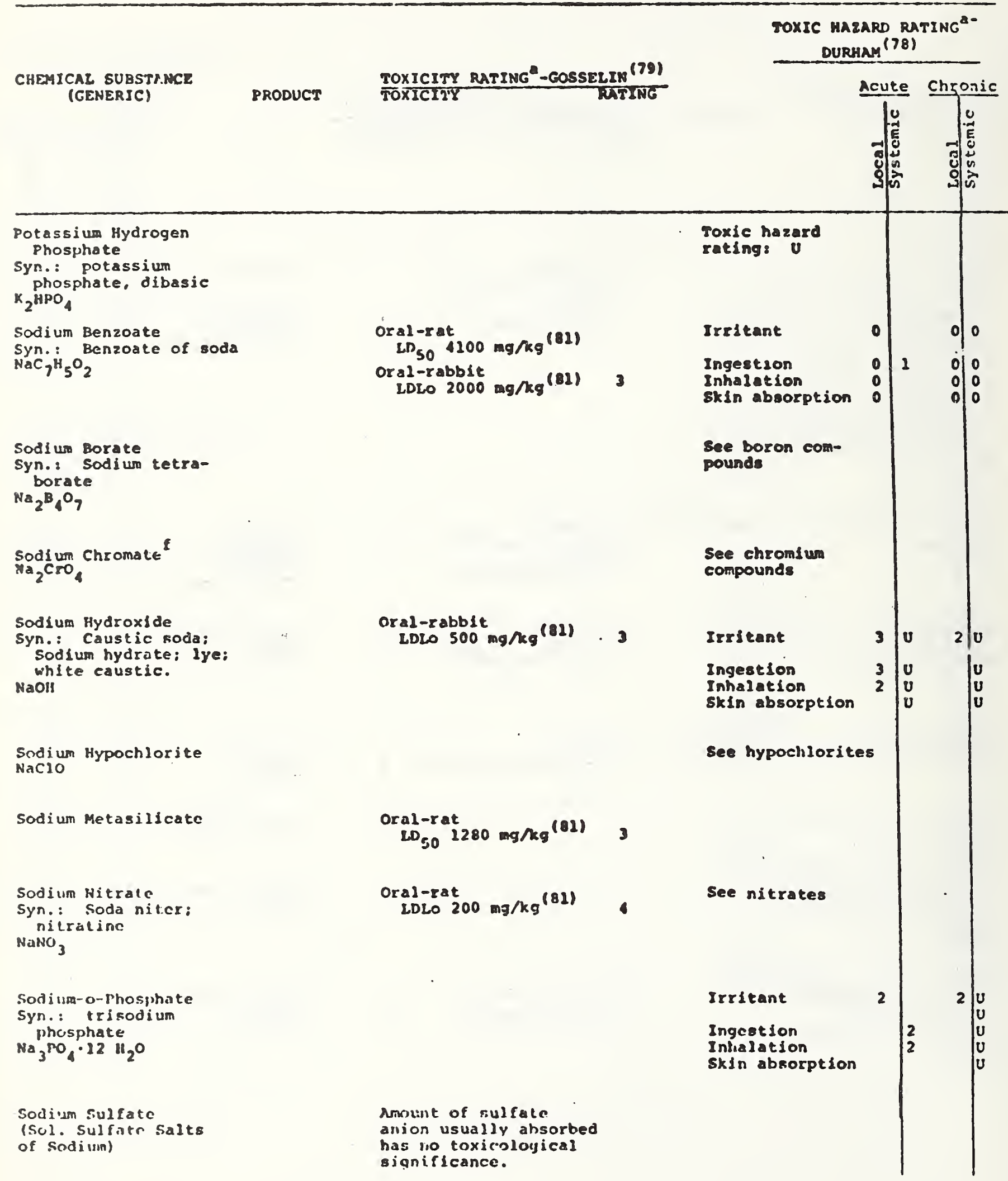




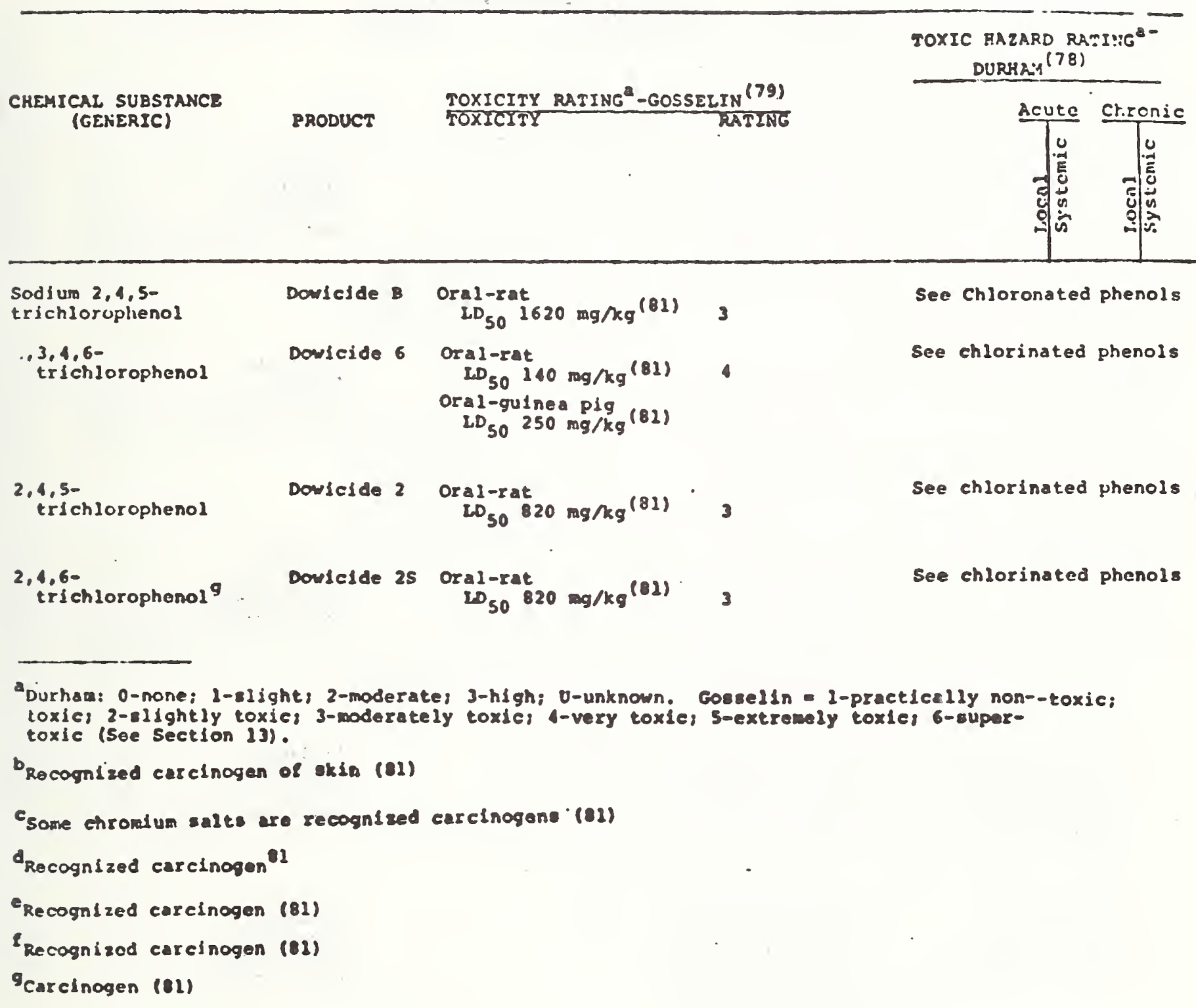




\begin{tabular}{|c|c|c|c|c|c|c|c|}
\hline $\begin{array}{l}\text { OUTGASSING SUBSTANCE } \\
\text { (GENPRIC) }\end{array}$ & $\frac{\text { ToxICIr? }}{\text { roXICITY }}$ & MATING -cos:it,I,IN ${ }^{(79)}$ & $\begin{array}{r}\text { matc } 11, \\
\text { rus }\end{array}$ & | & 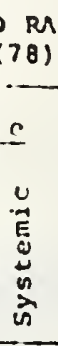 & $\operatorname{lnt;}$ & … \\
\hline $\begin{array}{l}\text { Argon } \\
\text { A }\end{array}$ & $\begin{array}{l}\text { SF 96, sllicones } \\
\text { Exxon Caloria } \\
\text { HT 43; UCON } \\
500 \text { : Therininol } \\
66 \text {; Mobiltherm } \\
603 \text {; Mobiltherm } \\
\text { Light; Dowtherm } \\
\text { A }\end{array}$ & . & $\begin{array}{l}\text { Irritant } \\
\text { Ingestion } \\
\text { Inhalation } \\
\text { Skin absorption }\end{array}$ & $\begin{array}{l}n \\
0 \\
n \\
0\end{array}$ & 1 & $\begin{array}{l}u \\
u \\
u \\
u\end{array}$ & $\begin{array}{l}u \\
U \\
U \\
U\end{array}$ \\
\hline $\begin{array}{l}\text { Carbon Dioxide } \\
\mathrm{CO}_{2}\end{array}$ & $\begin{array}{l}\text { SF 96, silicone: } \\
\text { UCON 500; Exxon } \\
\text { Process oil } 3029 ; \\
\text { Exxon Cilloria IIT- } \\
43 \text {; Dowtherm A; } \\
\text { Therminol } 66 ; \\
\text { Mobiltherm } 603 \text {; } \\
\text { Mobiltherm Light }\end{array}$ & & $\begin{array}{l}\text { Irritant } \\
\text { Ingestion } \\
\text { Inhalation } \\
\text { Skin Absorption }\end{array}$ & $\begin{array}{l}0 \\
0 \\
0 \\
0\end{array}$ & 1 & $\begin{array}{l}0 \\
0 \\
0 \\
0\end{array}$ & 1 \\
\hline $\begin{array}{l}\text { Carbon Monoxide } \\
\text { co }\end{array}$ & $\begin{array}{l}\text { SF } 96, \text { silicone; } \\
\text { UCON } 500 \text { : Exxon } \\
\text { Process Oli } 3029 \text {; } \\
\text { Exxon Caloria IIT- } \\
\text { 43; Dowtherm } \lambda ; \\
\text { Therminol } 66 ; \\
\text { Mobiltherm 603; } \\
\text { Mobiltherm Light }\end{array}$ & & $\begin{array}{l}\text { Irritant } \\
\text { Ingestion } \\
\text { Inhalation } \\
\text { Skin absorption }\end{array}$ & $\begin{array}{l}0 \\
0 \\
0 \\
0\end{array}$ & 3 & $\begin{array}{l}0 \\
0 \\
0 \\
0\end{array}$ & 1 \\
\hline $\begin{array}{l}\text { Ethane } \\
\text { Syn.: bimethyl: } \\
\text { methylmethane; } \\
\text { dimethyl: } \\
\text { ethyl hydride } \\
\mathrm{C}_{2} \mathrm{H}_{6}\end{array}$ & $\begin{array}{l}\text { sF 96, silicone: } \\
\text { Exxon process oll } \\
3029 \text {; Moblltherm } \\
603 \text {; Mobiltherr } \\
\text { light }\end{array}$ & & $\begin{array}{l}\text { Irritant } \\
\text { Ingestion } \\
\text { Inhalation } \\
\text { skin absorption }\end{array}$ & $\begin{array}{l}0 \\
0 \\
0 \\
0\end{array}$ & 2 & $\begin{array}{l}0 \\
0 \\
0 \\
n\end{array}$ & 1 \\
\hline $\begin{array}{l}\text { Ethylene } \\
\text { Syn.: ethene: } \\
\text { elayl; etherin } \\
\mathrm{CH}_{2} \mathrm{Cll}_{2}\end{array}$ & $\begin{array}{l}\text { SF 96, silicone: } \\
\text { UCON 500: Exxon } \\
\text { Process Oil } 3029 \text {; } \\
\text { Therminol } 66: \\
\text { Mobiltherm } 603 \text {; } \\
\text { Mobiltherm Light }\end{array}$ & & $\begin{array}{l}\text { Irritant } \\
\text { Ingestion } \\
\text { Inhalation } \\
\text { Skin absorption }\end{array}$ & $\begin{array}{l}0 \\
0 \\
0 \\
0\end{array}$ & 2 & $\begin{array}{l}0 \\
0 \\
0 \\
0\end{array}$ & $\begin{array}{l}0 \\
0 \\
0 \\
0\end{array}$ \\
\hline $\begin{array}{l}\text { Hydrogen } \\
\mathrm{H}_{2}\end{array}$ & $\begin{array}{l}\text { SF 96, silicone: } \\
\text { Exxon Process } \\
\text { Oil } 3029 \text { : Exxon } \\
\text { Caloria iT- } 43 \text {; } \\
\text { Therminol } 66 \text {; } \\
\text { Mobiltherm } 603 \text {; } \\
\text { Mobiltherm Light }\end{array}$ & . & $\begin{array}{l}\text { Irrltant } \\
\text { Ingestion } \\
\text { Inhalation } \\
\text { Skin absorption }\end{array}$ & $\begin{array}{l}0 \\
0 \\
0 \\
0\end{array}$ & 1 & $\begin{array}{l}0 \\
0 \\
0 \\
0\end{array}$ & $\begin{array}{l}0 \\
0 \\
0 \\
0\end{array}$ \\
\hline
\end{tabular}




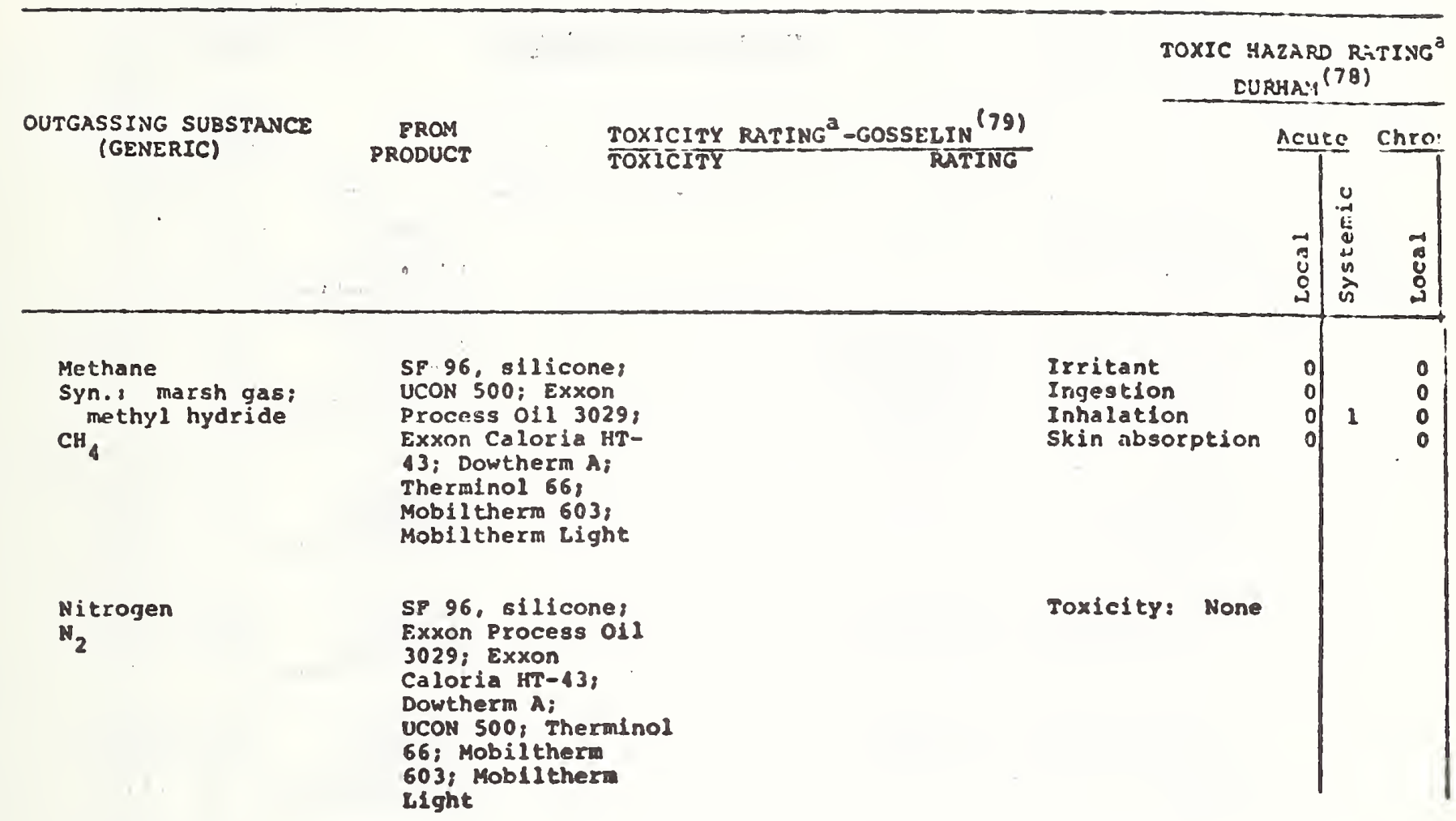

\footnotetext{
aurham: 0-none; 1-slight: 2-moderate; 3-high; U-unknown. Cosselin 1-practically non-toric; 2-silghtly toxie; 3-moderately toxic; 4-very toxici 5-extremely toxies 6-super-toxic.
} 


\section{Toxicity of Thermal Degradation Products}

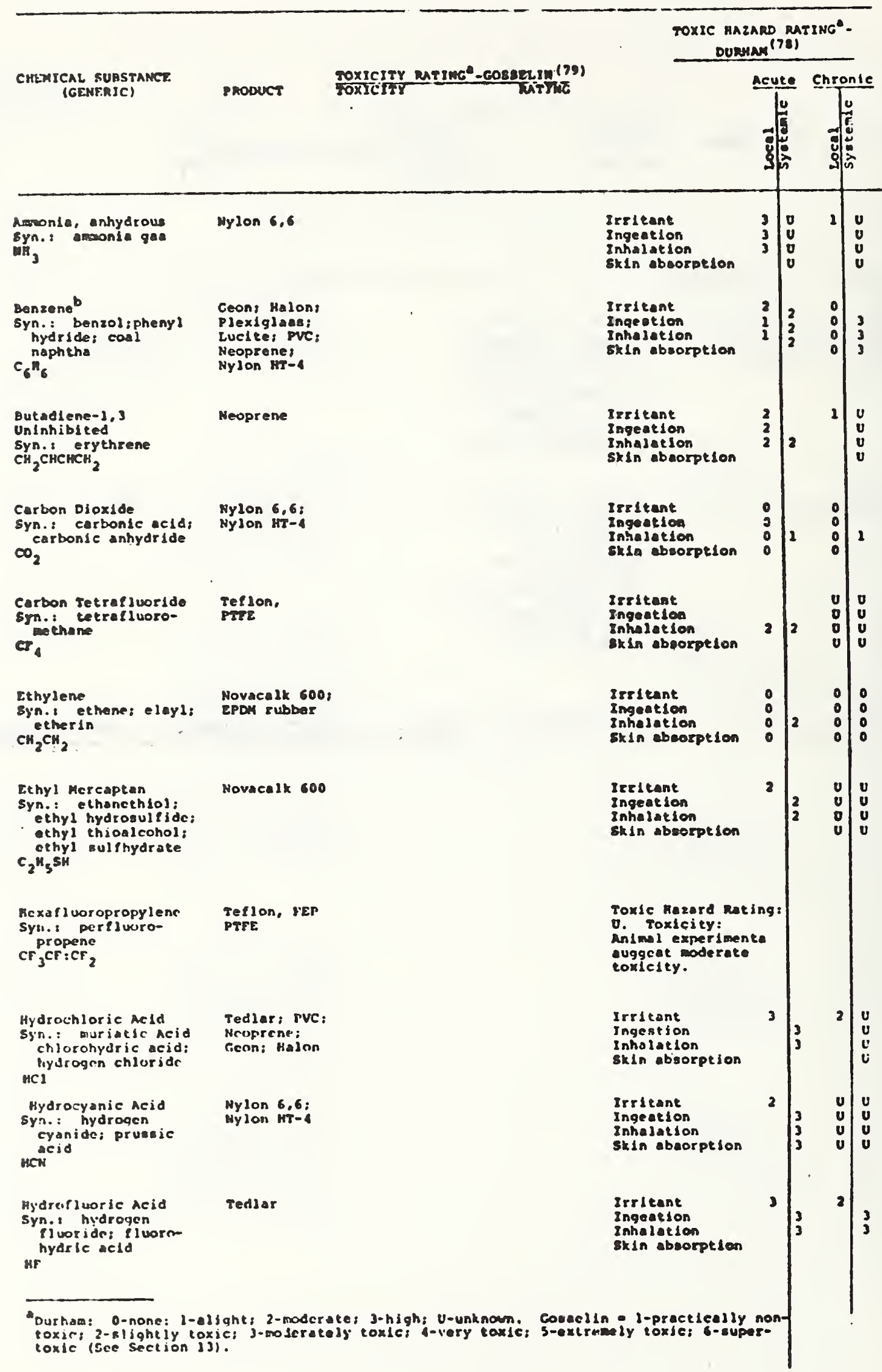




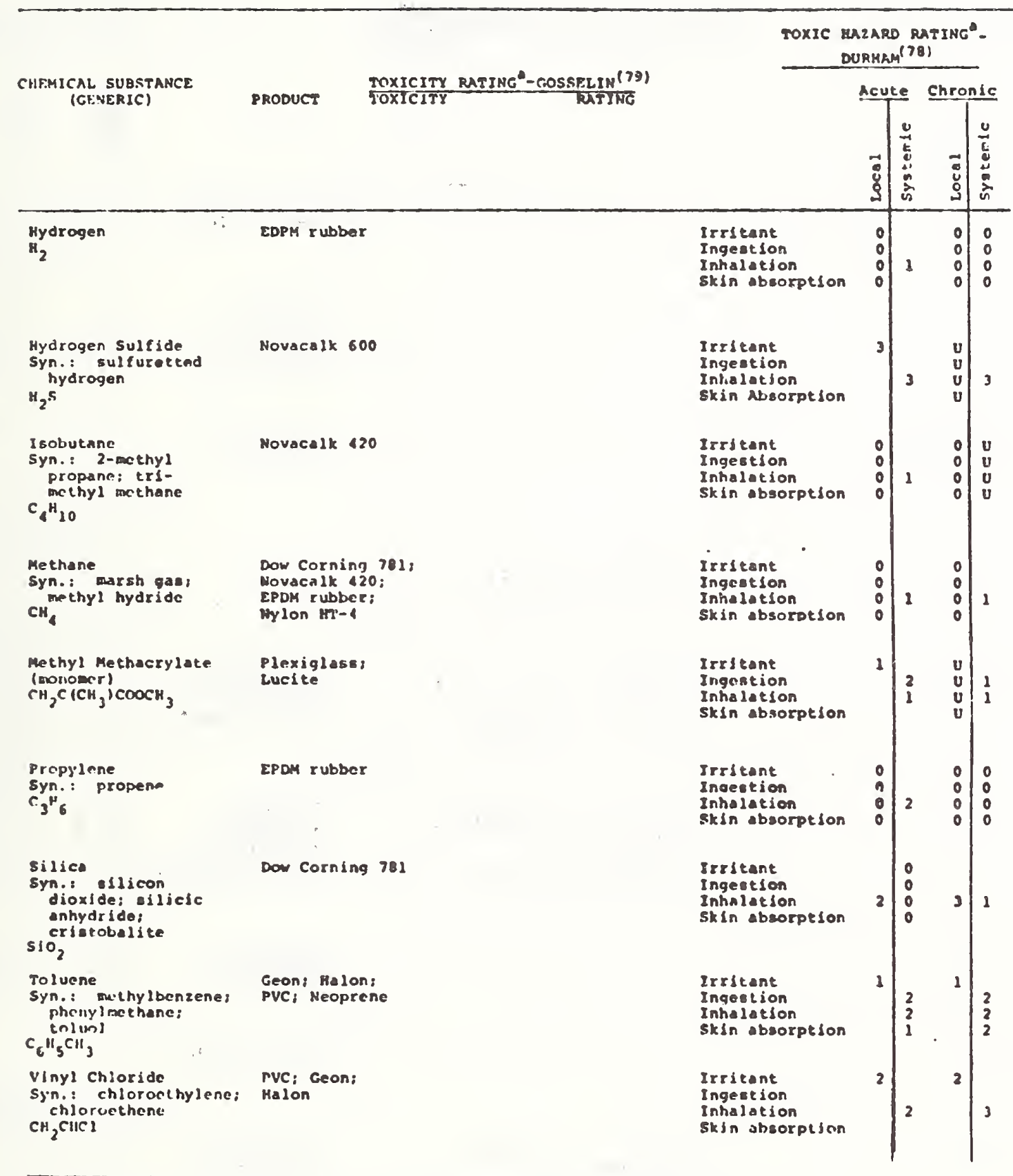

Durhja: 0-nonc; 1-slight: 2-moderate; 3-high; U-unknown. cosselin a 1-practieally non-toxic; 2-slightly Luxic: j-moderately toxic; i-very toxici b-extrcrely coxic; b-kuper-toxic. 
CHËTCAL SUBSTANCE (GENERTC)
PRODUCT
TOXICITY RATING - COSSELIN 791

MTINE
Ammonium Bromide

$\mathrm{NH}_{4} \mathrm{Br}$

Barium Compounds

(soluble)

Barlun Hydroxide

Syn.: Barium Hydrate;

Ba (OHI) $2 \cdot 8 \mathrm{H}_{2} \mathrm{O}$

caustic baryta

Benzamide

Eenzolc Acid

Syn.: phenylformic acid

$\mathrm{C}_{6} \mathrm{H}_{5} \mathrm{COOH}$

Bipheny 1

Syn.: Diphenyl

$\mathrm{C}_{6} \mathrm{H}_{5} \mathrm{C}_{6} \mathrm{H}_{5}$

Bromides

Calcjum Bromide

$\mathrm{CaBr} 2 . \mathrm{SH}_{2} \mathrm{O}$

Culciun chloride $\mathrm{CaCl}_{2}$

Calcium Compounds see bromides

Oral-móuse

$$
\mathrm{wD}_{50} 1160 \mathrm{mg} / \mathrm{kg}(81) 3
$$

Oral-rat

$$
\begin{aligned}
& \text { Oral-rat } \\
& \mathrm{LD}_{50} 3040 \mathrm{mg} / \mathrm{kg}(\mathrm{el}) \\
& \text { Oral-mouse } \\
& \mathrm{ID}_{50} 2370 \mathrm{mg} / \mathrm{kg}(81)
\end{aligned}
$$

Ora1-rat

$\mathrm{LD}_{50} 3280 \mathrm{mg} / \mathrm{kg}^{(81)} 3$

Oral-rabbit

$\mathrm{LD}_{50} 2400 \mathrm{mg} / \mathrm{kg}^{(93)}$

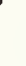

.

Oral-rat

$$
\mathrm{ID}_{50} 1000 \mathrm{mg} / \mathrm{kg}(81)
$$

Oral-rabblt

LDLO $2384 \mathrm{mg} / \mathrm{kg}^{(93)}$
DURKAM

(78)

Acute Chronic

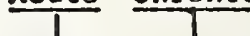

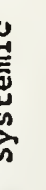

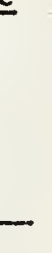


Acure Chronic sodium)

Sterric Acid

Sys.: octadecanoic acid

$\mathrm{CH}_{3}\left(\mathrm{CH}_{2}\right)_{16} \mathrm{COOH}$

Zine Nitrate

$\mathrm{nn}\left(\mathrm{NO}_{3}\right)_{2} \cdot 61 \mathrm{I}_{2} \mathrm{O}$

Oral-rat

$L_{50} 1190 \mathrm{mg} / \mathrm{kg}^{(81)} 3$ see ndtrates

aurhan: 0-none; 1-slight, 2-moderate: 3-high: U-unknown, Gosselin = 1-practically non-toxic: 2-slightly toxic: 3-moderatoly toxic: 4-verty toxic: 5-extremely toxic; 6-super-toxic (see Section 13 ).

becognized carcinogens of skin (81) 
Table B-6

Toxicity of Outgassing Products from Solids

$\begin{array}{cl}\text { CHEMICAL SUBSTANCE } & \text { FROM } \\ \text { (GENERIC) } & \text { TOXICITY RATING }{ }^{2}-\text { COSSELIN }^{(79)} \\ \text { TOXICITY } & \text { RATING }\end{array}$

TOXIC HAZARD RATING ${ }^{\mathrm{a}}$ DURHAM (78) (GENERIC)

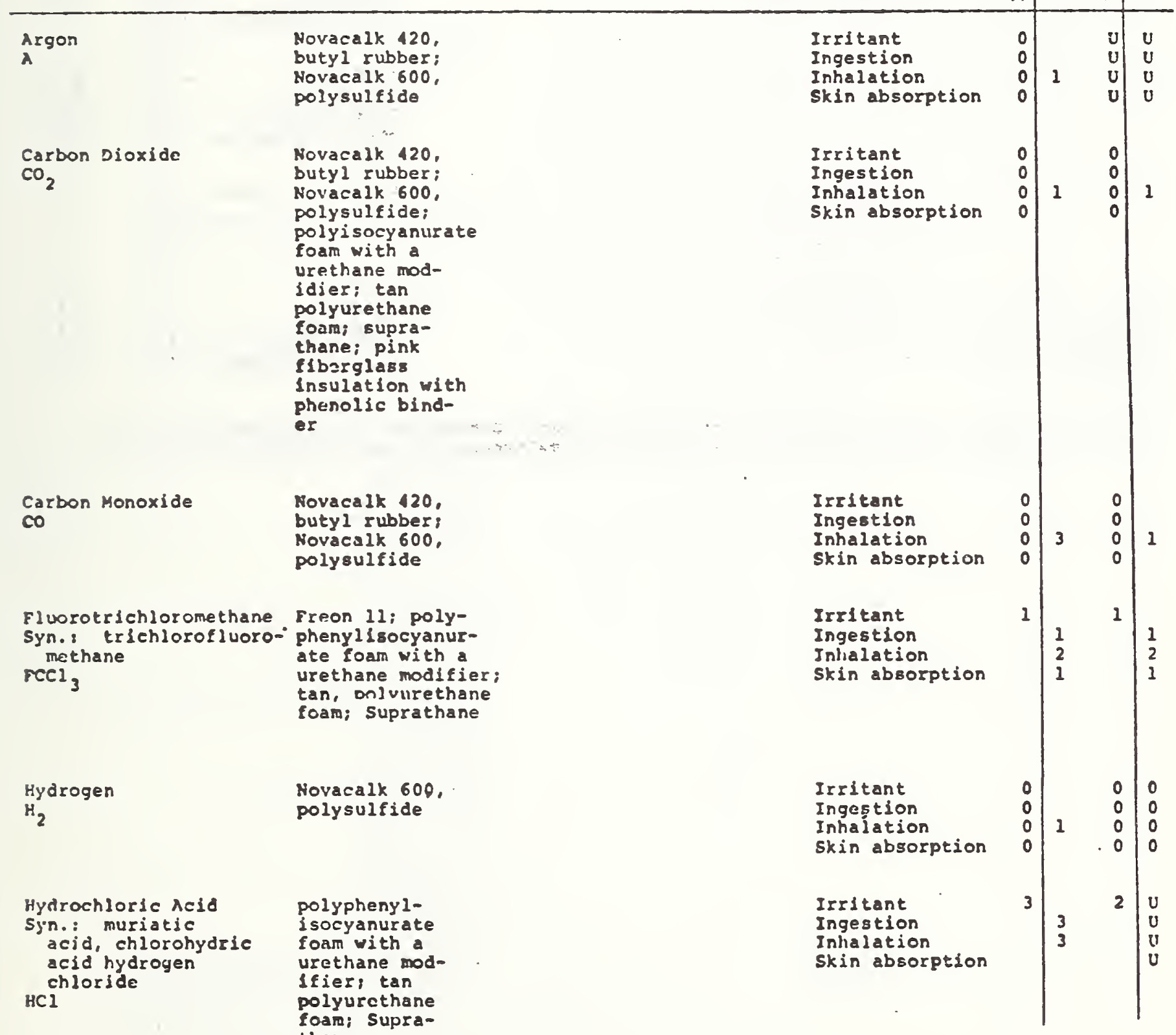




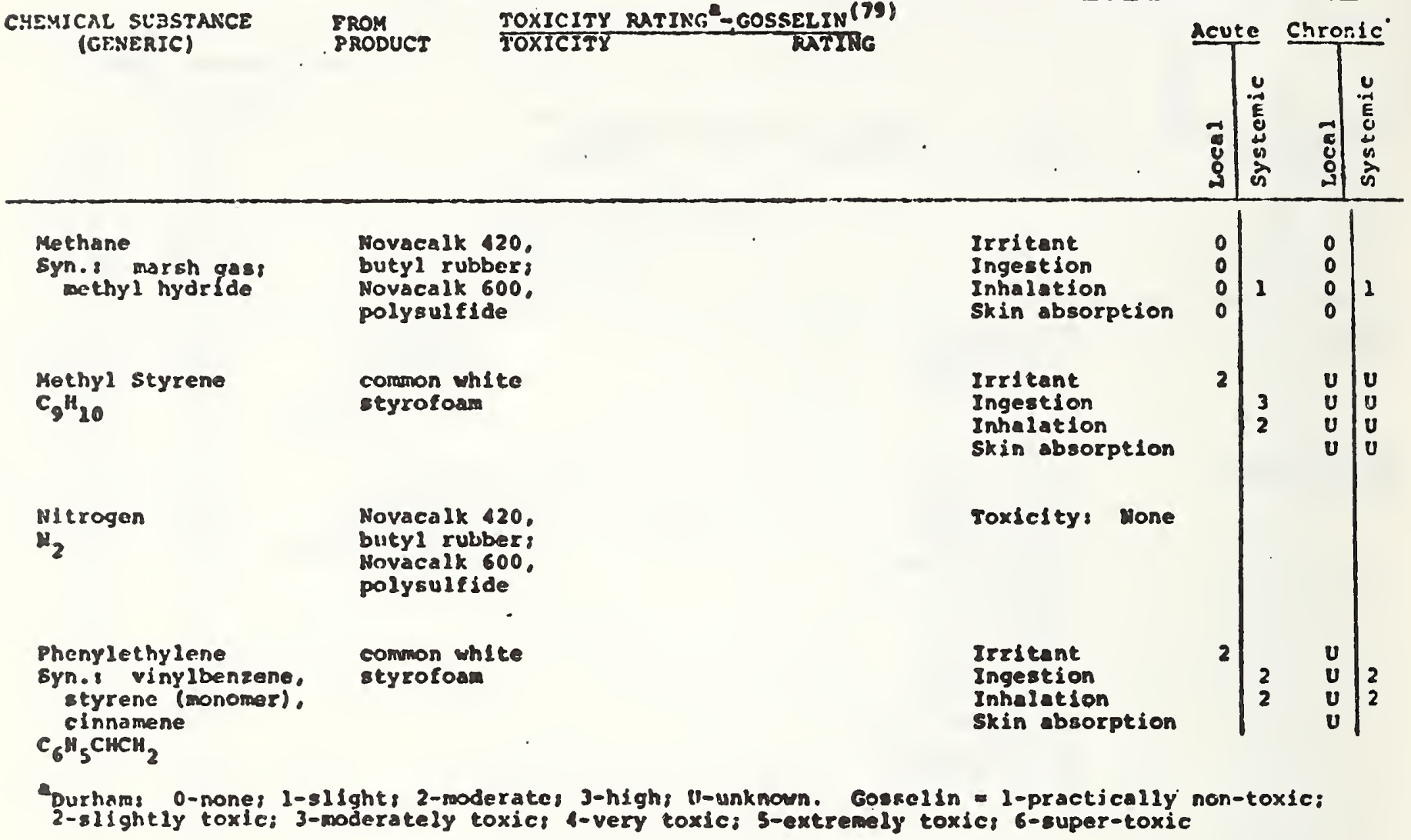


Chemical sUbSThCe (GENERIC)
PRODUCT
TOXIC HAZARD RATING" CURHAM ${ }^{(78)}$

TOXICITY RATINC - COSSELIN (79)

Buty 1 rubber, Hovacalk 420 ;

Nylon 6,6 Syn.: ethynei ethine
BCCB

Ammonia

Syn.: amonia gas

$\mathrm{NH}_{3}$

Nylon 6,6 Bghzẹnebenzol: phenyl
hydride; coal
naphtha

$c_{6}{ }_{6}$

Butadiene- 1,3

(uninhibited)

syn.: erythrene

$\mathrm{CH}_{2} \mathrm{CiCHCH}_{2}$

Carbon Dicxide

syn.: carbonic acidi carbonic anhydride

$\mathrm{CO}_{2}$

Neoprene: PVC

Gcon: Halon

Neoprene
Mydon HT-4

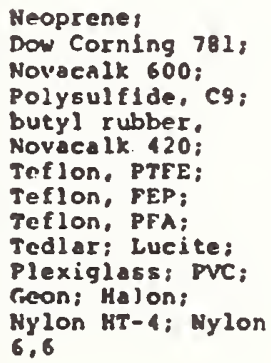

Carbon Monoxide co

Neoprene: Dow

Corning 781:

polysuifide.

Novacalk 600 :

polysulfide. $c 9$;

butyl rubber.

Novacalk 420;

Trflon, PTFE:

Teflon, FE.P:

Tellon. PFA:

Luclte:

Plexiglas:

PVi: Geons

Halon: Nylon HT-

4: Nyion 6,6

Carbonyl Fluorido

syn.: fluorolormyl

iluoride

Tellon, PTFE

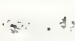

DXTYME

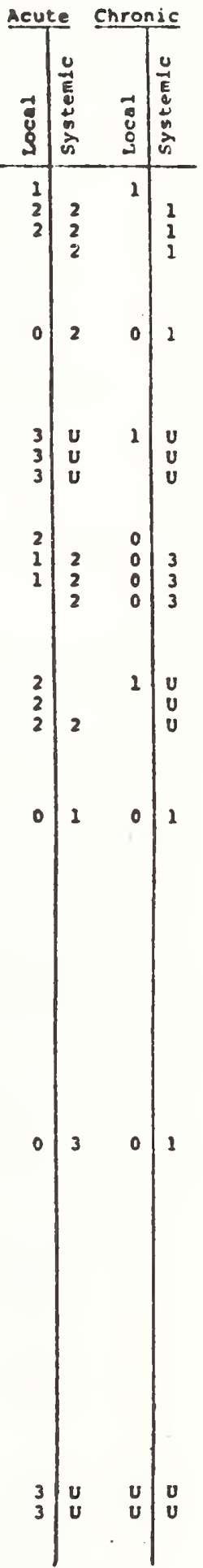

Durham: 0-none: 1-slight; 2-moderate: 3-high; U-unknown. cosselin: 1-practically nontoxlc:

2-slightly toxic; 3-mujeralely toxic: 4-very toxic; 3-extrencly toxic; 6-supertoxic.

becognized carcinogen of the blood-forming tissues (81). 
TOXIC HATARD RATINC ${ }^{a}$ -

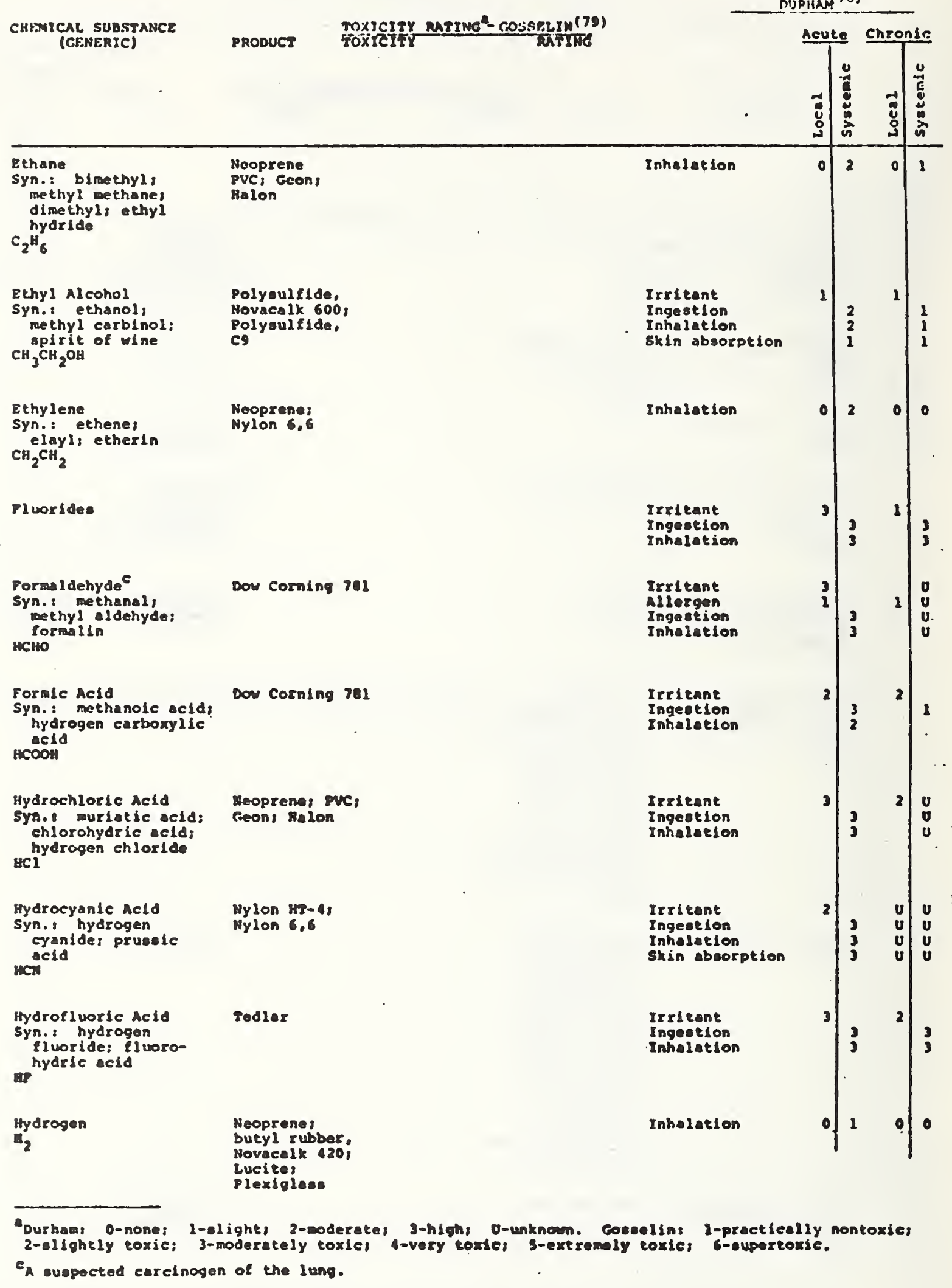




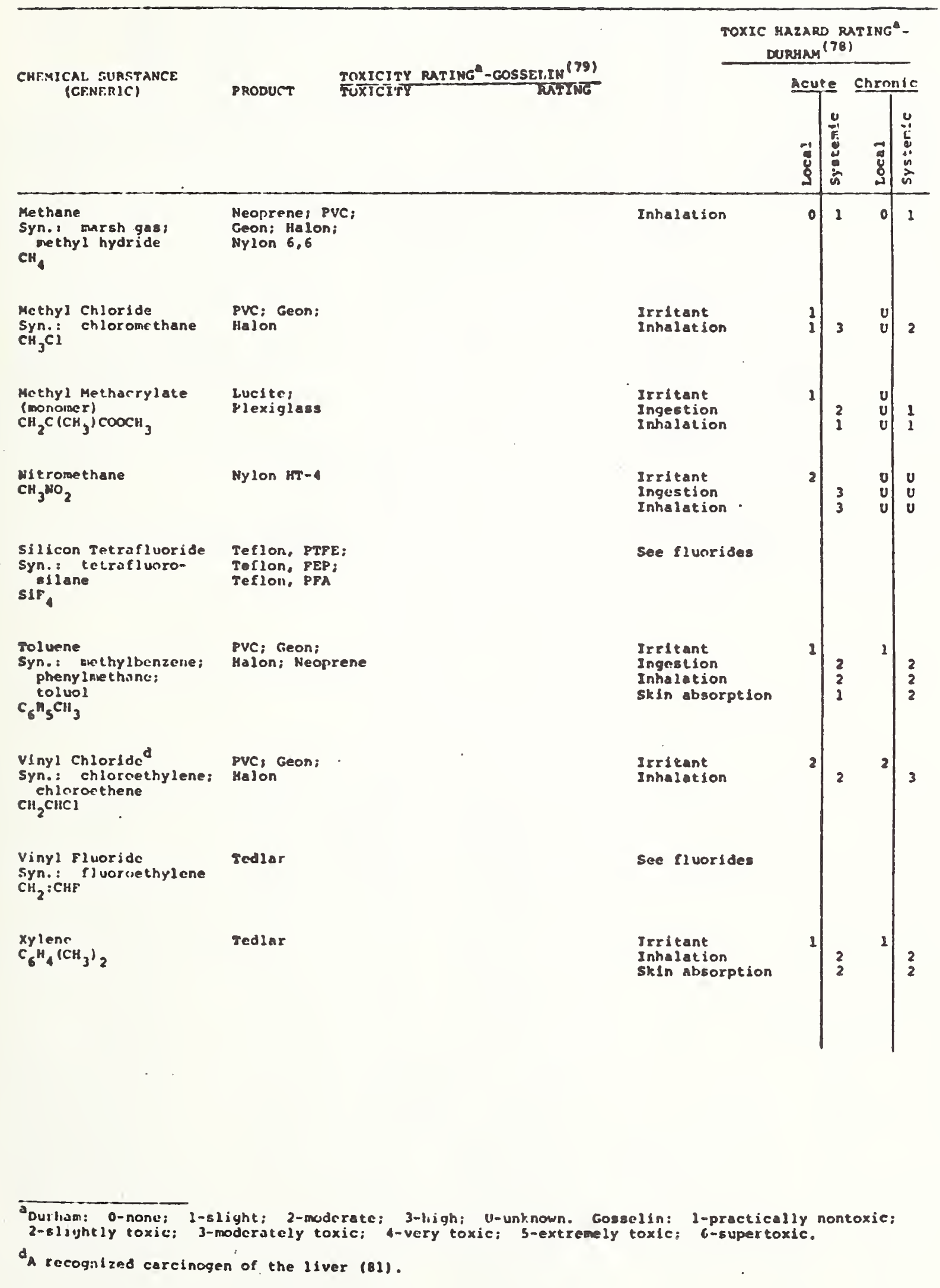


. 


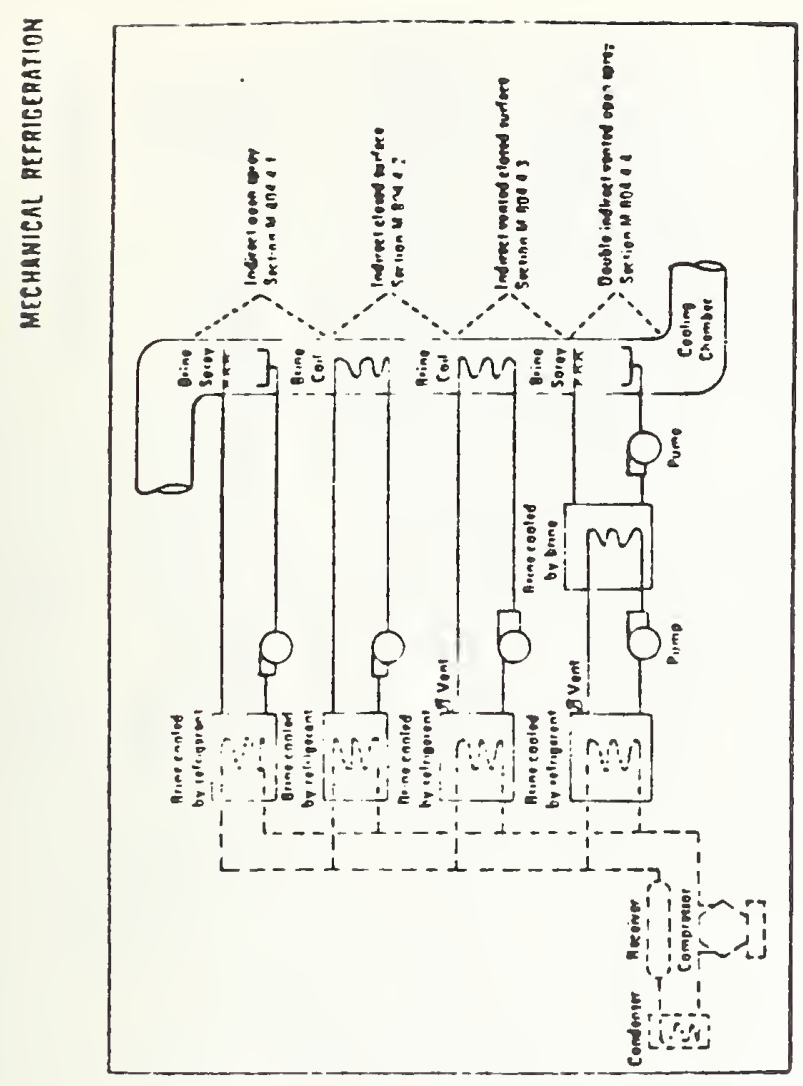

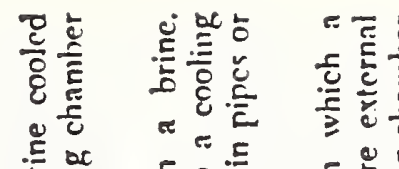

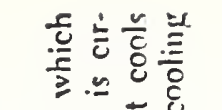

$\bar{c} . \subseteq$

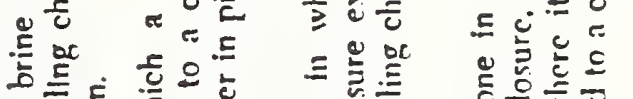

产

๙

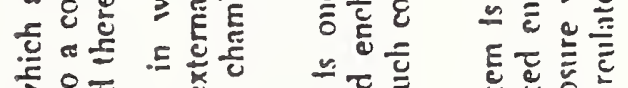

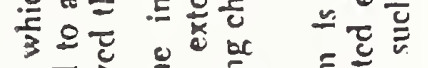

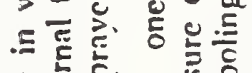

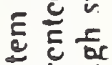

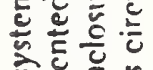

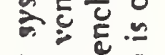

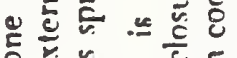

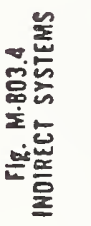

它

宊

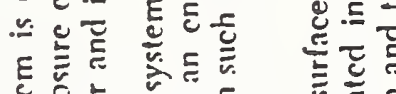

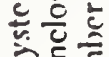

E亏

藏

跎.

윤.

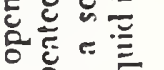

드 $2 . \underline{E}$

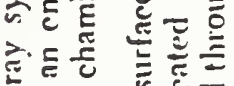

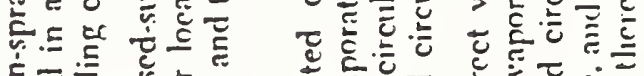

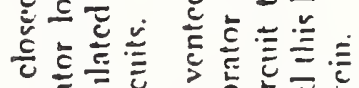

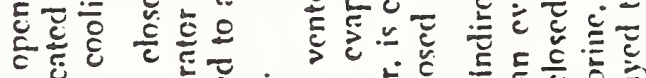

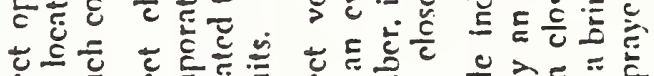

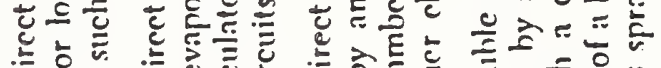

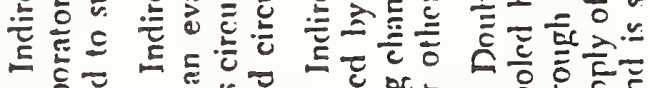

敋

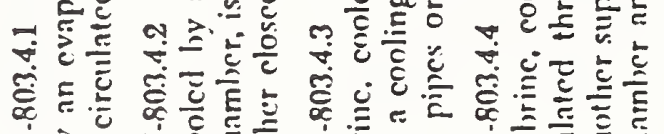

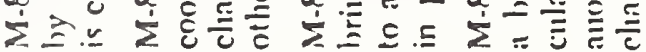

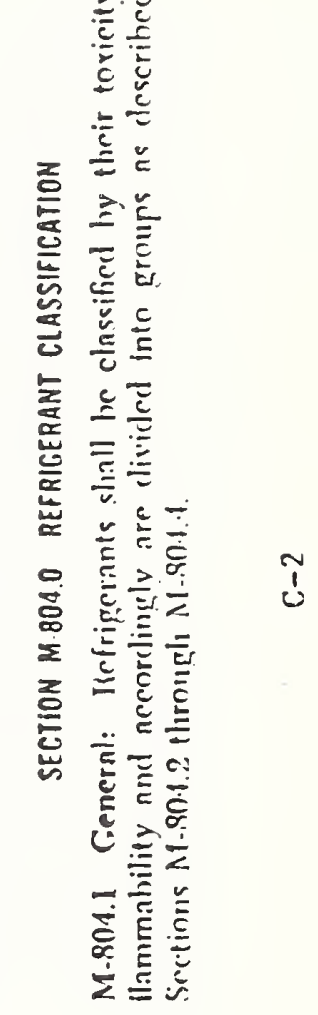

0
$\times$
$\vdots$
$\vdots$
$\vdots$
$\vdots$
$\vdots$
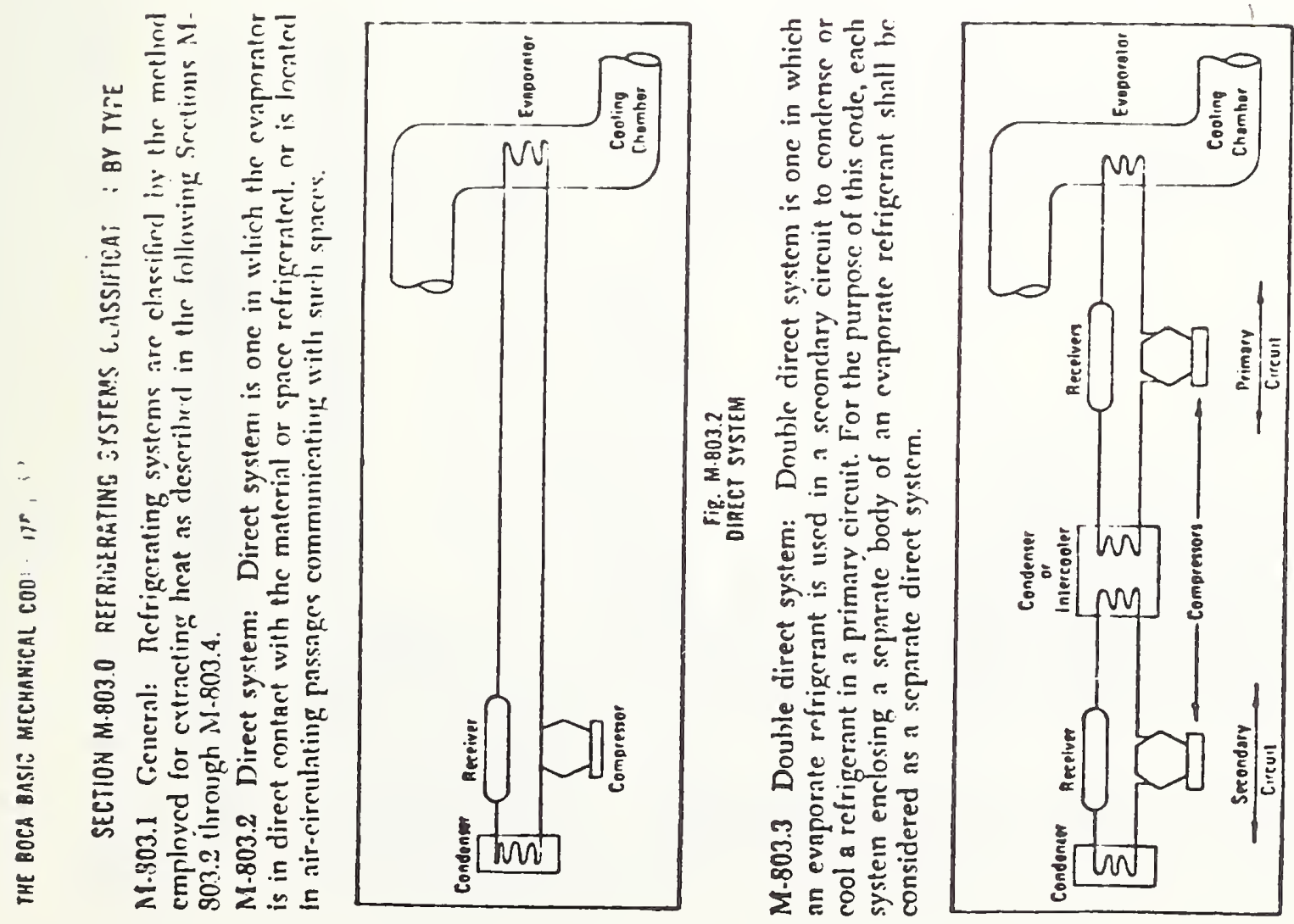

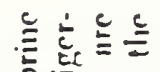

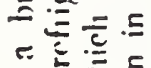
든

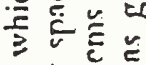

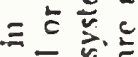
可

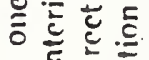

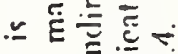
$\varepsilon \underline{\underline{E}}$

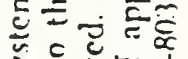

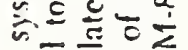

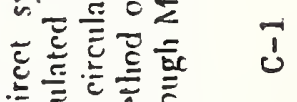

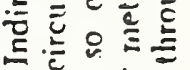

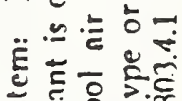
政品 些 든은.

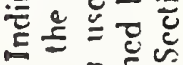

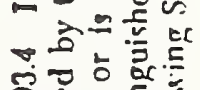

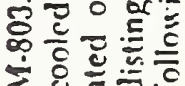




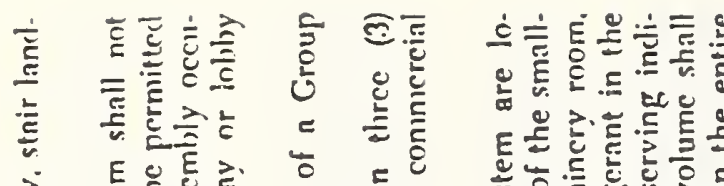

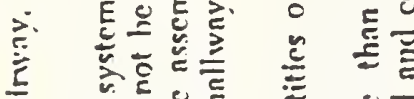

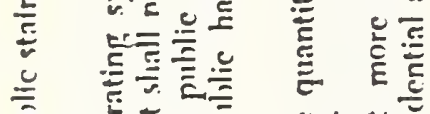

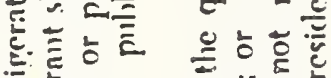

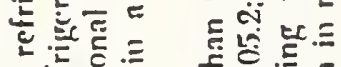

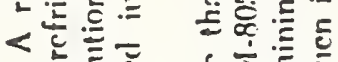

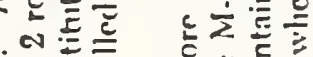

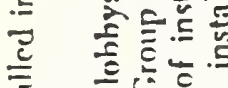
E苍政 比

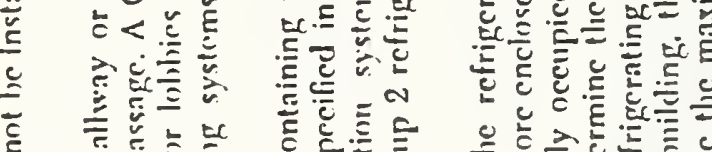

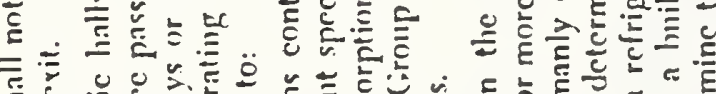

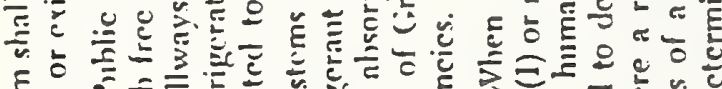
$E$ E

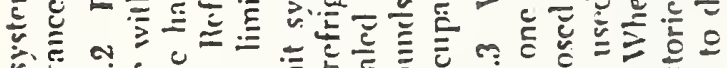

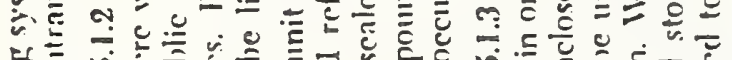

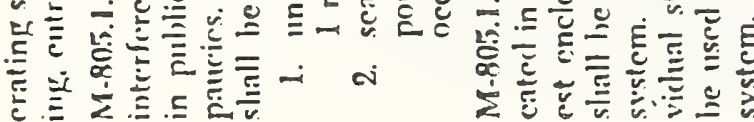

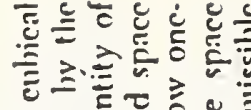

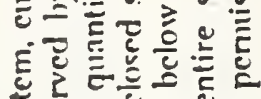

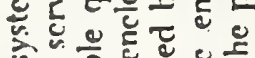

टू

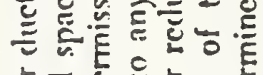

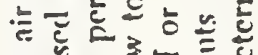

E

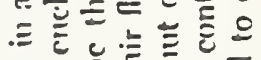

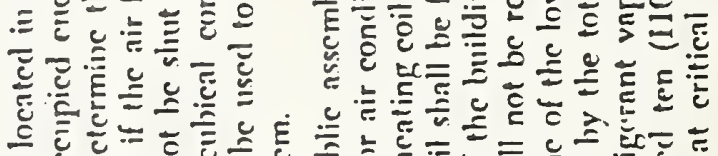

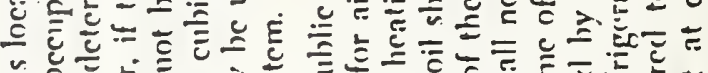

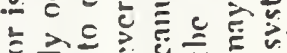

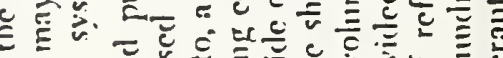

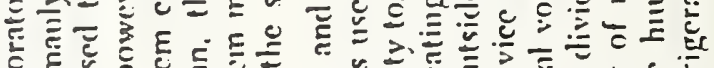

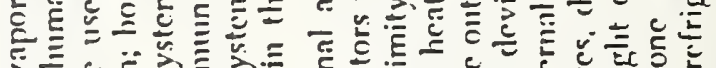

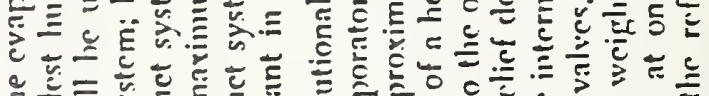

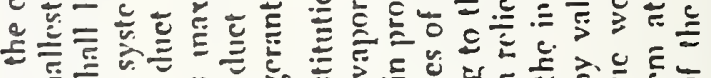

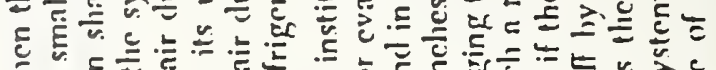

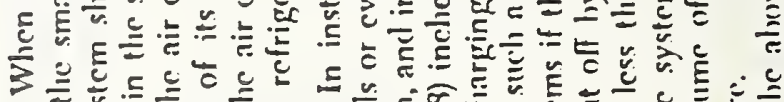

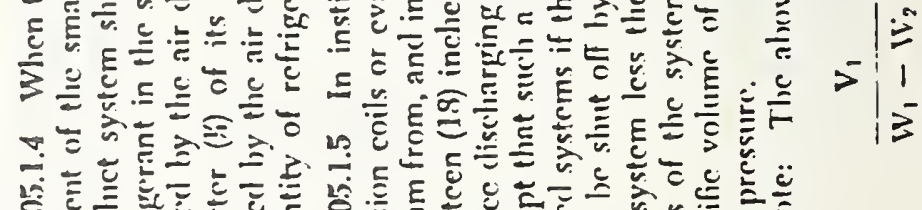

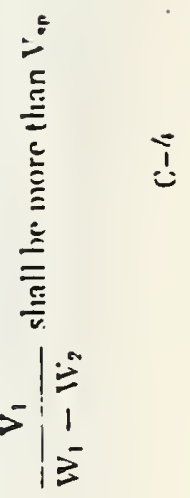

i
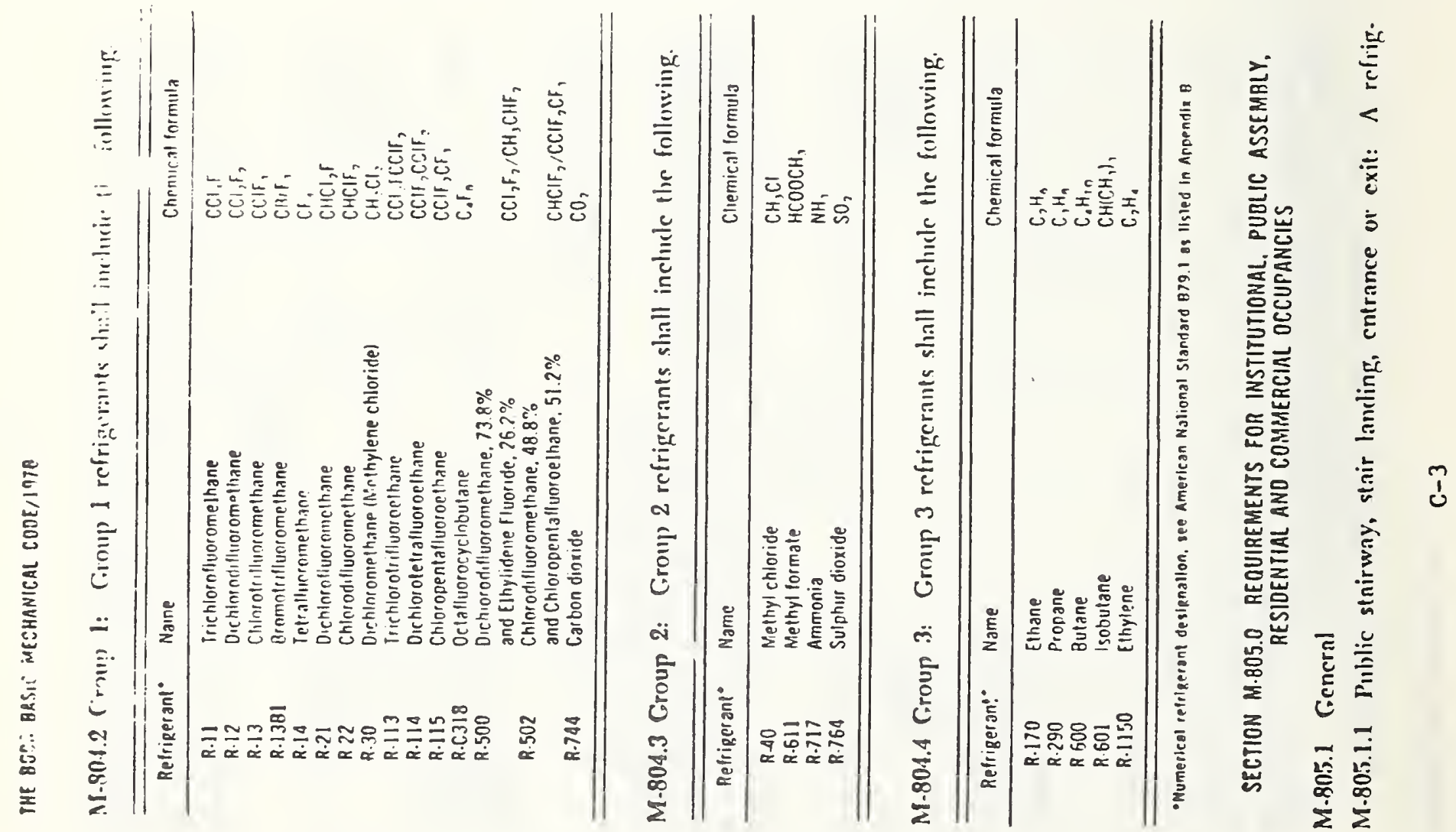


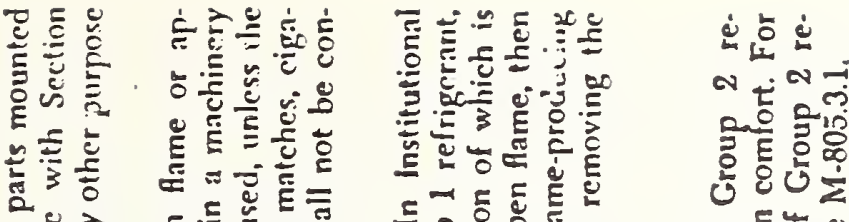

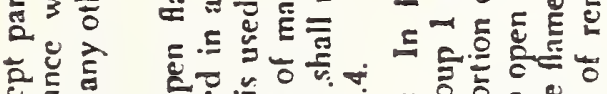

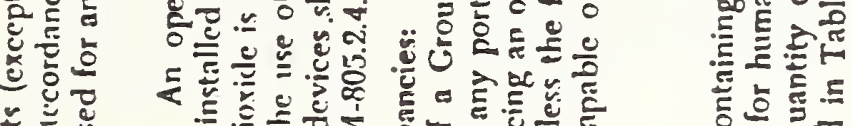

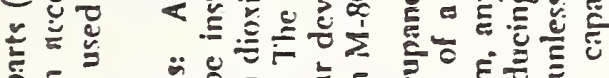

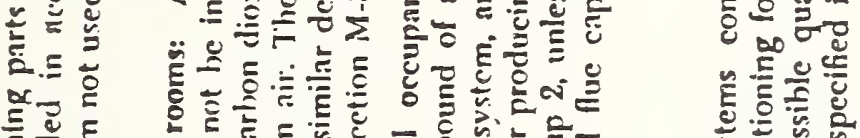

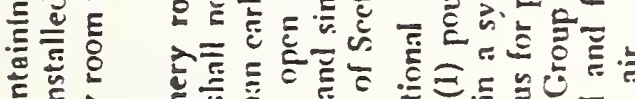

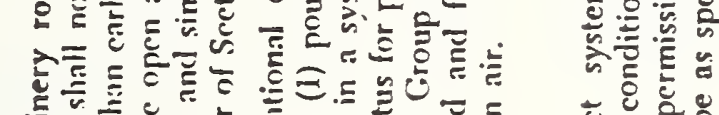

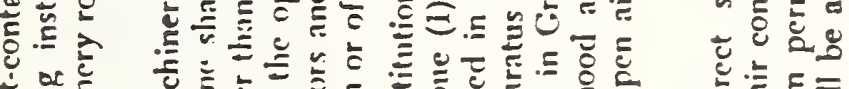

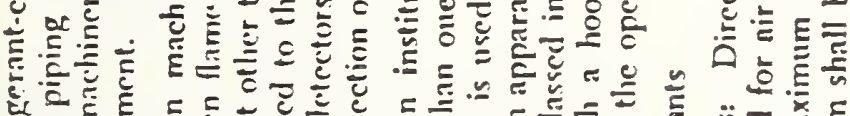

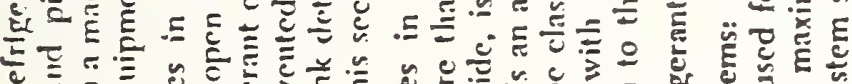

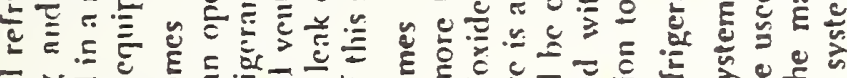

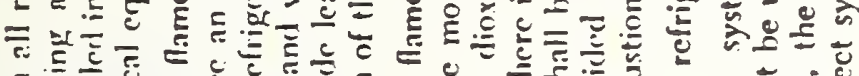

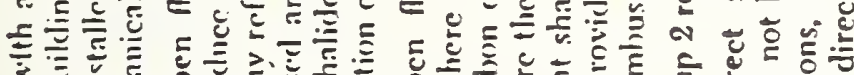

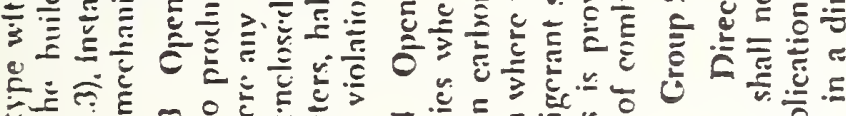

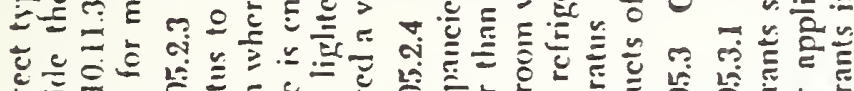

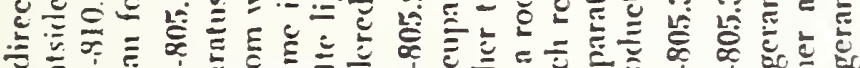

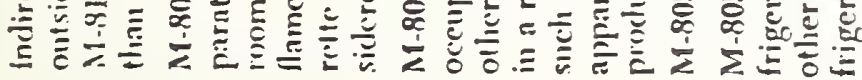
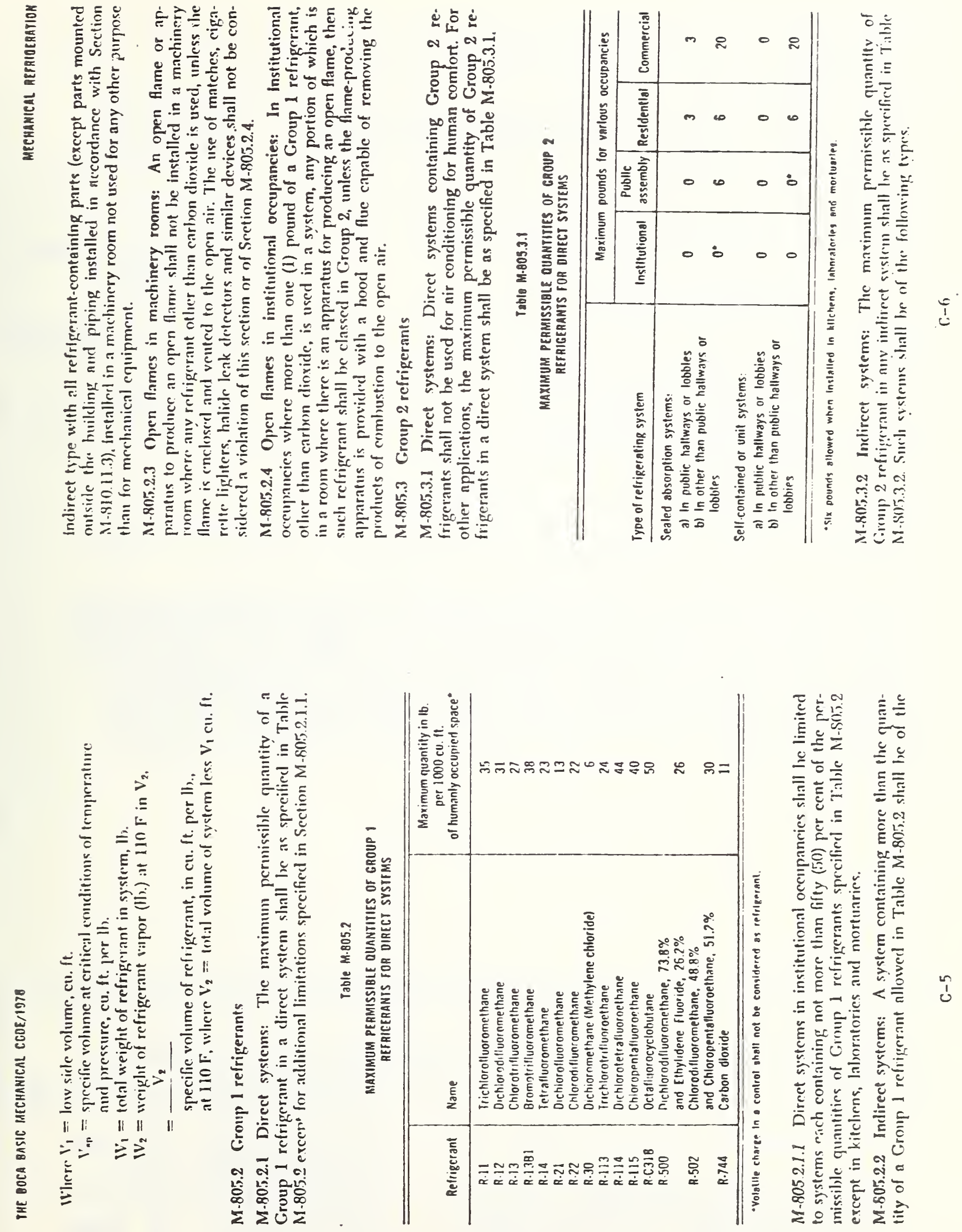


\begin{tabular}{|c|c|c|c|}
\hline $\begin{array}{l}\text { U.S. DEPT. OF COMM. } \\
\text { BIBLIOGRAPHIC DATA } \\
\text { SHEET }\end{array}$ & $\begin{array}{l}\text { 1. PUBLICATION OR REPORT NO. } \\
\text { NBSIR } 78-1542\end{array}$ & $\begin{array}{l}\text { 2. Gov't Accession } \\
\text { No. }\end{array}$ & 3. Recipient's Accession No. \\
\hline \multirow{3}{*}{\multicolumn{3}{|c|}{$\begin{array}{l}\text { 4. TITLE AND SUBTITLE } \\
\text { State-of-the-Art Study of Heat Exchangers Used with Solar } \\
\text { Assisted Domestic Hot Water Systems (Potential Contamination } \\
\text { of Potable Water Supply) }\end{array}$}} & 5. Publication Date \\
\hline & & & October 1978 \\
\hline & & & 6. Performing Organization Code \\
\hline \multicolumn{3}{|c|}{ 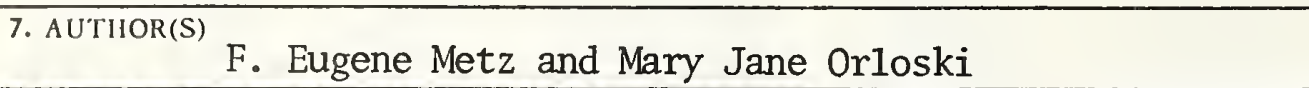 } & 8. Performing $O_{\text {igan. Repo }}$ \\
\hline \multirow{2}{*}{\multicolumn{3}{|c|}{$\begin{array}{l}\text { 9. PERFORMING ORGANIZATION NAME AND ADDRESS } \\
\text { NATIONAL BUREAU OF STANDARDS } \\
\text { DEPARTMENT OF COMMERCE } \\
\text { WASHINGTON, D.C. } 20234\end{array}$}} & $\begin{array}{l}\text { 10. Project/Task/Work Unit No. } \\
7446505 \\
\end{array}$ \\
\hline & & & $\begin{array}{l}\text { 11. Contract/Grant No. } \\
\text { IAA EA-77-A-01-6010 }\end{array}$ \\
\hline \multirow{2}{*}{\multicolumn{3}{|c|}{$\begin{array}{l}\text { 12. Sponsoring Organization Name and Complete Address (Street, City, State, ZIP) } \\
\text { Division of Solar Energy } \\
\text { Department of Energy } \\
\text { 20 Massachusetts Ayenue, NW } \\
\text { Washington, D.C. 20545. }\end{array}$}} & $\begin{array}{l}\text { 13. Type of Report \& Period } \\
\text { Covered } \\
\text { Final }\end{array}$ \\
\hline & & & 14. Sponsoring Agency Code \\
\hline
\end{tabular}

15. SUPPI.EMENTARY NOTES

16. ABSTRACT (A 200-word or less factual summary of most significant information. If document includes a significant bibliography or literature survey, mention it here.)

This report presents the results of a non quantitative state-of-the-art study of heat exchangers used with solar: assisted domestic hot water systems where a heat exchanger interface exists between the potable water supply and a heat transfer fluid. Emphasis is placed on the potential for contaminating the potable water supply if failures should occur. The study considers (1) characteristics of various heat exchanger types and their relative safety; (2) characteristics of heat exchanger fluids (toxicity, corrosivity, thermal properties, etc.); (3) regulatory considerations; and (4) designs of similar systems with potential for contamination.

17. KEY WORDS (six to twelve entries; alphabetical order; capitalize only the first letter of the first key word unless a proper name; separated by semicolons)

Contamination; corrosion; heat exchanger; heat transfer fluids; potable water; solar energy; standards; toxicity.

18. AVAILABILITY [X] Unlimited

For Official Distribution. Do Not Release to NTIS

Order From Sup. of Doc., U.S. Government Printing Office

Washington, D.C. 20402, SD Cat. No. C13

X Order From National Technical Information Service (NTIS) Springficld, Virginia 22151

\begin{tabular}{|l|c|}
\hline $\begin{array}{l}\text { 19. SECURITY CLASS } \\
\text { (THIS REPURT) }\end{array}$ & 21. NO. OF PAGES \\
UNCL ASSIFIED & 81 \\
\hline $\begin{array}{l}\text { 20. SECURITY CLASS } \\
\text { (THIS PAGE) } \\
\text { UNCLASSIFIED }\end{array}$ & $\begin{array}{l}\text { 22. Price } \\
\$ 6.00\end{array}$ \\
\hline
\end{tabular}



